\title{
High-Performance Computing to Enable Next-Generation Low-Temperature Waste Heat Recovery
}

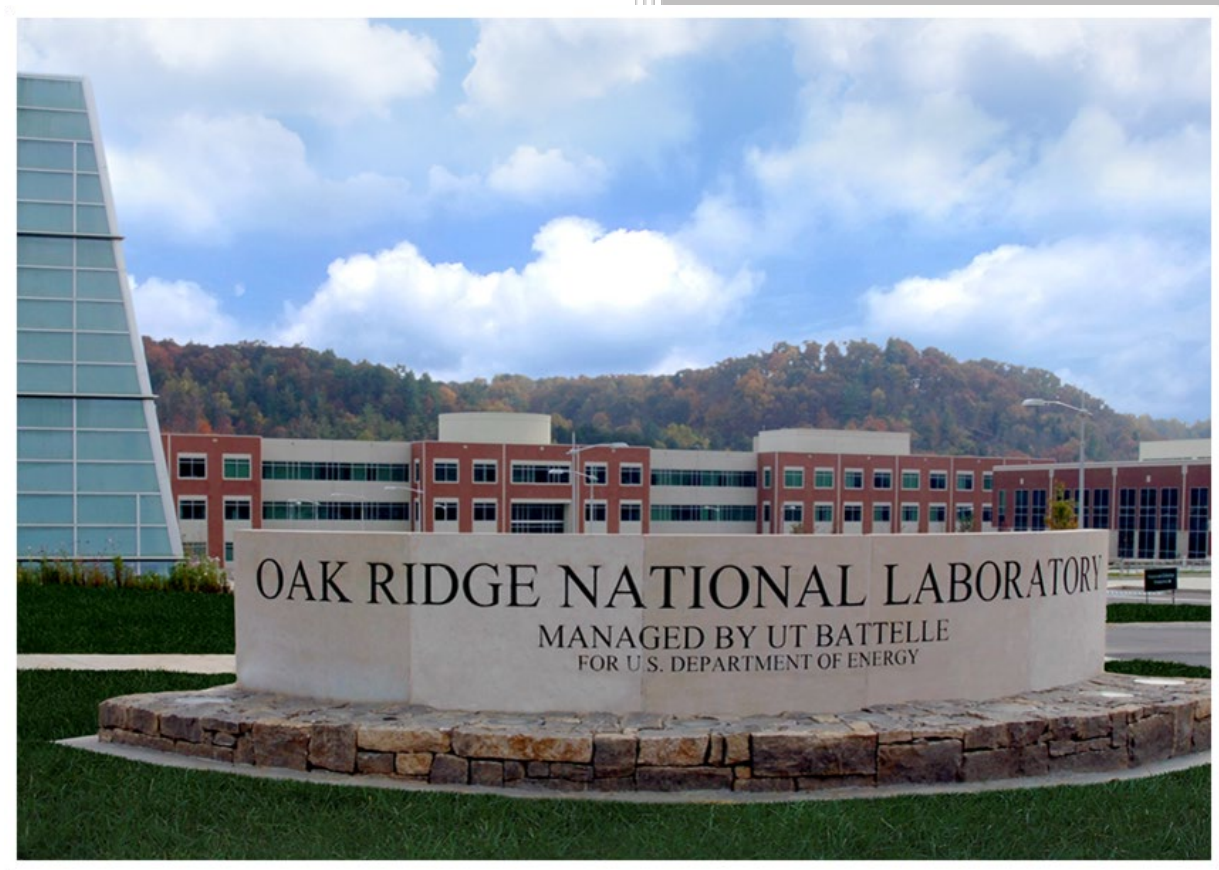

Approved for public release.

Distribution is unlimited.

Vivek M. Rao

Marc-Olivier G. Delchini Mohammad T. Bani Ahmad Prashant K. Jain

December 31, 2019 


\section{DOCUMENT AVAILABILITY}

Reports produced after January 1, 1996, are generally available free via US Department of Energy (DOE) SciTech Connect.

Website www.osti.gov

Reports produced before January 1, 1996, may be purchased by members of the public from the following source:

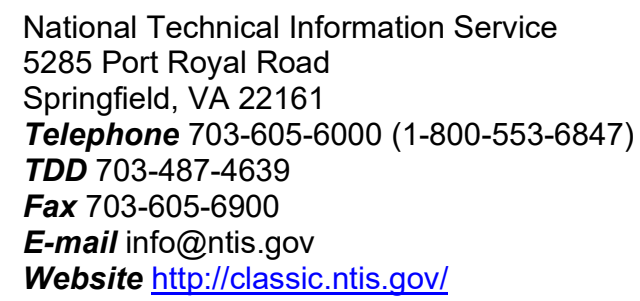

Reports are available to DOE employees, DOE contractors, Energy Technology Data Exchange representatives, and International Nuclear Information System representatives from the following source:

Office of Scientific and Technical Information

PO Box 62

Oak Ridge, TN 37831

Telephone 865-576-8401

Fax 865-576-5728

E-mail reports@osti.gov

Website http://www.osti.gov/contact.html

This report was prepared as an account of work sponsored by an agency of the United States Government. Neither the United States Government nor any agency thereof, nor any of their employees, makes any warranty, express or implied, or assumes any legal liability or responsibility for the accuracy, completeness, or usefulness of any information, apparatus, product, or process disclosed, or represents that its use would not infringe privately owned rights. Reference herein to any specific commercial product, process, or service by trade name, trademark, manufacturer, or otherwise, does not necessarily constitute or imply its endorsement, recommendation, or favoring by the United States Government or any agency thereof. The views and opinions of authors expressed herein do not necessarily state or reflect those of the United States Government or any agency thereof. 


\title{
Reactor and Nuclear Systems Division
}

\section{HIGH PERFORMANCE COMPUTING TO ENABLE NEXT-GENERATION LOW- TEMPERATURE WASTE HEAT-RECOVERY}

\author{
Author(s) \\ Vivek M. Rao \\ Marc-Olivier G. Delchini \\ Mohammad T. Bani Ahmad \\ Prashant K. Jain
}

Date Published:

December 31, 2019

\author{
Prepared by \\ OAK RIDGE NATIONAL LABORATORY \\ Oak Ridge, TN 37831-6283 \\ managed by \\ UT-BATTELLE, LLC \\ for the \\ US DEPARTMENT OF ENERGY \\ under contract DE-AC05-00OR22725
}





\section{CONTENTS}

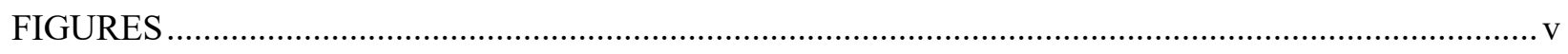

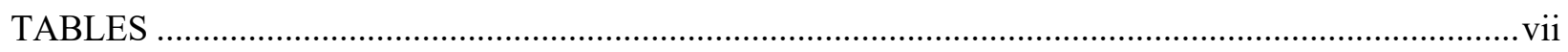

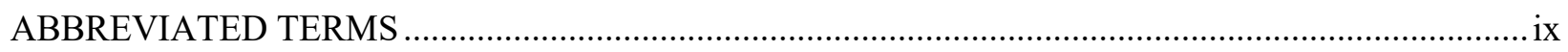

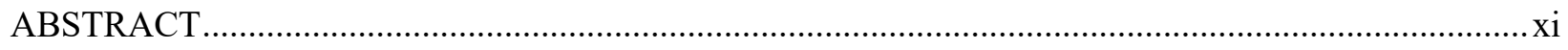

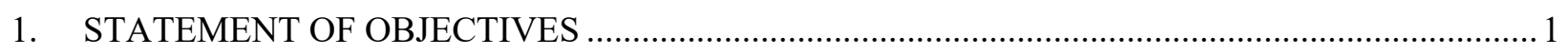

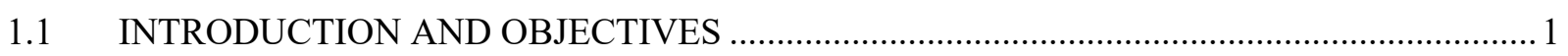

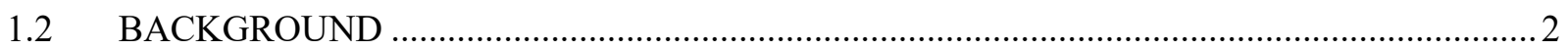

2. BENEFITS TO THE FUNDING DOE OFFICE'S MISSION …............................................ 7

3. TECHNICAL DISCUSSION OF WORK PERFORMED BY ALL PARTIES ................................. 8

3.1 MATHEMATICAL AND PHYSICAL MODELS ......................................................... 8

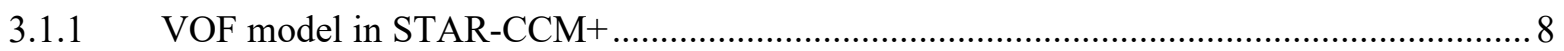

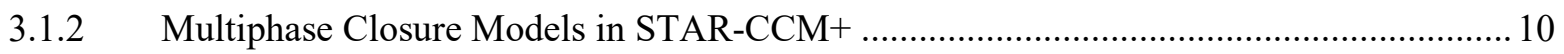

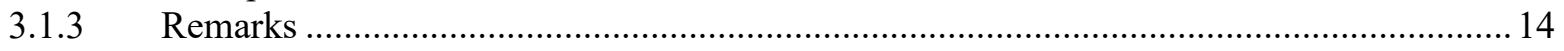

3.2 VERIFICATION AND VALIDATION OF THE CFD MODEL ….......................................... 14

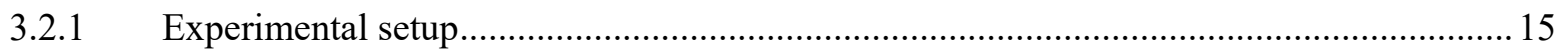

3.2.2 Geometry and mesh process for the experimental setup.............................................. 17

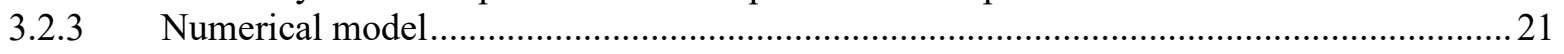

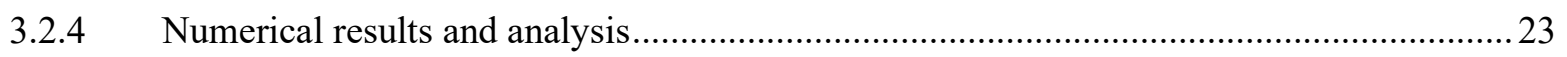

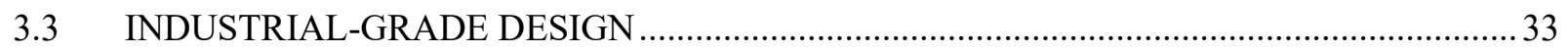

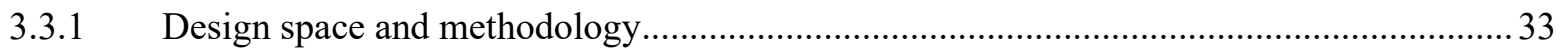

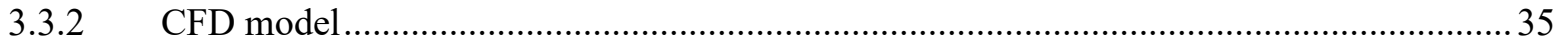

3.3.3 Numerical results for the industrial-grade design .......................................................... 38

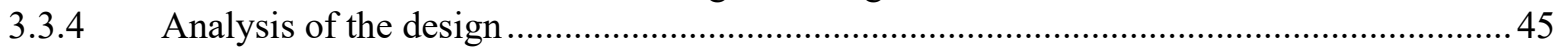

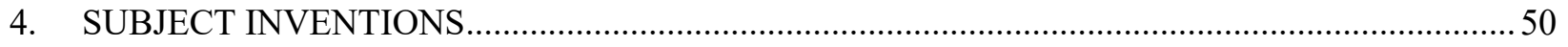

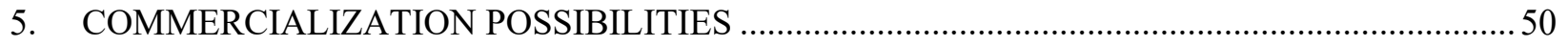

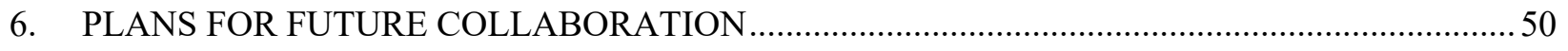

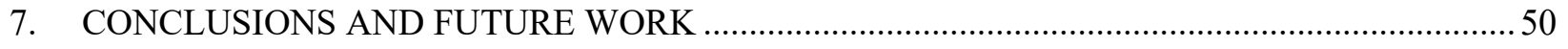

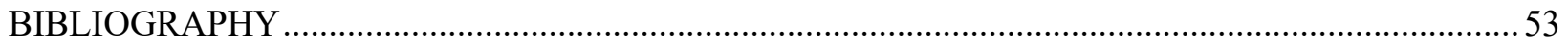





\section{FIGURES}

Figure 1. A liquid-liquid DCHE concept developed by Eaton Corporation.......................................... 2

Figure 2. Spray column DCHE design (Jacobs H. R., 2011) .................................................................. 3

Figure 3. Disk and donut baffle tray column DCHE design (Jacobs H. R., 2011) (Jacobs H. a., 1987).

Figure 4. Sieve tray column DCHE design (Jacobs H. R., 2011), (Jacobs H. R., 1986)........................... 4

Figure 5. Pipe-type DCHE design (Jacobs H. R., 2011) ...................................................................... 4

Figure 6. Mechanically agitated tower DCHE design (Jacobs H. R., 2011), (Treybal, 1966).................... 4

Figure 7. Schematic of the physical processes occurring in a DCHE between a continuous phase (exterior) and a dispersed phase (interior) (Kreith, 2013).................................................. 5

Figure 8. Schematic diagram of experimental configuration (Baqir A. M., 2016) ................................... 15

Figure 9. Sparger geometry used in the experiment: (a) 7-nozzle sparger, (b) 19-nozzle sparger,

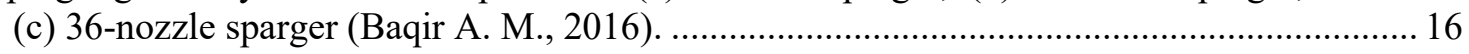

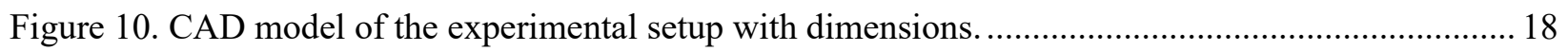

Figure 11. Zoomed-in views of the water inlet nozzle and the spargers used in the CFD models:

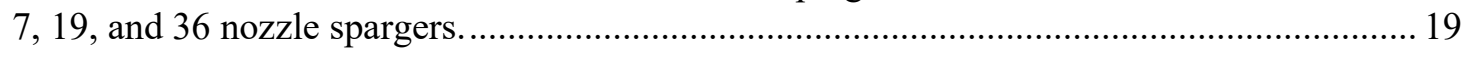

Figure 12. Quality assurance process to optimize the mesh of a CFD model......................................... 19

Figure 13. Mesh detail on lower surfaces (left) and upper surfaces (right) of the DCHE. ....................... 20

Figure 14. Velocity profile at steady state for the case with a seven-nozzle sparger...............................25

Figure 15. Temperature profile at steady state for the case with a seven-nozzle sparger.........................25

Figure 16.Volume fraction of gaseous pentane at steady state for the case with a seven-nozzle

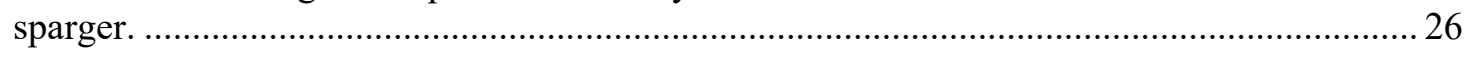

Figure 17. Volume fraction of liquid pentane at steady state for the case with a seven-nozzle

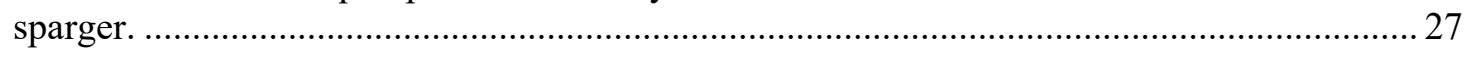

Figure 18. Volume fraction of water at steady state for the case with a seven-nozzle sparger.................27

Figure 19. Distribution of active length based on the definition given in Eq. (32) and for different

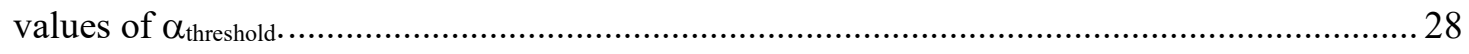

Figure 20. 3D CAD model views of 19-nozzle (left) and 36-nozzle (right) spargers............................... 30

Figure 21. Solution history of volumetric profiles for the 19-nozzle sparger (top) and 36-nozzle

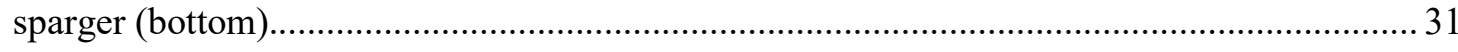

Figure 22. Volume fraction of pentane(1) dispersed by 19-nozzle (left) and 36-nozzle (right) spargers.

Figure 23. Active length of evaporation for 19-nozzle sparger (left) and 36-nozzle sparger (right) cases.

Figure 24. A comparative summary of the validation study in terms of active length $(\mathrm{cm}) \ldots \ldots \ldots \ldots \ldots \ldots \ldots . . . . . . . . .33$

Figure 25. Various DCHE designs tested before arriving at the optimized industrial grade design........... 34

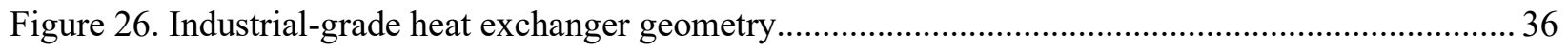


Figure 27. Volume-averaged volumetric profiles at an inlet temperature of $50^{\circ} \mathrm{C}$ for water.

Figure 28. Volume fraction averaged at the vent for outflow of pentane(g).

Figure 29. Turbulent intensity values of the mixture averaged over the volume (top) and of pentane $(\mathrm{g})$ at the vent (bottom).

Figure 30. Cross-sectional distribution of water for an inflow temperature of $50^{\circ} \mathrm{C}$ at flow rates $\mathrm{m} 1, \mathrm{~m} 2, \mathrm{~m} 3$ (top to bottom).

Figure 31. Cross-sectional distribution of pentane(1) for a water inflow at $50^{\circ} \mathrm{C}$ at flow rates $\mathrm{m} 1$, $\mathrm{m} 2, \mathrm{~m} 3$ (left to right).

Figure 32. Cross-sectional distribution of pentane $(\mathrm{g})$ for a water inflow at $50^{\circ} \mathrm{C}$ at flow rates $\mathrm{m} 1$, $\mathrm{m} 2, \mathrm{~m} 3$ (left to right).

Figure 33. Cross-sectional distribution of temperature for a water inflow at $50^{\circ} \mathrm{C}$.

Figure 34. Entrainment of pentane $(\mathrm{g})$ with water at higher temperatures $\left(80^{\circ} \mathrm{C}, 95^{\circ} \mathrm{C}\right)$ at $10 \mathrm{~g} / \mathrm{s} \mathrm{of}$ pentane(l) inflow.

Figure 35. Cross-sectional mixtures profiles of hydraulic data.

Figure 36. Lateral increase in turbulent intensity with higher temperature of water at inflow; $65^{\circ} \mathrm{C}, 80^{\circ} \mathrm{C}, 95^{\circ} \mathrm{C}$ (top to bottom).

Figure 37. Industrial-grade design modified with baffles to gradually expand available flow area.

Figure 38. Distribution of pentane(g) across the symmetry plane of the simulated DCHE.

Figure 39. Distribution of the mixture velocity across the symmetry plane of the simulated DCHE.

Figure 40. Distribution of mixture temperature across the symmetry plane of the simulated DCHE.

Figure 41. Outflow temperature profiles of vapor in all simulated scenarios (top) and the influence of baffles on superheat of vapor outflow (bottom). 


\section{TABLES}

Table 1. Physical properties of liquid and gaseous pentane (Baqir A. M., 2016).................................... 16

Table 2. Physical properties of water (https://webbook.nist.gov/chemistry/fluid/, 2018)...................... 16

Table 3. Experimental Parameters (Baqir A. M., 2016). ........................................................................ 17

Table 4. Mesh settings for the Trimmer and Surface Remesher models. ................................................ 20

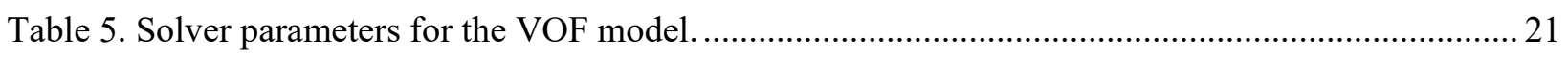

Table 6. Initial conditions used in the CFD model for the experimental setup......................................... 22

Table 7. Boundary conditions and boundary used in the CFD model of the experimental setup.............. 23

Table 8. Boundary condition used for the CFD model with the seven-nozzle sparger............................. 24

Table 9. Values of the active length for different mesh sizes and different $\alpha_{\text {threshold }}$ values...................... 28

Table 10. Boundary conditions for simulations using spargers with 19 nozzles and 36 nozzles. .............. 30

Table 11. Inlet temperatures of liquid water and liquid pentane........................................................... 35

Table 12. Mass flow rate values of liquid water and liquid pentane...................................................... 35

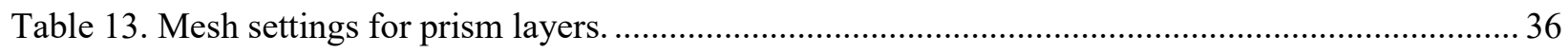

Table 14. Relaxation parameters used in the CFD model of the industrial-grade design......................... 37

Table 15. Physical operating conditions for the industrial-grade design. ............................................... 48 



\section{ABBREVIATED TERMS}

BTU British thermal unit

CAD computer-aided design

CFD computational fluid dynamics

$\mathrm{CNF} \quad$ continuum surface force

CPU central processing unit

DCHE direct-contact heat exchanger

HPC high-performance computing

HPC4Mfg High-Performance Computing for Manufacturing

ORNL

URF

Oak Ridge National Laboratory

$\mathrm{V} \& \mathrm{~V}$

VOF

under-relaxation factor

verification and validation

volume of fluid 



\begin{abstract}
The US manufacturing industry fails to recover an estimated 900 trillion BTU of low-temperature waste heat from its processes each year. A grand research challenge has been to develop waste heat recovery technology that can be applied to industrial manufacturing processes and vehicle operations. The Oak Ridge National Laboratory (ORNL) and Eaton Corporation research team have jointly performed computational research and development to design an innovative direct-contact heat exchanger (DCHE) technology to deliver a low-cost, compact, long-lifetime, high-efficiency waste heat recovery system that is optimized for a low-temperature organic Rankine cycle. ORNL resources and expertise in highperformance computing and multiphase flows were utilized to realize this goal while advancing the fundamental understanding of two-phase, two-immiscible-fluid turbulent flows and heat transfer for DCHEs.
\end{abstract}

In the first stage of the project, a computational fluid dynamics (CFD) model of a DCHE experiment, was developed as a benchmark. Limited verification and validation $(\mathrm{V} \& \mathrm{~V})$ of the numerical solution were performed using experimental data from the published literature. To support V\&V efforts, the research team also developed two-dimensional CFD models with the objective of investigating different boundary conditions to reach converged, numerically stable, steady-state solutions.

Based on the benchmarking efforts, a baseline industrial-grade design of a DCHE was developed. It consists of two horizontal pipes of different cross-sectional areas joined by a converging-diverging nozzle in the middle and operating with cocurrent flows of three different phases. Evaporation of the cold liquid refrigerant (n-pentane or methanol) by the hot liquid water occurs in the first pipe. The first pipe contains two inlets for liquid water and liquid refrigerant. The second pipe (the pipe with the larger cross-sectional area) serves as a gravity-driven phase separator. It contains two outlets that are staggered to avoid entrainment of the liquid water phase by the gas phase. This baseline design resulted from several performance evaluations using two-dimensional CFD models. Confirmatory three-dimensional CFD models were also run for different mass flow rates and inlet temperatures (e.g., inlet water temperature ranging from $50^{\circ} \mathrm{C}$ to $90^{\circ} \mathrm{C}$ ), and efficiency plots were produced to fully characterize the proposed industrial-grade design of the DCHE. 



\section{STATEMENT OF OBJECTIVES}

\subsection{INTRODUCTION AND OBJECTIVES}

The exponential growth of mankind coupled with the scientific and technological development in the past 50 years has put an enormous pressure on the energy industry. With about 900 trillion BTU of energy wasted in the United States manufacturing industry alone, finding efficient means to recover and utilize this extravagant amount of energy will provide an immense economic benefit. To utilize this energy, which is mostly available in the low temperature range, we need a heat exchanger technology that is lowcost and can recover energy in a useful form. A key to the challenge in the design of efficient energy conversion systems is to achieve effective heat transfer at temperatures that can extract the maximum thermodynamic potential of the system's heat source.

In a classical heat exchanger, heat transfer takes place through a wall that separates the hot and cold fluid streams. Thus, conventional heat exchangers are limited in their ability to tap the maximum thermodynamic potential because they have built-in thermal losses associated with the separation of the fluid streams by an intervening solid wall. This type of configuration is not adequate for low temperature ranges because a large temperature difference (between the hot and cold fluids) is needed to overcome the built-in thermal losses. An alternative to the classical surface-type heat exchanger is the direct contact heat exchanger (DCHE). In DCHEs, heat and mass transfers directly occur between the two immiscible fluids (e.g., gas-solid, gas-liquid, liquid-liquid, or liquid-solid) under different temperatures in contact for heat exchange, eliminating the built-in thermal loss due to the intervening solid wall.

DCHEs have been used by heat transfer practitioners for heat recovery in a variety of applications (e.g., open-feed water heaters in power plants, open-evaporative cooling towers, barometric condensers throughout the petroleum industry, gas (air) separation, sea-water desalination, ocean thermal energy conversion, thermal energy storage systems). Compared with the traditional heat exchangers, DCHEs present many advantages due to their simpler designs, low-temperature driving forces, and higher heat transfer efficiencies. Additionally, DCHEs negate the need for the plates found in the plate-type heat exchangers, which conduct heat across the plates, thus minimizing the heat losses.

Costs are often more favorable for direct-contact heat transfer devices than for their traditional counterparts. The thermal resistances present in traditional heat exchangers result in less heat transfer than might be accomplished in direct contact, and this often translates to lower operating costs for the latter. In addition, the equipment required to accomplish the direct-contact processes is generally less expensive than the alternatives. Both aspects can result in considerable life-cycle cost savings for the direct contact approach over that of conventional heat exchangers. There are, however, several limitations to the use of DCHEs. For example, stream contamination can occur depending on the degree of miscibility of one working fluid into the other and could require additional components downstream of the DCHE to separate the phases, which would result in additional costs. In addition, the two streams must also be at the same pressure in a direct contactor, which could also lead to additional costs.

Despite a wide use of DCHEs, the inherent nature of mixing and heat transfer is not as well understood as that of surface-type heat exchangers. Development of a more compact and efficient DCHE and phase separator is thus critical for a next-generation low-temperature waste heat recovery system. Advanced modeling and simulation capabilities that include multiphase turbulent heat transfer within immiscible fluids, immiscible fluid droplet dynamics, and interface tracking methods, are needed to support further design improvements for DCHEs. These important physical phenomena are resolved using transient formulations of computational models and further calibrated as predictive tools using high-performance computing (HPC) capabilities. The objective is to deliver low-cost, compact, long-lifetime, high- 
efficiency waste heat recovery that is optimized for a low-temperature, organic Rankine cycle. The primary research tasks in this project were to (1) develop fast, reliable, and scalable HPC computational fluid dynamics (CFD) models to study the fundamental physics underlying the thermodynamic performance of DCHE components and (2) leverage HPC modeling to develop and optimize an industrial-grade design of a liquid-liquid DCHE to be tested by industry in the future (Figure 1).
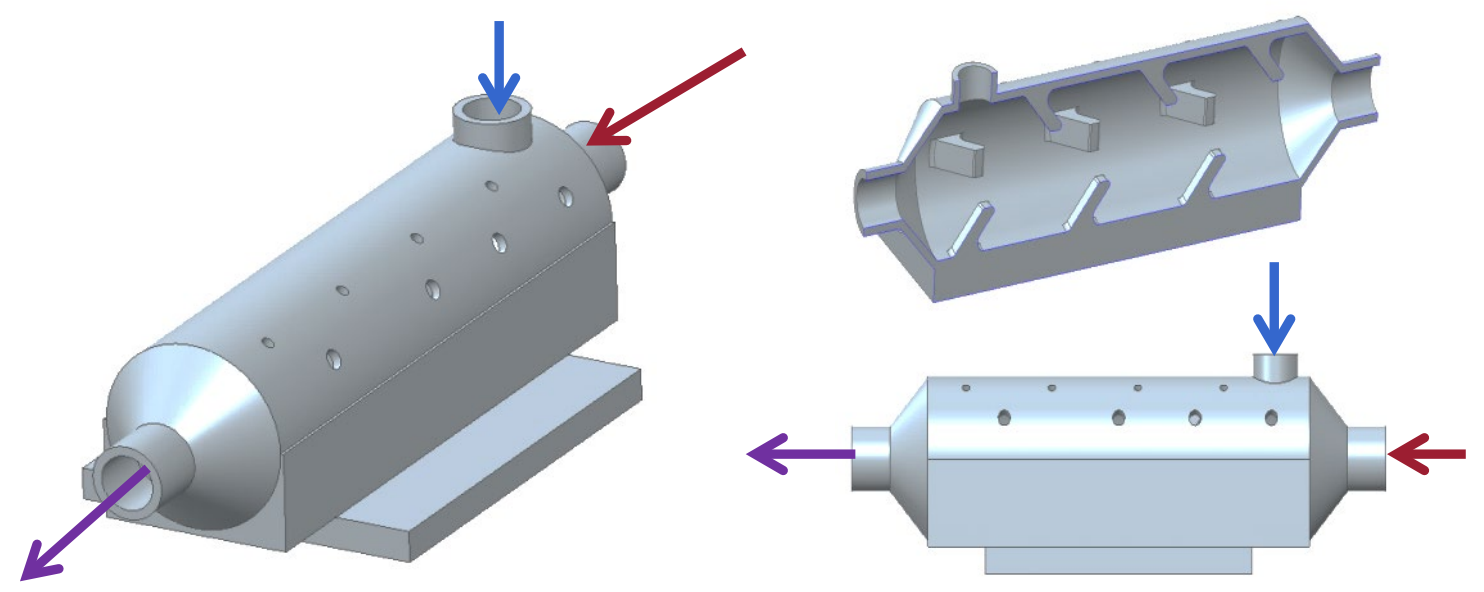

Figure 1. A liquid-liquid DCHE concept developed by Eaton Corporation.

\subsection{BACKGROUND}

In a typical DCHE, heat and mass transfer (i.e., evaporation or boiling), occur between two immiscible fluid streams. The driving process is the heating, or cooling, of one fluid by the other. For most applications, we can categorize the fluids into a dispersed phase that experiences phase change while surrounded by a bulk continuous phase. In the case of heating, the temperature of the continuous phase is higher than the saturation temperature of the dispersed phase. In the case of cooling, the temperature of the continuous phase is lower than the saturation temperature of the dispersed phase. In either the heating or the cooling process, the dispersed phase can experience phase change, leading to a three-phase system.

Most of the direct-contact applications can be accomplished with the following devices (Jacobs H. R., 2011): spray columns (Figure 2), baffle tray columns (Figure 3), bubble tray columns (Figure 4), pipeline contactors (Figure 5), and mechanically agitated contactors (Figure 6). All the above designs, except the pipeline contactor, consist of a vertical column where the continuous phase (heavy fluid) is injected at the top of the column and the dispersed phase (light fluid) is injected at the bottom of the column. It is a common practice to use a sparger for the injection of the dispersed phase with the goal of increasing the surface-contact area with the continuous phase. The continuous and dispersed phases exit the DCHE from the bottom and the top of the column, respectively. In the case of a horizontal pipe, the flow is cocurrent, and the continuous and dispersed phases enter the DCHE from distinct inlets but exit as a mixture through a single outlet. If needed, separation of the continuous and the dispersed phases is then achieved by a separator downstream of the DCHE. In the vertical column design, separation of phases is achieved by buoyancy forces and the flow is counter-current and primarily driven by the force of gravity. For both the vertical and horizontal designs, static or moving baffles can be used to enhance the mixing between the dispersed and continuous phases. Baffles improve heat transfer by breaking up bubbles (increased exchange area), thus leading to a better mass transfer (if mass transfer is occurring) and resulting in superheated gas phases at the outlet of the DCHE. 


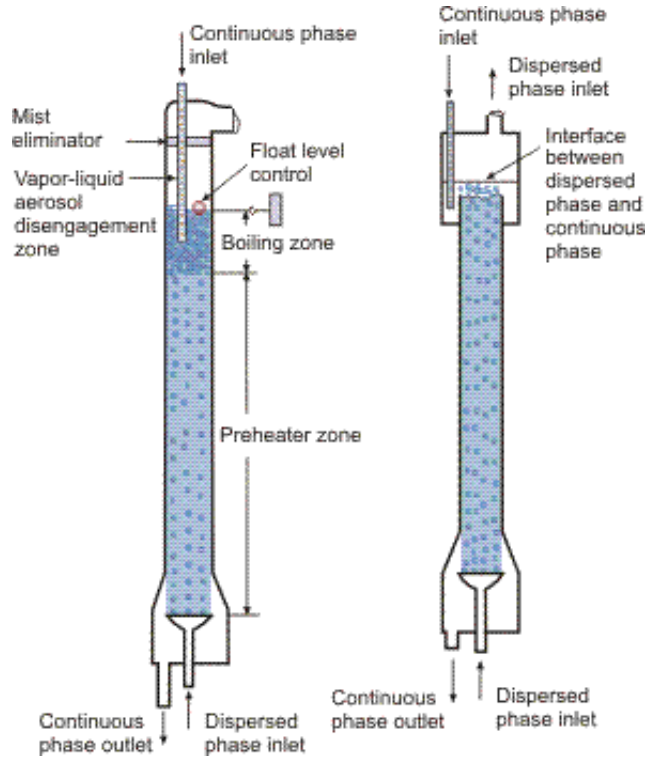

Figure 2. Spray column DCHE design (Jacobs H. R., 2011).

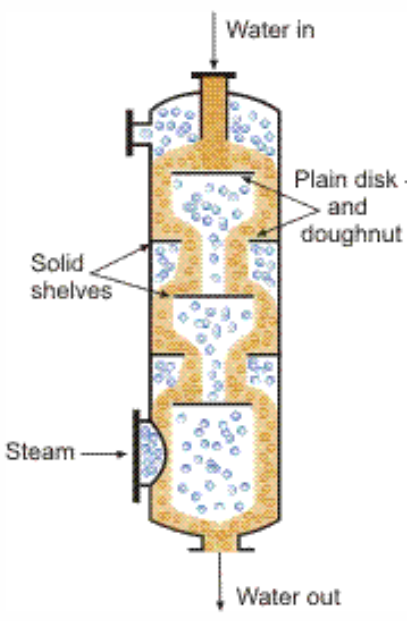

Figure 3. Disk and donut baffle tray column DCHE design (Jacobs H. R., 2011) (Jacobs H. a., 1987). 


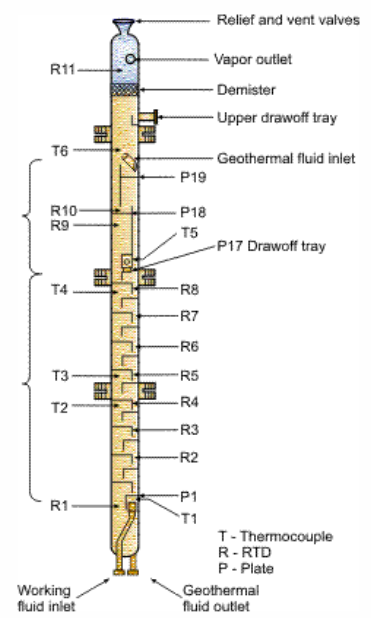

Figure 4. Sieve tray column DCHE design (Jacobs H. R., 2011), (Jacobs H. R., 1986).

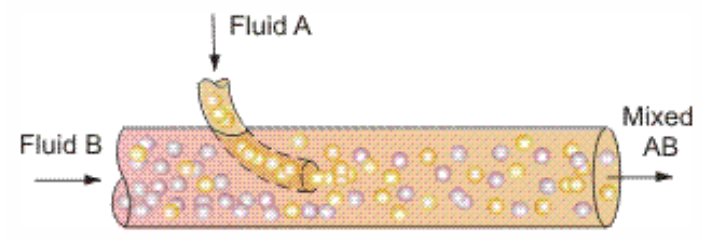

Figure 5. Pipe-type DCHE design (Jacobs H. R., 2011).

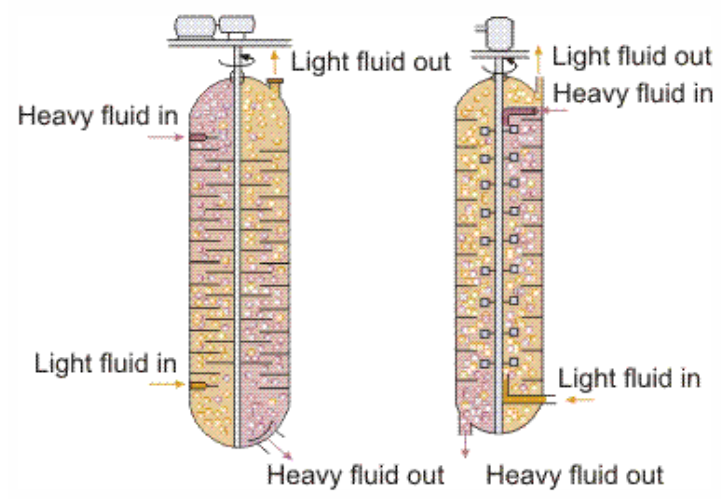

Figure 6. Mechanically agitated tower DCHE design (Jacobs H. R., 2011), (Treybal, 1966).

The physics involved in a DCHE system are quite complex and have transient, turbulent, and multiphase characteristics. Each phase motion is subject to buoyancy force and drag forces. Surface tension force controls immiscibility effects and phase change. The transient and turbulent qualities of the flow in a DCHE are also strongly tied to phase change and therefore require appropriate correlations and turbulent models. Modeling such a complex multiphase flow system would require algorithms that can accurately track multiple phases with a numerical method that is robust enough to numerically stabilize stiff source terms while preserving the physical aspect of a numerical solution.

In a DCHE, once the continuous and dispersed phases come in contact, energy is transferred from the continuous phase to the dispersed phase, leading to an increase in temperature of the dispersed phase. If enough energy is available in the continuous phase, the dispersed phase reaches its saturation temperature. Any further heat transferred to the dispersed phase will be used as latent heat of vaporization, and mass 
transfer occurs to a third phase (i.e., the corresponding gas phase of the dispersed liquid phase). Then, buoyancy force and an interphase conservation of momentum cause the bubbles to rise. During ascent, bubbles are subject to drag force and convective heat transfer with the continuous phase. The gas phase can then superheat before being collected at the outlet of the DCHE. Buoyancy and drag forces also act on the liquid phases and cause them to stratify. Processes involving a transfer of mass and/or heat are not local to near-wall flow in a DCHE. They occur in the bulk of the domain through interfaces between the continuous and dispersed phases, as shown in Figure 7.

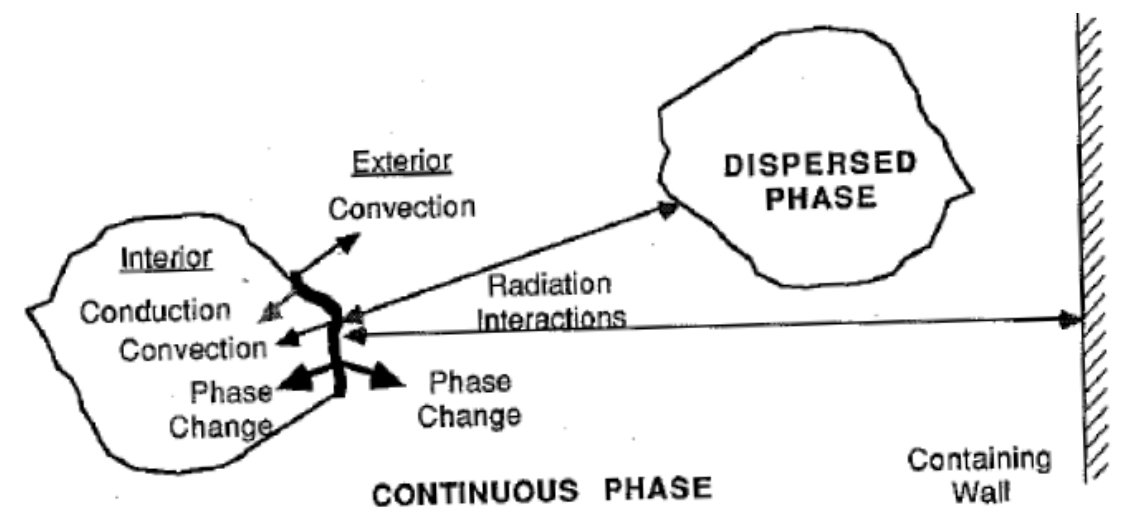

Figure 7. Schematic of the physical processes occurring in a DCHE between a continuous phase (exterior) and a dispersed phase (interior) (Kreith, 2013).

Convection, conduction, and radiation processes occur simultaneously between the phases to move and/or exchange energy. At low temperatures, the convection is the main driver to transfer energy within a given organic phase in a liquid-liquid DCHE. Interfacial physical processes play a key role in the transfer of energy from the continuous phase to the dispersed phase, thus being linked to the performance of a DCHE. It is a common practice to improve the DCHE performance through increasing the interfacial area, e.g., using a sparger to inject the dispersed phase (Baqir A. M., 2016), or using Dixon rings (Jiang, 2015) (Jin, 2017) to break bubbles. Surface tension, the physical parameter driving phase change and immiscibility, is expected to strongly influence overall performance of a DCHE. Although the phase change causes the flow to be locally transient and turbulent, a steady-state behavior can be recovered using appropriate time-averaging techniques and statistics.

Interest in designing DCHEs is not new, and a literature review has shown that extensive experimental and modeling research has been performed over the years. Sideman and Gat (Sideman, 1966) carried out an experimental investigation on a perforated plate-spray column in a counterflow arrangement of pentane and water. Their work reports several important parameters such as the optimal column heights, volumetric heat transfer coefficient, holdups, and others as functions of mass flow rate and temperature. The optimal height found varied from 100 to $160 \mathrm{~mm}$; the volumetric heat transfer coefficients varied between $10^{5}$ to $2 \times 10^{5} \mathrm{kcal} / \mathrm{m}^{3} \mathrm{~h}-\mathrm{K}$, and the holdup ratio varied between $15 \%$ and $22 \%$. Blair et al. (Blair, 1976) evaluated the performance of a DCHE in a counterflow arrangement. They used water as their continuous phase and refrigerant-113 as their dispersed phase. Their results show that the UA factor (overall heat transfer coefficient $\times$ area) is moderately affected by the operating height of the heat exchanger vessel and the water inlet temperature. The UA factor was largely affected by the mass flow rate of the refrigerant.

Fujita et al. (Fujita, 1988) investigated the flow and heat transfer characteristics of refrigerant R113 injected into hot water as a dispersed phase. Their investigation is based on the observation of flow 
patterns and the local flow and heat transfer measurements. They concluded that heat transfer characteristics are strongly affected by the boiling regime just downstream of the nozzle outlet. The regime depends on the inlet temperature of both fluids and the inlet Reynolds number. Baqir et al. (Baqir A. M., 2016) carried out an experiment to investigate the average volumetric heat transfer coefficient in a spray column with water and pentane. The experiment was run for different sparger geometries as well as varied flow rate permutations for dispersed and continuous phases. Their results show that the flow rates had a significant effect on the volumetric heat transfer coefficient.

Modeling of DCHEs can be quite challenging due to the complexity of the equations that have to be solved in order to capture the physics behind the various phenomena that take place in DCHEs. The processes can be categorized as transient, turbulent, and multiphase. Several attempts were made to model such phenomena. For example, Wohak and Beer (Wohak, 1998) carried out a full numerical simulation of direct-contact evaporation of a drop rising in a hot, immiscible and less-volatile liquid using a solution algorithm for transient fluid flow with multiple free boundaries. Banerjee (Banerjee R. a., 2006) performed a numerical study to determine the rate of evaporation of gasoline flowing through an inclined two-dimensional channel. The flow was classified as a stratified two-phase flow. The volume-of-fluid (VOF) multi-phase model was used to simulate two-phase flow. The equations were solved using a continuous thermodynamic approach. Banerjee (Banerjee R. , 2007) also conducted a numerical study to determine heat and mass transfer from the surface of liquid ethanol flowing in an inclined channel. The VOF multiphase model was used. In addition to that, Banerjee (Banerjee R. , 2008) performed a numerical study to determine evaporation rate from the surface of a binary mixture of ethanol and isooctane flowing in an inclined 2D channel. The liquid and gas phases are flowing in countercurrent directions. The VOF multiphase model was used to model stratified two-phase flow.

Strotos et al. (Strotos, 2011) presented a numerical model for the complete thermo-fluid-dynamic and phase-change transport processes of droplets consisting of n-heptane, $n$-decane, and a mixture of the two in various compositions. The model was validated by comparing it with experimental data for both singlecomponent and binary-mixture droplets, showing a good agreement. The experimental data were surface temperature and size regression with time for droplets suspended on a small-diameter pipe in a hot-air environment under convective flow conditions. Cui et al. (Cui, 2012) carried out a numerical study of direct-contact heat and mass transfer of a multicomponent two-phase film flow in an inclined channel at subatmospheric pressure. The process in the channel includes direct-contact condensation of hydrocarbon mixtures, with and without noncondensable gas, and the effect of distillation. They used ANSYS Fluent software for their simulation study. Wang et al. (Wang, 2015) did a numerical study on the discharge of the direct-contact phase-change energy storage system, also using ANSYS Fluent, to carry out 2D simulations, which were later validated with experimental data.

Abdulrahman (Abdulrahman, 2016) carried out a CFD simulation for a slurry bubble column of heliumwater-alumina using ANSYS Fluent as well. His study investigated the effects of superficial gas velocity, static liquid height, and solid particle concentration on the volumetric heat transfer coefficient of the slurry bubble column reactor. The study showed that the volumetric heat transfer coefficient increases by increasing the superficial gas velocity and decreases by increasing the static liquid height and the solid concentration at any given superficial gas velocity. Apanasevich et al. (Apanasevich, 2015) modeled a stratified two-phase flow that involves heat and mass transfer across a moving steam-water interface because of direct contact condensation. Their approach used the two-fluid phase-average model. The interfacial friction was modeled using an algebraic interfacial area density framework. Their model was validated with steady-state experimental data and produced better agreements in comparisons to the simulations where a constant drag coefficient was used. Gulawani et al. (Gulawani, 2006) modeled direct-contact steam condensation steam jet injectors and direct contact feed water heaters using CFD simulations. They compared their simulation to experimental data of plume length and axial and radial temperature profiles. 


\section{BENEFITS TO THE FUNDING DOE OFFICE'S MISSION}

The High-Performance Computing for Manufacturing (HPC4Mfg) Program unites the world-class computing resources and expertise of Department of Energy (DOE) national laboratories with US manufacturers to deliver solutions that could revolutionize manufacturing. Led by Lawrence Livermore National Laboratory, and joined by principal national laboratories, Lawrence Berkeley and Oak Ridge national laboratories, HPC4Mfg offers a low-risk path for manufacturing companies interested in adopting HPC technology to advance clean energy technologies and increase energy efficiency while reducing risk of HPC adoption.

The DOE Advanced Manufacturing Office within the Energy Efficiency and Renewable Energy Office, sponsors this program. Through HPC4Mfg, industrial partners collaborate with national laboratory experts in advanced modeling, simulation, and data analysis on project teams to address process optimization and design, quality improvement, performance and failure prediction, accelerating or eliminating testing, shortening time-to-adoption, and decision-making.

This project with Eaton Corporation helped to realize the following benefits in support of the DOE mission:

- Infuse advanced CFD computing expertise and technology into the manufacturing industry.

- Develop advanced numerical CFD capabilities for highly resolved multiphase simulations.

- Develop new design concepts for low-temperature waste heat recovery technologies.

- Strengthen industrial competitiveness through advanced research and development. 


\section{TECHNICAL DISCUSSION OF WORK PERFORMED BY ALL PARTIES}

\subsection{MATHEMATICAL AND PHYSICAL MODELS}

In this section, the mathematical models (Sect. 3.1.1.1) and physical models (Sect. 3.1.2) used in the computational models within the CFD commercial package STAR-CCM+ (Siemens, 2018) are detailed. The VOF model was selected to model multiphase flow in the DCHE, as this model has been calibrated, verified, and validated against benchmark data for a variety of industrial applications. The VOF model was deemed capable of resolving the interface between immiscible phases and offers a variety of closure models for primary interphase interactions such as phase change, drag force, and surface tension force.

\subsubsection{VOF model in STAR-CCM+}

The VOF multiphase model is an interface-capturing method that predicts the distribution and the movement of the interface of immiscible phases. The discretization method employed in STAR-CCM+ to solve for the multiphase flow model is the finite volume method that requires the geometry to be meshed (hexahedral, polyhedral, or tetrahedral). The numerical solution is solved at each time step using an iterative method controlled by a set of relaxation parameters. First- and second-order temporal and spatial numerical discretization can be selected in the STAR-CCM+ input deck to control the numerical diffusion (i.e. accuracy) of the numerical solution. Choice of the discretization and the solver parameters are tightly coupled to the performance of the solver and the accuracy of the numerical solution (sharp interface in multiphase flow, for instance). Great care is generally recommended when selecting solver parameters to ensure convergence of the solver and obtaining a physical numerical solution. The stability of the numerical solution and the solver can be greatly affected by source terms and, more specifically, by stiff source terms present in phase change. Unsteady solvers are preferred for multiphase flow applications, as the use of steady-state solvers are often prohibited by the stiff source terms modeling phase change.

In STAR-CCM+, the VOF model consists of a mixture continuity equation, a mixture momentum equation, a mixture energy equation, and one volume fraction equation per phase $i$. The distribution of phases and the position of the interfaces are described by the fields of phase volume fraction $\alpha_{i}$ that is defined as:

$$
\alpha_{i}=\frac{V_{i}}{V}
$$

where $V_{i}$ is the volume of phase $i$ in the cell and $V$ is the volume of the cell. Cells are the smallest units that collectively make up the computational domain or mesh. The volume fractions of all phases in a cell must sum up to one:

$$
\sum_{i=1}^{N} \alpha_{i}=1,
$$

where $N$ is the total number of phases. 
The interface in which different phases exist is, like every other part of the domain, made of cells. The fluids in these cells are treated as a mixture, and their properties are calculated accordingly:

$$
\begin{gathered}
\rho=\sum_{i}^{N} \rho_{i} \alpha_{i} \\
\mu=\sum_{i}^{N} \mu_{i} \alpha_{i} \\
C_{p}=\sum_{i}^{N} \frac{\left(C_{p}\right)_{i} \rho_{i}}{\rho} \alpha_{i}
\end{gathered}
$$

where $\rho_{i}$ is the phase density, $\mu_{i}$ is the phase dynamic viscosity, and $\left(C_{p}\right)_{i}$ is the phase specific heat of phase $i$.

The phase mass conservation equation that gives the distribution of phase $i$ is

$$
\frac{\partial}{\partial t} \int_{V} \alpha_{i} d V+\oint \alpha_{i} v \cdot d a=\int_{V}\left(S_{\alpha, i}-\frac{\alpha_{i}}{\rho_{i}} \frac{D \rho_{i}}{D t}\right) d V-\int_{V} \frac{1}{\rho_{i}} \nabla \cdot\left(\alpha_{i} \rho_{i} v_{d, i}\right) d V
$$

where $a$ is the area vector; $v$ is the mixture (mass-averaged) velocity; $v_{d, i}$ is the diffusion velocity; $S_{\alpha, i}$ is a user-defined source term of phase $I$; and $\frac{D \rho i}{D t}$ is the material, or Lagrangian, derivative of the phase densities $\rho_{i}$.

When there are three or more VOF phases present, the volume fraction transport is solved for all the phases. The volume fraction of each phase is then normalized based on the sum of the volume fractions of all phases in each cell.

As the VOF models are part of the high-resolution interface capturing family, the VOF model uses a sharpening factor to reduce numerical diffusion in the simulation. The valid values are 0.0 through 1.0. The default value of the sharpening factor is zero, as the recommended second-order discretization scheme is enough to achieve a sharp interface between the two phases. If the value of the sharpening factor is set to 1.0, there will be less numerical diffusion, and hence, a very sharp interface can be obtained.

If a nonzero sharpening factor is specified, the following term is added to the VOF transport equation:

$$
\nabla \cdot\left(v_{c, i} \alpha_{i}\left(1-\alpha_{i}\right)\right)
$$

where $\alpha_{\mathrm{i}}$ is the volume fraction of phase $i, C_{\alpha}$ is the sharpening factor, $v$ is the fluid velocity, and $v_{c, i}$ is defined as follows:

$$
v_{c, i}=C_{\alpha} \times|v| \frac{\nabla \alpha_{i}}{\left|\nabla \alpha_{i}\right|}
$$


The mass conservation for all phases is given by

$$
\frac{\partial}{\partial t}\left(\int_{V}(\rho d V)+\oint_{A} \rho v \cdot d a=\int_{V} S d V\right.
$$

where $S$ is a mass source term that is related to the phase source term by the following equation:

$$
S=\sum_{i} S_{\alpha, i} \cdot \rho_{i}
$$

The momentum equation is given by

$$
\begin{aligned}
\frac{\partial}{\partial t}\left(\int_{V}(\rho v d V)+\oint_{A} \rho v \bigotimes v \cdot d a\right. & =-\oint_{A} \rho I \cdot d a+\oint_{A} T \cdot d a+ \\
& \int_{V} \rho g d V+\int_{V} f_{b} d V-\sum_{i} \int_{A} \alpha_{i} \rho_{i} v_{d, i} \bigotimes v_{d, i} \cdot d a
\end{aligned}
$$

where $p$ is the pressure, $I$ is the unity tensor, $T$ is the stress tensor, and $f_{b}$ is the vector of body forces.

The energy equation is given by

$$
\begin{array}{r}
\frac{\partial}{\partial t} \int_{V} \rho E d V+\oint_{A}\left[\rho H v+p+\sum_{i} \alpha_{i} \rho_{i} H_{i} v_{d, i}\right] J \cdot d a=-\oint_{A} \dot{q}^{\prime \prime} \cdot d a+ \\
\oint_{A} T \cdot v d a+\int f_{b} \cdot v d V+\int_{V} S_{E} d V,
\end{array}
$$

where $E$ is the total energy, $I$ is the total enthalpy, $\dot{q}^{\prime \prime}$ is the heat flux vector, and $S_{E}$ is a user-defined energy source term.

The system of equations to solve is composed of $N+3$ equations and requires an equation of state for each phase along with closure models for the source terms. Depending on the flow type, turbulent models can also be used and are available within STAR-CCM+ (Siemens, 2018). The next section presents all closure models that are required to model the multiphase flow of a DCHE system.

\subsubsection{Multiphase Closure Models in STAR-CCM+}

In this section, the physical models used to close the system of equations described in Sect. 3.1.1.1 are provided: Rohsenow boiling model, slip-velocity force, drag force, equation of state, surface tension and gravity forces, and turbulent model. Further details about these closure models can be retrieved from the STAR-CCM+ theory manual (Siemens, 2018).

\subsubsection{Rohsenow Boiling Model}

Rohsenow provided an empirical correlation to calculate the surface heat flux due to boiling: 


$$
q_{b, w}=\mu_{l} h_{\text {lat }} \sqrt{\frac{g\left(\rho_{l}-\rho_{v}\right)}{\sigma}}\left(\frac{C_{p, l}\left(T_{w}-T_{\text {sat }}\right)}{C_{q, w} h_{\text {lat }} \operatorname{Pr}_{l}^{n_{p}}}\right)^{2}
$$

where $\mu_{l}, h_{l a t}, C_{p, l}, \rho_{l}$, and $P_{r l}$ are the dynamic viscosity, latent heat, specific heat, density, and Prandtl number of the liquid phase, $n_{p}$ is the Prandtl number exponent (1.73 by default), $g$ is gravity, $\rho_{v}$ is the vapor density, $\sigma$ is the surface tension coefficient at the liquid-vapor interface, $T_{w}$ is the wall temperature, $T_{s a t}$ is the saturation temperature, and $C_{q, w}$ is an empirical coefficient varying with the liquid-surface combination.

The vapor mass generation rate $m_{e w}^{\cdot}$ (over the area that nucleation sites cover) is

$$
m_{e w}=\frac{C_{e w} q_{b w}}{h_{\text {lat }}}
$$

where $C_{e w}$ is a model constant stating how much of the boiling heat flux is used for creation of vapor bubbles.

If the Rohsenow correlation is applied outside its range of applicability (for example, to the film boiling regime), then high, unrealistic values of heat fluxes will be obtained. Fluid temperatures can become higher than the near-wall temperature. This behavior stems from the fact that the Rohsenow correlation does not depend on the fluid temperature; heat enters the domain irrespective of the fluid temperature. To prevent this condition, the heat flux that the correlation calculates is multiplied by

$$
\max \left[0, \min \left(\left(\frac{T_{w}-T}{T_{w}-T_{\text {sat }}}\right), 1\right)\right],
$$

where $T$ is the fluid temperature near the heated wall. Thus, if $T<T_{\text {sat }}$, the Rohsenow correlation is used directly, and if $T>T_{\mathrm{w}}$ the boiling heat flux is zero. For fluid temperatures which are between the wall and the saturation temperature, only a fraction of the heat flux predicted by the correlation is used.

\subsubsection{Slip velocity}

The presence of the slip velocity in the VOF method gives better modeling of physical behavior of the multiphase system in cases where the interface is not resolved. This causes the VOF model to behave like the Eulerian multiphase mixture (n-phase mixture) and improves the modeling significantly while restoring a sharp interface.

Including the slip between the phases allows STAR-CCM+ to model the effects of phases moving at different velocities. Incorporating the slip velocity to the VOF method causes the recovery of a sharp interface.

\subsubsection{Drag}

Generally, the inter-phase force is computed as a function of the drag coefficient. For a continuousdispersed phase interaction, the force on the dispersed phase $i$ due to the drag of phase $j$ is given by

$$
F_{i, j}^{D}=A_{D} v_{r}
$$

where $A_{D}$ is the linearized drag coefficient and $v_{r}$ is the relative velocity between phases $i$ and $j$, and is defined as 


$$
v_{r}=v_{j}-v_{r}
$$

$A_{D}$ acts as a linear multiplier of the relative velocity.

For a multiphase flow regime phase interaction, the total drag force is calculated by

$$
F_{i, j}^{D}=\sum_{t=f r, i r, s r} W_{t} A_{D, t} v_{r}
$$

where $W_{t}$ is the weight function, and the subscripts $f r, i r$, and $s r$ refer to the first regime, second regime, and interface regime, respectively. The calculation of the linearized drag is analogous to the continuousdispersed phase interaction. For the first regime, the primary phase is considered as the continuous phase and the secondary phase as the dispersed phase. For the second regime, the secondary phase is considered as the continuous phase and the primary phase as the dispersed phase.

The linearized drag coefficient is related to the standard engineering definition of the drag coefficient $C_{D}$ for particles by

$$
A_{D}=C_{D} \frac{1}{2} \rho_{c}\left|v_{r}\right|\left(\frac{a_{c d}}{4}\right)
$$

where $a_{c d}$ is the interfacial area density. The factor $\frac{a_{c d}}{4}$ is the projected area of the equivalent spherical particle. The slip velocity is based on body forces. The drag coefficient for the simulation has been chosen to be the Schiller-Naumann drag coefficient. In the Schiller-Naumann correlation for Newtonian fluids, the drag coefficient of spherical, rigid particles is given by

$$
C_{D}= \begin{cases}\frac{24}{R e_{d}}\left(1+0.15 R e_{d}^{0.678}\right) & 0<R e_{d} \leq 1000 \\ 0.44 & R e_{d}>1000\end{cases}
$$

The dispersed-phase Reynolds number, $R_{d}$, is defined as

$$
R e_{d}=\frac{\rho_{c}\left|v_{r}\right| l}{\mu_{c}}
$$

where $\rho_{c}$ is the density of the continuous phase, $\mu_{c}$ is the dynamic viscosity of the continuous phase, and $l$ is the interaction length scale, or bubble size.

\subsubsection{Equation of state}

The equation of state is a thermodynamic equation that relates density to state variables (pressure and temperature). An equation of state is required for each phase of the multiphase flow model in order to model the phase density and mixture density variations with respect to pressure and temperature changes. STAR-CCM+ has multiple built-in equations of state and allows for implementation of custom equations of state. Choice of the equation of state is dependent upon flow and operating conditions. In the case of 
the DCHE that operates under atmospheric conditions, compressibility effects of liquid phases can be neglected, and thus liquid phase densities were assumed to be constant. Unlike liquid phases, the gas phase is more subject to compressibility effects. In the case of a DCHE, the gas phase is generated by boiling and becomes slightly superheated. Thus, density variations are relatively small, and the density of the gas phase can be assumed constant as well.

\subsubsection{Surface tension and gravity forces}

The surface tension force is a tensile force tangential to the interface separating two fluids. This force acts to hold the fluid molecules at the free surface in contact with the rest of the fluid. Surface tension is a result of cohesive and adhesive forces. Cohesion forces between, coupled with the nature of fluids, causes fluids to be immiscible. The ease with which fluids can mix can be expressed with $\sigma$, the surface tension coefficient, an experimentally determined parameter. $\sigma$ is defined as the amount of work needed to create a unit area of free surface.

STAR-CCM+ models surface tension, an interfacial surface force, as a volumetric force using the continuum surface force (CSF) approach. The magnitude of the surface of the surface tension force depends mainly on the nature of the fluid pair and the temperature.

For a curved interface, the surface tension force $\sigma$ can be divided into two components:

$$
f_{\sigma}=f_{\sigma, n}+f_{\sigma, t}
$$

where

$$
f_{\sigma, n}=\sigma \kappa \mathbf{n}
$$

and

$$
f_{\sigma, n}=\frac{\partial \sigma}{\sigma t} t
$$

where $\boldsymbol{n}$ is the unit vector normal to the free surface and directed from liquid to gas, $t$ is the unit vector in the tangential direction to the free surface, and $\kappa$ is the mean curvature of the free surface.

The surface tension force is calculated according to the CSF model, which uses the smooth field of the phase volume fraction $\alpha_{i}$ to calculate to a vector normal to the interface:

$$
\mathbf{n}=\boldsymbol{\nabla} \cdot \alpha_{i}
$$

The curvature of the interface can therefore be expressed in terms of the divergence of the unit normal vector $\mathbf{n}$ :

$$
\begin{gathered}
\kappa=-\nabla \cdot \frac{\boldsymbol{\nabla} \cdot \alpha_{i}}{\left|\boldsymbol{\nabla} \cdot \alpha_{i}\right|} \\
f_{\sigma, n}=-\sigma \nabla \cdot\left(\frac{\boldsymbol{\nabla} \cdot \alpha_{i}}{\left|\boldsymbol{\nabla} \cdot \alpha_{i}\right|}\right) \nabla \cdot \alpha_{i}
\end{gathered}
$$


The CSF model was extended for a two-fluid model. The surface tension force is divided among the phases existing in a cell according to

$$
f_{\sigma, i}=\beta_{i} f_{\sigma}
$$

where the subscripts $i$ indicates the $i^{\text {th }}$ phase and $\beta$ denotes the splitting factor of the surface tension force. The pressure gradient within the two-fluid model is the summation of the momentum equations:

$$
\sum_{i} \alpha_{i} \nabla \cdot p=\nabla \cdot p=\sum_{i} \beta_{i} f_{\sigma}
$$

At kinetic equilibrium, the pressure gradient is equal to surface tension force, thus

$$
\sum_{i} \beta=1
$$

This form of surface tension force is implemented as

$$
f_{\sigma, i}=\alpha_{i} \sigma \kappa \nabla \cdot \alpha_{i}
$$

The gravity force is also enabled as the flow is gravity-driven using the default parameters (earth gravity).

\subsubsection{Turbulent models}

STAR-CCM+ offers a selection of turbulent models for both single-phase and multiphase flows (Siemens, 2018). For single-phase flow, the turbulent nature of the flow commonly depends on the geometry and the Reynolds number. For multiphase flow, the turbulent nature of the flow is also influenced by the physics itself such as phase change, drag, and surface tension. For instance, boiling is a chaotic physical phenomenon and an unsteady process that can enhance mixing at an interface or at a heating wall boundary. The low-Reynolds k-Epsilon model and SST k-omega model were selected to perform the numerical analysis presented in later sections.

\subsubsection{Remarks}

Once a CFD model of the geometry and the physics to solve is developed, the next task consists of verifying and validating the numerical solution using the available experimental data. This is commonly the most time-consuming step of a CFD project as it involves all aspects of the computation (mesh, solver, mathematical and physical models, and experimental data) and primarily serves as building confidence in the model's predictive fidelity and defining limits of its application. The process to verify and validate the CFD model is described in the next section.

\subsection{VERIFICATION AND VALIDATION OF THE CFD MODEL}

The objective of this section is to describe the work performed to verify and validate the CFD model using the experimental data from the published literature (Baqir A. M., 2016). 


\subsubsection{Experimental setup}

For the purpose of verifying and validating the CFD model, it was decided to rely on the experimental results published in Baqir et al. (Baqir, Mahood, Hameed, \& Campbell, 2016). In this section, an overview of the experimental setup is provided. For further details, see (Baqir, Mahood, Hameed, \& Campbell, 2016) and (Baqir A. M., 2016).

A schematic of the experimental setup is shown in Figure 8. It is divided into three sections: the test section, the continuous-phase supply system, and the dispersed-phase supply system. The test section is a $1 \mathrm{~m}$ long Perspex tube with an internal diameter of $10 \mathrm{~cm}$. Twenty holes, spaced $7.5 \mathrm{~cm}$ apart, provide allowance for $20 \mathrm{~K}$-type thermocouples.

The dispersed-phase supply system is connected to the test section through a sparger at the bottom. The continuous-phase inlet tube is at the top of the test section. The continuous-phase supply system is composed of a large constant temperature water bath with a controller, water pump, pipes, and valves. The water bath capacity is $500 \mathrm{~L}$; the bath is heated by three electric heaters, each of $3 \mathrm{~kW}$ capacity. The dispersed-phase supply system consists of a plastic 20 L capacity storage tank, peristaltic pump, pipes, and valves.

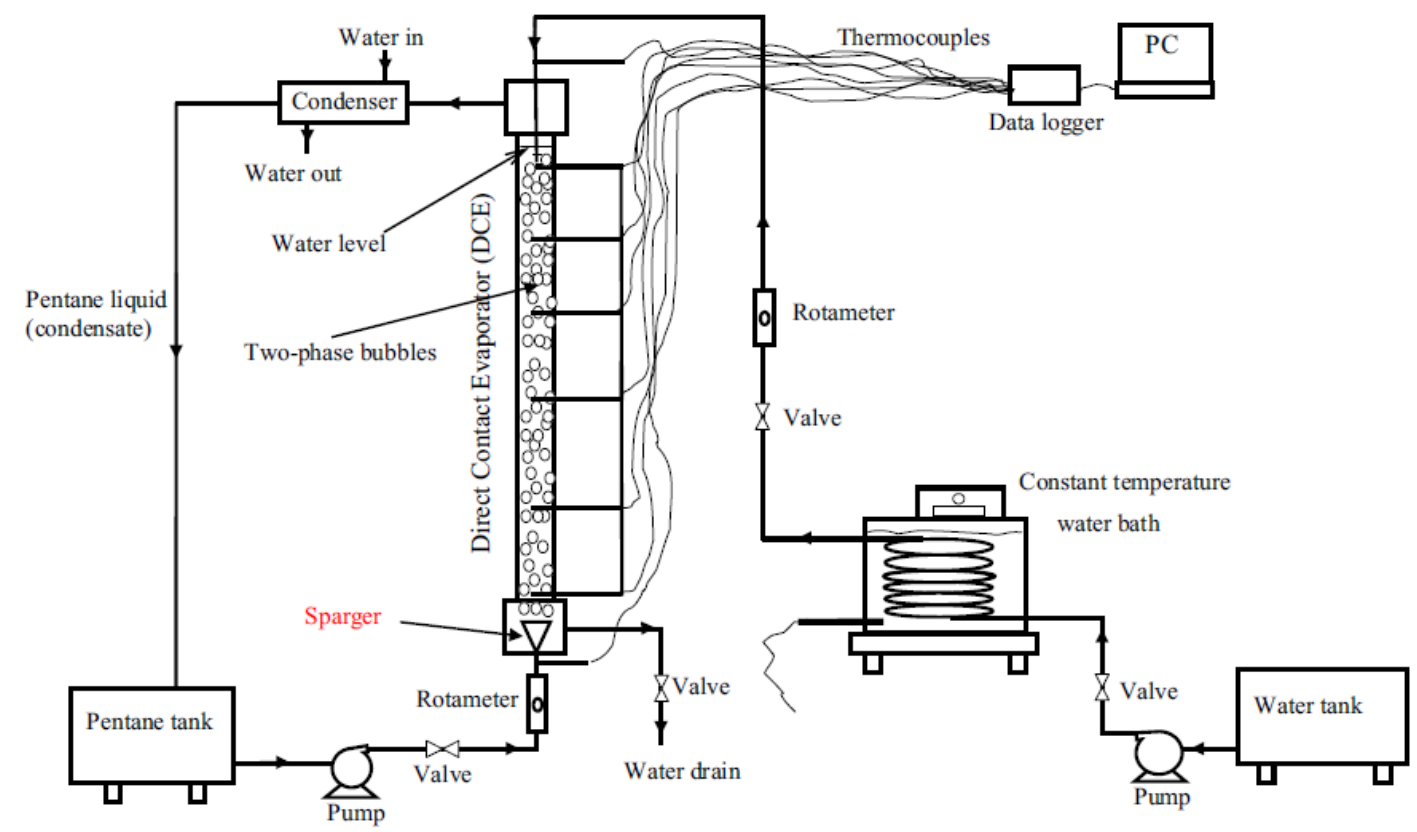

Figure 8. Schematic diagram of experimental configuration (Baqir A. M., 2016).

The thermodynamic properties of the liquid pentane, gaseous pentane, and water used in the experimental setup are shown in Table 1 and Table 2, respectively. 
Table 1. Physical properties of liquid and gaseous pentane

(Baqir A. M., 2016).

\begin{tabular}{|l|c|}
\hline \multicolumn{1}{|c|}{ Property } & Value \\
\hline Saturation temperature $\left({ }^{\circ} \mathrm{C}\right)$ & 36 \\
\hline Molar mass $(\mathrm{kg} / \mathrm{kmol})$ & 72.15 \\
\hline Thermal diffusivity $\left(\mathrm{m}^{2} / \mathrm{s}\right)$ & $7.953 \times 10^{-8}$ \\
\hline Specific heat of liquid $(\mathrm{kJ} / \mathrm{kgK})$ & 2.363 \\
\hline Specific heat of gas $(\mathrm{kJ} / \mathrm{kgK})$ & 1.66 \\
\hline Thermal conductivity of liquid $(\mathrm{W} / \mathrm{mK})$ & 0.1136 \\
\hline Thermal conductivity of gas $(\mathrm{W} / \mathrm{mK})$ & 0.015 \\
\hline Kinematic viscosity $\left(\mathrm{m}^{2} / \mathrm{s}\right)$ & $2.87 \times 10^{-7}$ \\
\hline Viscosity $(\mathrm{kg} / \mathrm{m} . \mathrm{s})$ & $1.753 \times 10^{-4}$ \\
\hline Latent heat of vaporization $(\mathrm{kJ} / \mathrm{kg})$ & 359.1 \\
\hline Density of liquid $\left(\mathrm{kg} / \mathrm{m}^{3}\right)$ & 621 \\
\hline Density of gas $\left(\mathrm{kg} / \mathrm{m}^{3}\right)$ & 2.89 \\
\hline Surface tension $\left(\mathrm{N} / \mathrm{m}^{3}\right)$ & 0.01432 \\
\hline
\end{tabular}

Table 2. Physical properties of water (https://webbook.nist.gov/chemistry/fluid/, 2018).

\begin{tabular}{|l|c|}
\hline \multicolumn{1}{|c|}{ Property } & Value \\
\hline Density $\left(\mathrm{kg} / \mathrm{m}^{3}\right)$ & 997.561 \\
\hline Dynamic viscosity $(\mathrm{Pa}-\mathrm{s})$ & $8.8871 \mathrm{E}-04$ \\
\hline Specific heat $(\mathrm{J} / \mathrm{kg}-\mathrm{K})$ & $4,181.72$ \\
\hline Thermal conductivity $(\mathrm{W} / \mathrm{m}-\mathrm{K})$ & 0.620271 \\
\hline Heat of formation $(\mathrm{J} / \mathrm{kg})$ & 192,070 \\
\hline
\end{tabular}

The experiment initiates by injecting water from the top of the test section at the specified temperature. The water was circulated through the test section to establish a constant temperature in the tube. Liquid pentane, the dispersed phase, was then injected from the bottom via the sparger. Three different sparger configurations were used for this experiment and are shown in Figure 9: 7-nozzle sparger, 19-nozzle sparger, and 36-nozzle sparger.

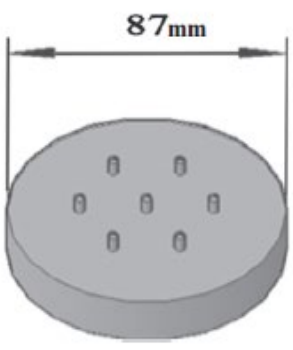

(a)

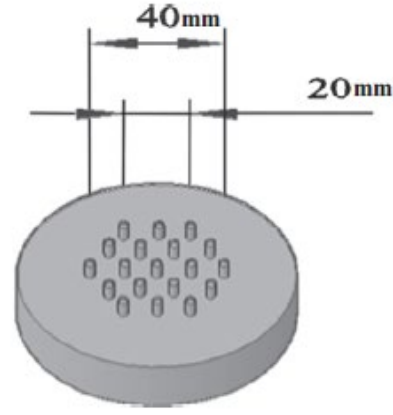

(b)

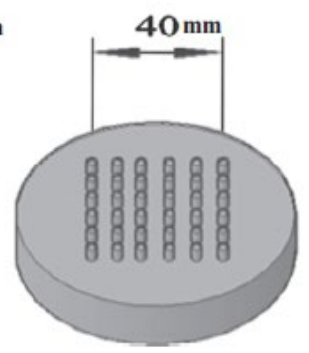

(c)

Figure 9. Sparger geometry used in the experiment: (a) 7-nozzle sparger,

(b) 19-nozzle sparger, (c) 36-nozzle sparger (Baqir A. M., 2016). 
The temperature and flow rates of the continuous and dispersed phases were recorded and are provided in Table 3. Multiple flow-rate combinations were investigated for each sparger while the inlet temperature remained fixed.

Table 3. Experimental Parameters

(Baqir A. M., 2016).

\begin{tabular}{|l|c|}
\hline \multicolumn{1}{|c|}{ Parameter } & Values \\
\hline Inlet water temperature $\left({ }^{\circ} \mathrm{C}\right)$ & 45 \\
\hline Inlet dispersed temperature $\left({ }^{\circ} \mathrm{C}\right)$ & 36 \\
\hline Pressure at top of pipe $($ atm $)$ & 1 \\
\hline Water volume flow rate $(\mathrm{L} / \mathrm{h})$ & $10-40$ \\
\hline Liquid pentane flow rate $(\mathrm{L} / \mathrm{h})$ & $10-20$ \\
\hline
\end{tabular}

Since the temperature of the continuous phase is well above the saturation temperature, dispersed liquid pentane droplets started forming at the sparger. The drops rise along the test section under the action of buoyancy force, while water, being the denser fluid, is falling under gravity. Contact with the water superheats the droplets of pentane to above their inlet saturation temperature, where further absorption of heat is used as latent heat and the droplet now comprises a saturated mixture of liquid and vapor phases of pentane. As all mass from the liquid phase is replaced by the vapor phase, the droplets transition to vapor altogether, and a plume of vapor ascends the DCHE.

The height over which evaporation occurs is termed the "active length." Heat transfer still occurs beyond the active length, which causes the vapor collected at the top to be slightly superheated (up to $5^{\circ} \mathrm{C}$ above $\left.\mathrm{T}_{\text {sat }}\right)$. The superheated vapor is condensed and returned to the liquid pentane storage tank to be injected again into the test section. The liquid pentane is fully evaporated, and only gaseous pentane exits at the top outlet while liquid water exits at the bottom outlet below the sparger.

\subsubsection{Geometry and mesh process for the experimental setup}

In this section, the assumptions made on the geometry and the process to generate the mesh are discussed.

\subsubsection{Geometry and computer-aided design (CAD) model}

The computer-aided design (CAD) geometry of the experimental setup had to be created from scratch through identifying relevant geometrical details from Baqir et al. (Baqir, Mahood, Hameed, \& Campbell, 2016). It was determined that modeling a quarter of the full geometry was sufficient to capture the physics using symmetry planes to support our verification and validation objectives. The CAD models used in the CFD analysis are shown in Figure 9 and Figure 10. 


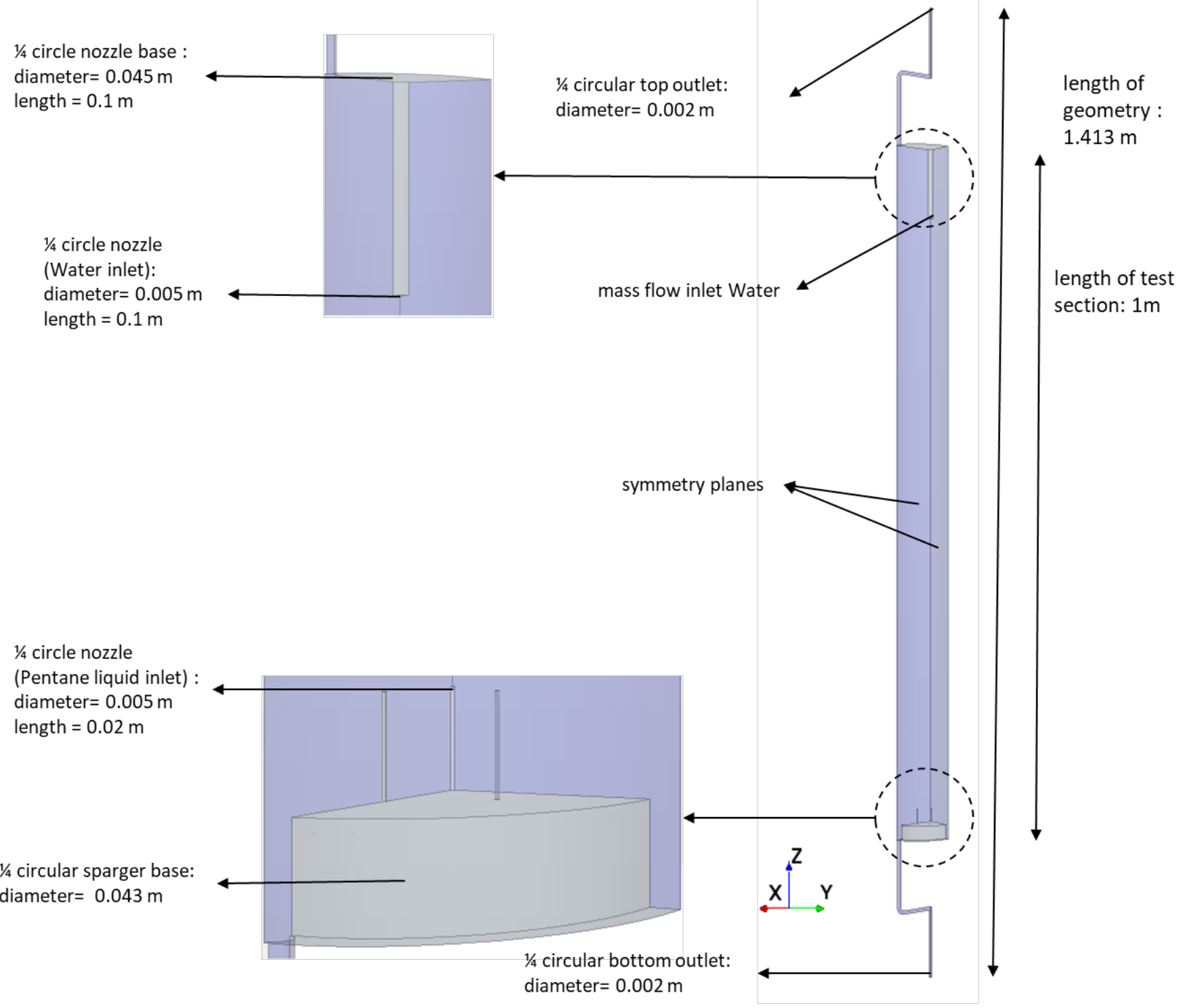

Figure 10. CAD model of the experimental setup with dimensions.

Zoomed-in views of the liquid water and liquid pentane inlets located at the bottom and at the top of the geometry, respectively, are also provided in Figure 11. Since a quarter of the geometry is being modeled, the pipe serving as the liquid water inlet and some of the nozzles of the sparger are trimmed. 


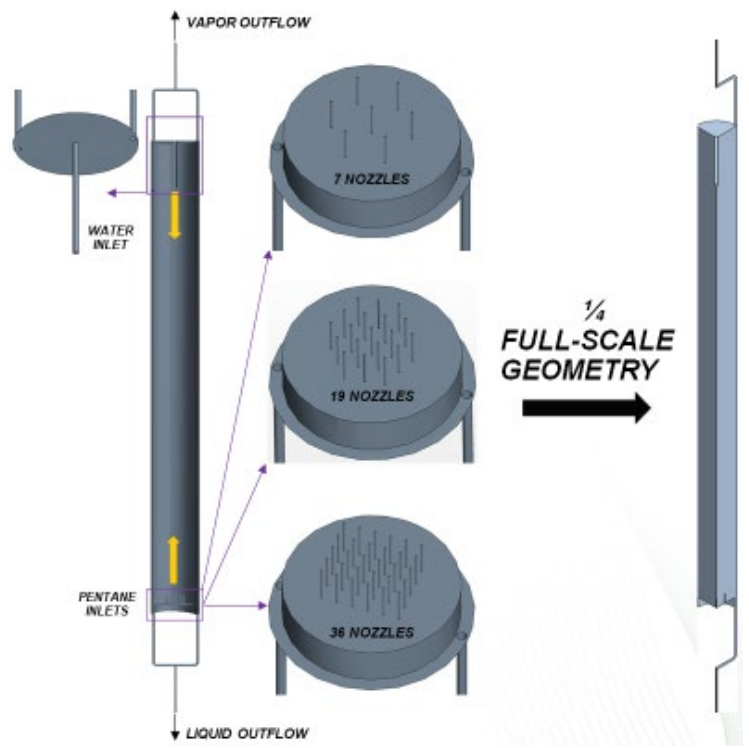

Figure 11. Zoomed-in views of the water inlet nozzle and the spargers used in the CFD models: 7, 19, and 36 nozzle spargers.

\subsubsection{Mesh settings and mesh generation}

STAR-CCM+ supports multiple surface and volume meshing tools (Siemens, 2018). The choice of the meshing tool is tied to the complexity of the geometry and the assumptions made on the geometry and can also influence the accuracy of the numerical solution. Since the focus of this project is to model turbulent multiphase flows with phase change, the CAD models described in section 3.2.2.1 were meshed using a Trimmer model in STAR-CCM+. The Trimmer model produces cells that are aligned with the cartesian coordinate system and thus is better suited to capturing physics near the symmetry planes. Generating a mesh for a given geometry and physics relies on a quality assurance process (see Figure 12).

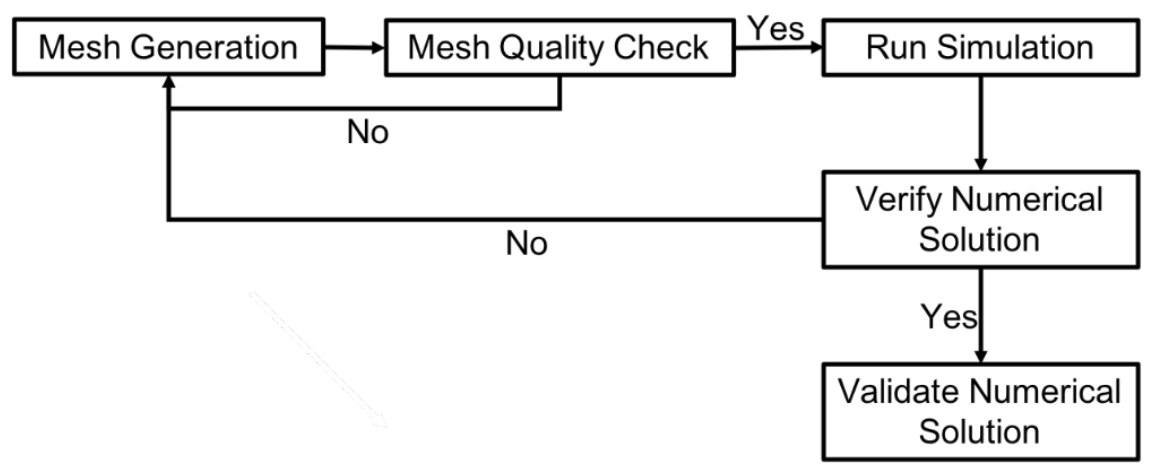

Figure 12. Quality assurance process to optimize the mesh of a CFD model.

There are several factors to consider when constructing a mesh for a computational domain. The factors include the time and memory required to build the mesh, the target solution accuracy and convergence rate, and the quality and/or properties of the domain's geometry. The remainder of this section highlights the settings for the optimized mesh, i.e., the mesh to accurately capture the physics of interest. Surface and volume meshing tools are briefly described, and mesh settings are provided. 
The Trimmer model is not directly dependent on the surface quality of the starting surface and as such is more likely to produce a good quality mesh for most situations. Compared with other mesh types supported by STAR-CCM+, hexahedral meshes are known to generate more accurate numerical solutions. The Trimmer model has proven to be an efficient and robust tool for simple and complex geometries. The Trimmer model produces hexahedral cells with minimal cell skewness but usually generates a mesh with a higher cell count than other meshing tools for a given geometry. The Surface Remesher model was used to improve the overall quality of the surface with adequately small surface sizes at the wall boundaries to properly capture the wall behavior. Since transients occur in the bulk flow and are not dominated by near-wall gradients, prism layers were excluded from the mesh. The mesh metrics for the Trimmer and Surface Remesher models are shown in Table 4.

Table 4. Mesh settings for the Trimmer and Surface Remesher models.

\begin{tabular}{|l|l|}
\hline \multicolumn{1}{|c|}{ Parameter } & \multicolumn{1}{c|}{ Value } \\
\hline Meshing tool & Trimmer and Surface Remesher \\
\hline Base size (m) & 0.005 \\
\hline Maximum cell size $(\mathrm{m})$ & 0.005 \\
\hline Surface growth rate & 1.3 \\
\hline Surface relative minimum size $(\mathrm{m})$ & $2.5 \mathrm{E}-4$ \\
\hline Surface relative target size $(\mathrm{m})$ & 0.001 \\
\hline Total number of cells & 658,575 \\
\hline
\end{tabular}

Volumetric control modules were also used to locally refine the mesh around the sparger, the water inlet, and at the location of the interface. Volume control parameters are given in Table 4, and scenes of the mesh obtained with STAR-CCM+ are provided in Figure 13, near the sparger area, the water inlet area and the location of the interface, respectively.
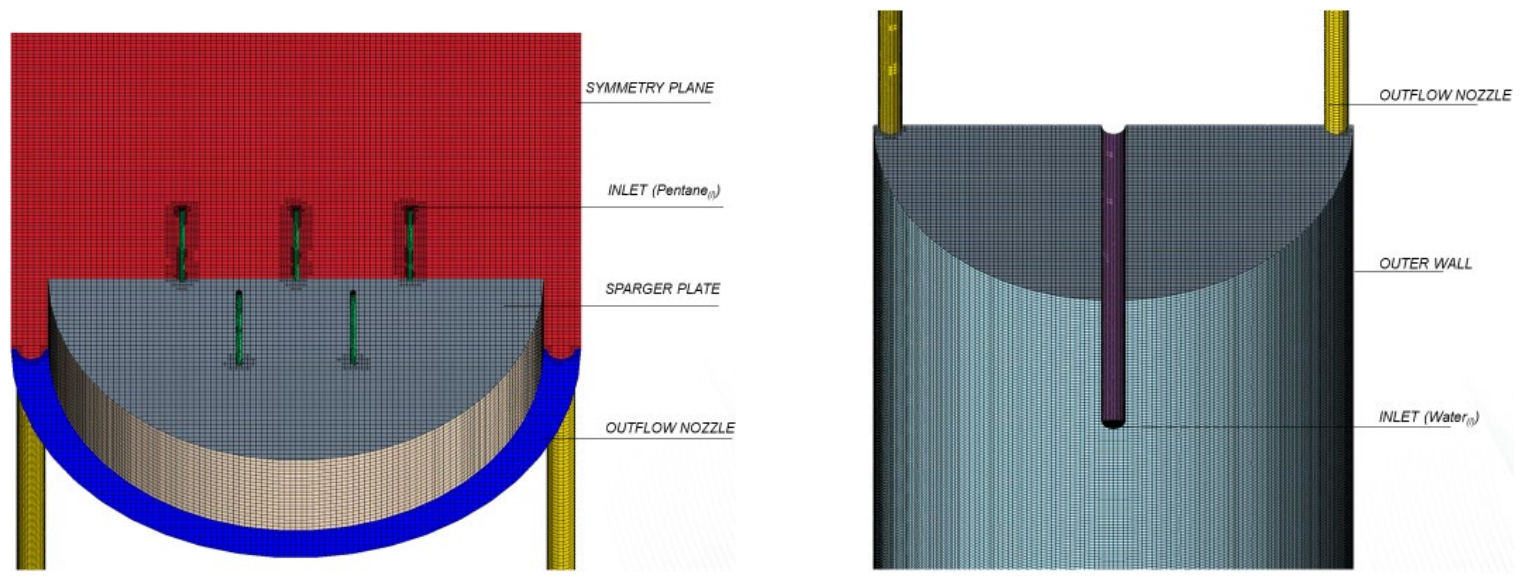

Figure 13. Mesh detail on lower surfaces (left) and upper surfaces (right) of the DCHE.

This strategy was helpful in reducing the total cell count of the mesh while preserving the solver convergence and the accuracy of the numerical solution. For the initial runs, a coarse mesh was generated by increasing the base size and was used to develop the flow. Once the numerical solution was sufficiently developed, the mesh was refined by simply reducing the base size before the code was run again until a steady-state solution was obtained. Since all mesh parameters were defined as a function of the base size, this process was as simple as modifying the base size value. 


\subsubsection{Numerical model}

Once a mesh is generated, the next step consists of selecting the appropriate physics, solvers and their settings, the boundary and initial conditions, and the criteria to determine when the convergence is achieved. The CFD model is then run, and the numerical solution is analyzed.

\subsubsection{Physics, numerical model, and solver settings}

To simulate the behavior of a DCHE, we must take into consideration the presence of multiple phases (see Sect. 1.2.) Although the flow is laminar at the specified flow rates, turbulence effects at the interface, where phase change occurs, should be accounted for. Although the goal of the simulation is to reach a steady-state solution with a stable interface, the nature of the given phenomena is transient. Thus, a transient solver needs to be used.

In STAR-CCM+, the Eulerian multiphase module offers a variety of multiphase flow models to be used for multiphase flow applications. The transient version of the VOF model was adopted for its ability to simulate flows of several immiscible fluids and resolve the interface between the mixture of phases. The VOF model treats each phase as a distinct substance with distinct physical properties while solving for mixture velocity, mixture density, and mixture temperature. The standard k-epsilon low-Re model was selected to model turbulent effects along with the all $y^{+}$wall treatment. The all $y^{+}$wall treatment is a hybrid treatment that emulates the low $y^{+}$wall treatment for fine meshes and the high $y^{+}$wall treatment for coarse meshes. All numerical methods were set to second-order accuracy.

While selecting the multiphase flow model, STAR-CCM+ automatically enables a set of solvers with parameters to control solver methods and convergence criteria for inner and outer iterations at each time step. Influence of each solver on the convergence is mostly controlled by relaxation parameters. These relaxation parameters can be tuned to ensure convergence of the solver during the transient runs. The setting of the relaxation parameters highly depends on the physics to be solved, and the values used in our models are summarized in Table 5.

Table 5. Solver parameters for the VOF model.

\begin{tabular}{|l|l|}
\hline \multicolumn{1}{|c|}{ Solver name } & \multicolumn{1}{c|}{ Values } \\
\hline Implicit unsteady & second order \\
\hline Time step (s) & 0.001 \\
\hline Phase slip velocity (m/s) & 0.3 \\
\hline Segregated flow & Velocity $=0.2 /$ Pressure $=0.1$ \\
\hline Segregated VOF & 0.3 \\
\hline Segregated energy & 0.3 \\
\hline K-epsilon turbulence & 0.3 \\
\hline K-epsilon turbulent viscosity & 0.3 \\
\hline
\end{tabular}

After the physics are selected and the appropriate solver parameters are set, the phases and their respective material properties are selected. As stated in Section 3.1.2.4, all material properties were assumed to be constant and set to values provided in Table $\mathbf{1}$ and Table 2. Interactions between the phases are controlled by the material interaction module. One module is required per phase interaction pair(e.g., liquid water-gaseous pentane, liquid pentane-gaseous pentane and liquid water-liquid pentane. Through the material interaction module, interfacial forces can be set along with the phase-change models. The following phase interaction models were selected: drag-based slip velocity, interaction area density, interaction length-scale model, interface momentum dissipation, and VOF-VOF phase interaction. For the 
liquid and gaseous pentane interactions, in addition to the previously mentioned interactions, VOF boiling and Rohsenow Boiling interactions were selected to model the phase change. Surface tension force was selected for the liquid water-gaseous pentane and liquid water-liquid pentane phase interaction pairs to account for the surface tension effects that cause the immiscibility.

\subsubsection{Initial and boundary conditions}

Initial conditions and boundary conditions are required in a CFD model to achieve a physical numerical solution. From a mathematical perspective, partial differential equations are well posed when initial and boundary conditions are supplied. As the VOF model falls in this category, the initial and boundary conditions must be specified in the CFD model, so that the correct transient and steady-state solutions can be obtained.

For the experimental setup described in (Baqir, Mahood, Hameed, \& Campbell, 2016) and in Section 3.2.1, the vertical column is initially filled with liquid water at rest and liquid pentane (refrigerant) is injected in the vertical column from the bottom sparger. Since the experimental data in (Baqir, Mahood, Hameed, \& Campbell, 2016) and (Baqir A. M., 2016) do not contain any transient results, only the steady-state results are of interest to verify and validate the CFD model. Therefore, initial conditions of the CFD model can be chosen to minimize central processing unit (CPU) resources, i.e. to recover the steady-state solution with as few time steps as possible. Investigations with two-dimensional CFD model were performed to determine the optimal initial conditions that are summarized in Table 6.

Table 6. Initial conditions used in the CFD model for the experimental setup.

\begin{tabular}{|l|c|c|}
\hline \multicolumn{1}{|c|}{ Variable } & Initial value & Units \\
\hline Temperature & 45.0 & ${ }^{\circ} \mathrm{C}$ \\
\hline Pressure & 101,325 & $\mathrm{~Pa}$ \\
\hline Velocity vector & {$[0.0,0.0,0.0]$} & $\mathrm{m} / \mathrm{s}$ \\
\hline Liquid water volume fraction & 1.0 & $\mathrm{~N} / \mathrm{A}$ \\
\hline Liquid pentane volume fraction & 0.0 & $\mathrm{~N} / \mathrm{A}$ \\
\hline Gaseous pentane volume fraction & 0.0 & $\mathrm{~N} / \mathrm{A}$ \\
\hline
\end{tabular}

Since only a quarter of the vertical column is modeled, boundary conditions must be specified to close the mathematical CFD model and mimic the closed-loop system of the experimental setup. Five types of boundary conditions were used in the CFD model: inlet velocity, pressure outlet, no-slip wall, and symmetry conditions. The velocity magnitude was specified at the inlet conditions for the liquid water and liquid pentane at the nozzle and the sparger, respectively. The velocity magnitudes were computed from the mass flow rates and the material properties given in Table 3. At the bottom outlet, a pressure outlet condition was specified with a target mass flow rate for the liquid water (Baqir, Mahood, Hameed, \& Campbell, 2016). The outlet mass flow rate target was set to the same as the inlet mass flow rate of the liquid water. The top outlet condition is set to "outlet," which is equivalent to a vent: the phases (gaseous pentane at steady state) reaching the outlet are allowed to exit the computational domain. The no-slip wall condition and symmetry condition were selected for the walls and the symmetry planes, respectively. A summary of the boundary conditions and boundary values is provided in Table 7 . 
Table 7. Boundary conditions and boundary used in the CFD model of the experimental setup.

\begin{tabular}{|l|c|c|}
\hline \multicolumn{1}{|c|}{ Boundary } & STAR-CCM+ boundary type & Boundary value \\
\hline Liquid water inlet & Mass Flow Inlet & $0.004 \mathrm{~kg} / \mathrm{s}$ \\
\hline Liquid pentane inlet & Inlet velocity: $[7,19,36]$ nozzles & {$[1.01 \mathrm{~m} / \mathrm{s}, 0.372 \mathrm{~m} / \mathrm{s}, 0.196 \mathrm{~m} / \mathrm{s}]$} \\
\hline Bottom outlet & Pressure outlet & $1500,4500,7500 \mathrm{~Pa}$ \\
\hline Top outlet & Pressure outlet & $-1000 \mathrm{~Pa}$ \\
\hline Wall boundaries & No-slip wall & $\mathrm{N} / \mathrm{A}$ \\
\hline Symmetry planes & Symmetry & $\mathrm{N} / \mathrm{A}$ \\
\hline
\end{tabular}

\subsubsection{Convergence criteria}

Unlike for the single-phase CFD models, detecting a steady-state solution when performing a multiphase flow simulation can be quite challenging. Some of the forces and physical phenomenon are highly unsteady and only achieve a steady-state behavior in a statistical manner. It is then customary to rely on surface and volume average quantities to detect a steady state for multiphase flows. Surface-average quantities are commonly used at boundaries to monitor variations as a function of time. For instance, volume-average quantities provide insight on the bulk flow behavior where phase change occurs and provide information on physical patterns when tracked as a function of time. Mass conservation between the inlets and outlets are also good indicators to assess the convergence of the numerical solution. Temporal variations of the turbulent intensity are commonly used to assess the convergence of the turbulence model.

For the purpose of assessing the performance of the numerical solution, the following metrics were monitored as a function of time and to identify when a stationary state has been reached:

- volume-average mixture temperature,

- volume-average volume fraction of all phases,

- turbulence intensity,

- pressure and phase volume fractions at outlet conditions,

- conservation of mass flow rates for all phases, and

- mass imbalance.

Plots of the monitors will be provided in later sections that deal with the analysis of the numerical solution.

\subsubsection{Numerical results and analysis}

In this section numerical results for the CFD model of the experimental setup are presented and analyzed. Three sets of numerical simulations were performed with three different sparger types: 7-nozzle sparger (Section 0), 19-nozzle sparger, and 36-nozzle sparger (Section 3.2.4.2). For each set of results, evidence that the numerical solution has reached a steady state is provided, and limited validation is performed by comparing the predicted active length to the experimental active length. All the cases were initialized with the same initial conditions (Table 6) but with different boundary conditions, which were specified for each case.

The following workflow to reach a stable steady-state solution was used to minimize CPU resources while conserving the desired degree of accuracy. A coarser mesh was initially used to develop the flow with first-order spatial and temporal numerical methods. Once the numerical solution was close to reaching a steady state, second-order numerical methods were triggered to improve accuracy after the mesh was refined to a desired level. 


\subsubsection{The seven-nozzle sparger case}

Numerical results for the CFD model of the seven-nozzle sparger case are presented in this section. The mesh contains $6.5 \mathrm{M}$ cells and required 2,304 CPU hours (48 processors for $48 \mathrm{~h}$ ) to reach the steady state. The boundary condition settings are shown in Table 8 . The pressure values are relative to the atmospheric pressure (101,325 Pa), and the pressure differential of 2,500 $\mathrm{Pa}$ was found to yield the correct steady-state solution. The liquid pentane is injected in the column at saturation temperature. The temperature of the liquid water (hot source) is set to $318.6 \mathrm{~K}$.

Table 8. Boundary condition used for the CFD model with the seven-nozzle sparger.

\begin{tabular}{|l|c|c|}
\hline \multicolumn{1}{|c|}{ Boundary } & STAR-CCM+ boundary type & Boundary value \\
\hline Liquid water inlet & Inlet velocity and temperature & $0.42773 \mathrm{~m} / \mathrm{s}, 318.16 \mathrm{~K}$ \\
\hline Liquid pentane inlet & Inlet velocity and temperature & $1.01 \mathrm{~m} / \mathrm{s}, 309.16 \mathrm{~K}$ \\
\hline Bottom outlet & Pressure outlet & $1,500 \mathrm{~Pa}$ \\
\hline Top outlet & Pressure outlet & $-1,000 \mathrm{~Pa}$ \\
\hline Wall boundaries & No-slip wall & $\mathrm{N} / \mathrm{A}$ \\
\hline Symmetry planes & Symmetry & $\mathrm{N} / \mathrm{A}$ \\
\hline
\end{tabular}

The mixture velocity and mixture temperature distributions at steady state are given in Figure $\mathbf{1 4}$ and Figure 15, respectively. Distribution of the volume fraction of gaseous pentane, liquid pentane and liquid water, all at steady state, are provided in Figure 16, Figure 17, and Figure 18, respectively. All figures show the numerical solution on a center vertical plane and on multiple vertical planes located at the following y coordinates: $0.1,0.2,0.4,0.6$ and $0.8 \mathrm{~m}$.

The steady-state solution consists of a stratified flow with an interface located above the sparger. The gaseous pentane occupies most of the volume available above the interface; below the interface, a mixture of liquid water and liquid pentane is present. Thermal stratification occurs in the vertical column as well. Above the interface, the temperature uniformly decreases as it loses heat to the surrounding gaseous pentane phase by heat transfer. At the interface, the temperature shows a sharp variation, which is consistent with the occurrence of phase change. Below the interface, the temperature remains constant and equal to the saturation temperature.

The velocity distribution (Figure 14) displays a plume that starts from the inlet of liquid water and reaches the middle of the vertical column. This plume corresponds to the accelerating liquid water because of the buoyancy force before losing momentum by drag to the gaseous pentane, or pentane $(\mathrm{g})$, that flows upward. The temperature profile (Figure 15) shows the same plume configuration as for the liquid water. The temperature is maximum near the water inlet and decreases when moving toward the bottom and top outlets. As soon as the water enters the vertical column it starts losing energy to the surrounding pentane $(\mathrm{g})$. The pentane $(\mathrm{g})$ phase becomes super-heated near the inlet of the liquid water and flows towards the top outlet, while the liquid pentane, or pentane(l) phase heats up to reach saturation temperature before converting to pentane $(\mathrm{g})$ at the interface. Below the interface, only liquid water and pentane(l) are present at a temperature close to the saturation temperature of pentane. The pentane(l) phase is injected through the sparger in the vertical column at a temperature slightly below its saturation temperature. The liquid water is at its lowest temperature as it has lost energy to pentane(l) through heat transfer and phase change, and to pentane (g) through heat transfer while flowing downwards. Above the interface, only the pentane $(\mathrm{g})$ and a stream of liquid water are present that form a counter-current flow. The stream of liquid water breaks apart as it flows downward because of the drag force and forms a dip in the interface. The interface shows slushing behavior with a dip but statistically remains at a stable height when the steady state is reached. 

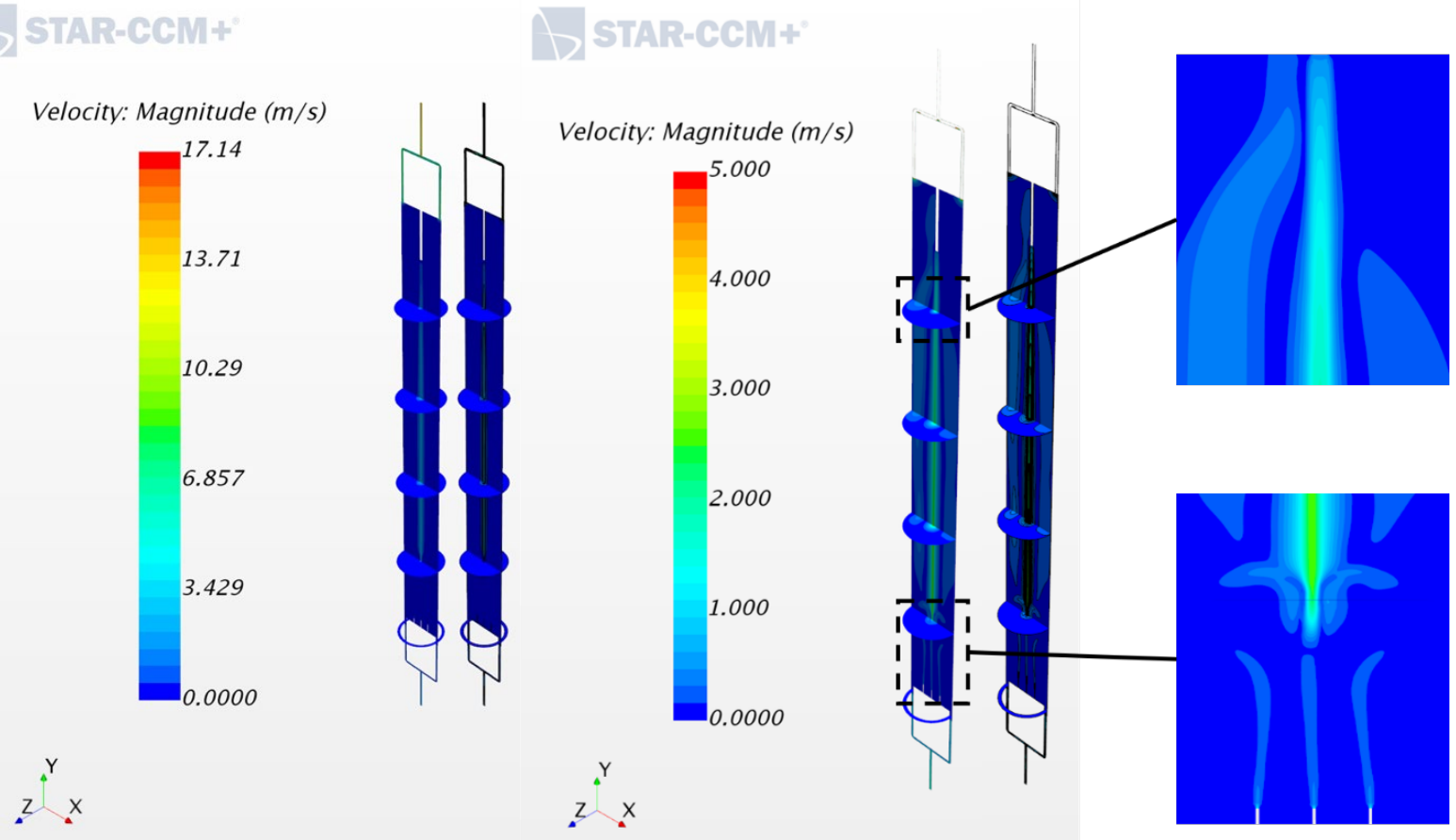

Figure 14. Velocity profile at steady state for the case with a seven-nozzle sparger.

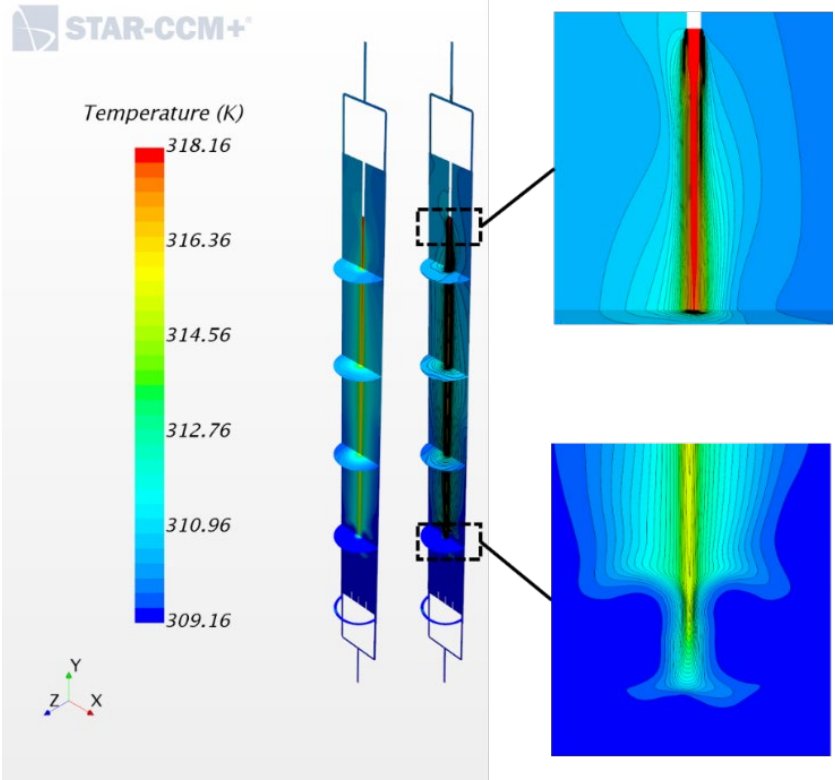

Figure 15. Temperature profile at steady state for the case with a seven-nozzle sparger. 

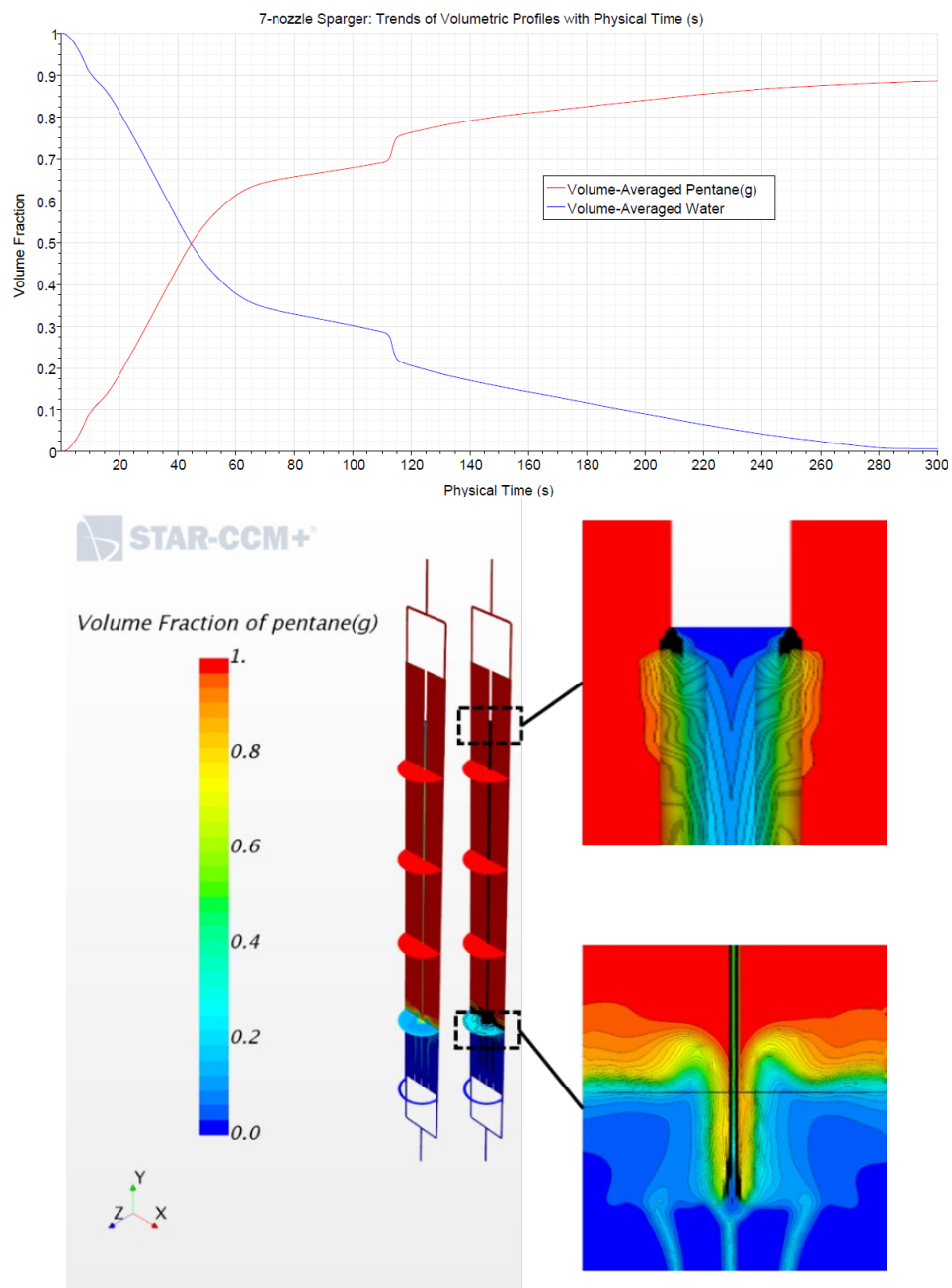

Figure 16. Volume fraction of gaseous pentane at steady state for the case with a seven-nozzle sparger. 


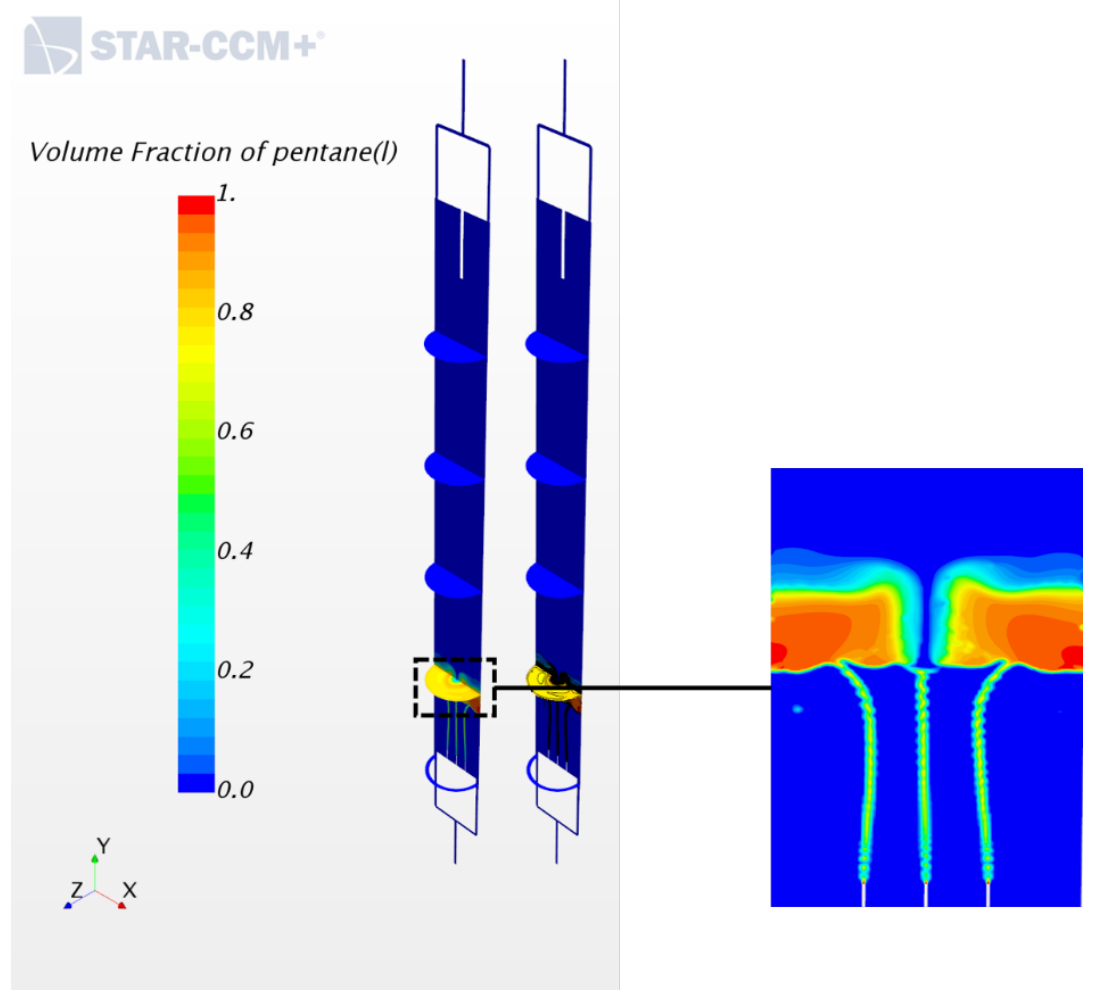

Figure 17. Volume fraction of liquid pentane at steady state for the case with a seven-nozzle sparger.

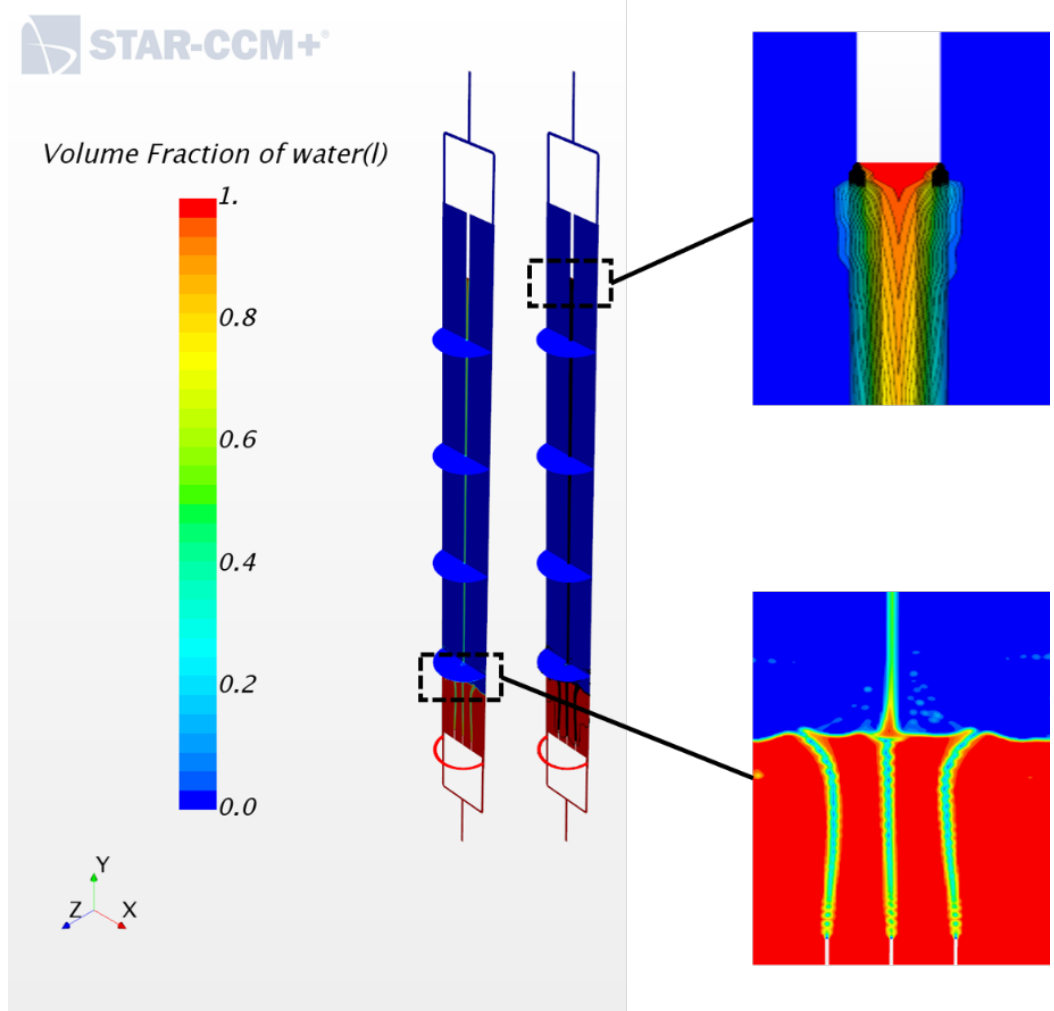

Figure 18. Volume fraction of water at steady state for the case with a seven-nozzle sparger. 
The distance between the tip of the nozzles and the location of the interface is defined as the active length per (Baqir A. M., 2016). Numerically determining the active length is not a straightforward task as the value extracted from the numerical solution will be sensitive to both the mesh size and the numerical definition. The definition of the active length given in (Baqir A. M., 2016) and adopted in this work would need to be translated in a mathematical form that is referred to as numerical definition. The following numerical definition was chosen to derive the active height and is function of a threshold value $\alpha_{\text {threshold: }}$

$$
\text { active height }=\left\{\begin{array}{c}
y \text { if } \alpha_{\text {liq pent }}>\alpha_{\text {threshold }} \\
0.0 \text { else }
\end{array}\right.
$$

For the seven-sparger nozzle experiment, the active length was found to be $16.5 \mathrm{~cm}$ (Baqir A. M., 2016) with an experimental uncertainty that is not documented. Figure 19 displays the results of the field function implementing Eq. (32) for four values of the threshold value $\alpha_{\text {threshold }}(0.05,0.1,0.15$, and 0.2$)$ and for three different mesh base sizes $(6.65,5.0$, and $3.75 \mathrm{~mm})$ to investigate their influence on the numerical active length.

The threshold value, $\alpha_{\exp }$, that gives the same numerical and experimental active length is also documented in Figure 19 (left of the red vertical line). All values are summarized in Table 9.
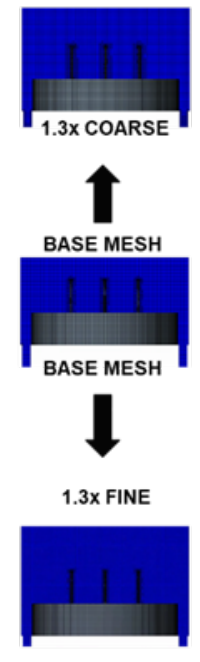

value $\sim 16.75 \mathrm{~cm}$

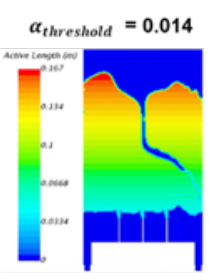

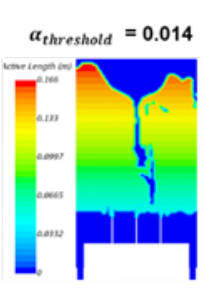
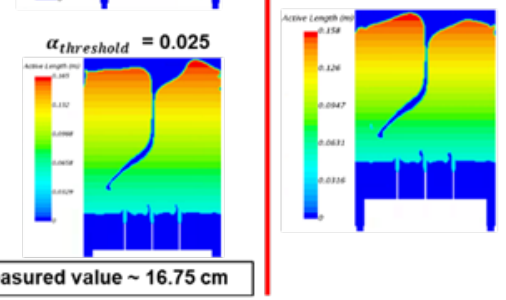
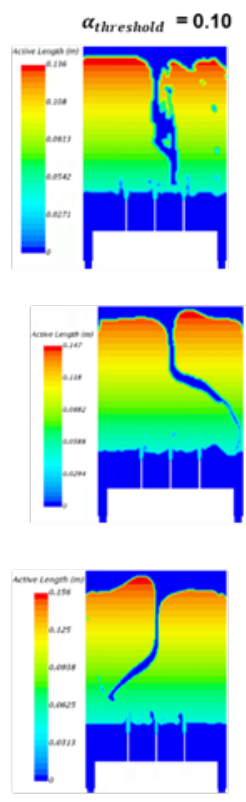
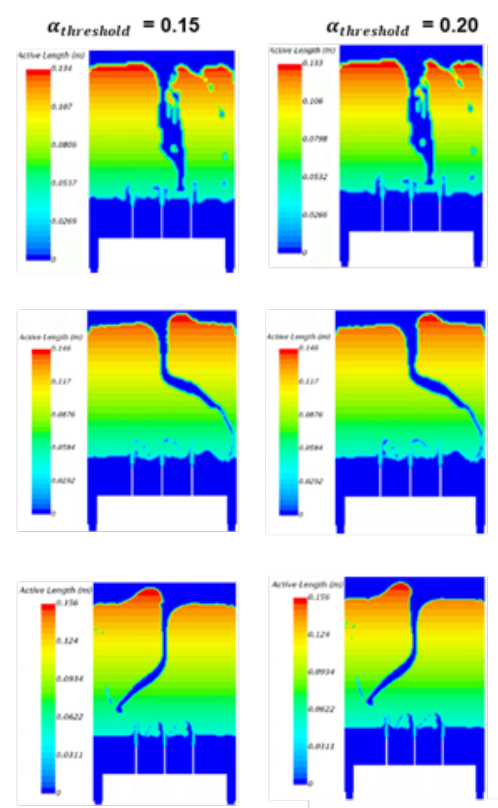

Figure 19. Distribution of active length based on the definition given in Eq. (32) and for different values of $\alpha_{\text {threshold. }}$

Table 9. Values of the active length for different mesh sizes and different $\alpha_{\text {threshold values. }}$

\begin{tabular}{|l|c|c|c|c|c|}
\hline Base size (mm) & $\begin{array}{c}\boldsymbol{\alpha}_{\text {exp }} \mid \text { Height } \\
(\mathbf{m m})\end{array}$ & $\begin{array}{c}\boldsymbol{\alpha}_{\text {threshold }}=\mathbf{0 . 0 5} \mid \\
\text { Height (mm) }\end{array}$ & $\begin{array}{c}\boldsymbol{\alpha}_{\text {threshold }}=\mathbf{0 . 1} \mid \\
\text { Height (mm) }\end{array}$ & $\begin{array}{c}\boldsymbol{\alpha}_{\text {threshold }}=\mathbf{0 . 1 5} \text { Height (mm) } \\
\text { Height }\end{array}$ & $\begin{array}{c}\boldsymbol{\alpha}_{\text {threshold }}=\mathbf{0 . 2} \mid \\
\text { Height (mm) }\end{array}$ \\
\hline 6.65 & $0.014 \mid 166$ & 142 & 136 & 134 & 133 \\
\hline 5 & $0.014 \mid 167$ & 149 & 147 & 146 & 146 \\
\hline 3.76 & $0.025 \mid 165$ & 158 & 156 & 156 & 156 \\
\hline
\end{tabular}


The distribution of active length displayed in Figure 19 shows a dip in the center of the interface that is caused by the impingement of the liquid water stream on the interface. It was also observed during early investigations (not shown here) that the dip in the interface was not captured with the first-order numerical methods available in STAR-CCM+ but only became visible when switching to solvers with second-order accuracy. This observation raises the question of whether the dip is a physical feature, or a numerical artifact. As the experimental data do not provide any clear answer to this question, we must rely on physical inference.

When moving downward, the stream of liquid water accelerates because of gravitational force. The drag effect of the surrounding pentane $(\mathrm{g})$ phase moving upward is not sufficient to counteract the force of gravity. Thus, the liquid water stream is expected to reach the interface with enough momentum to break it and create a dip. The dip predicted by the CFD model was then deemed physical and not a numerical artifact.

Another important feature of each of the scalar scenes in Figure 19 is the shape of the dip created by the impingement of the liquid water stream on the interface. For the coarse mesh, the dip is centered and not very well resolved by the mesh. While the mesh is being refined, the dip is better resolved but opposite shapes are shown between the base mesh and the finer mesh.

From the values reported in Table 9, it can be concluded that the numerical active length converges to the experimental value of $167 \mathrm{~mm}$ independently of the threshold value (all values are the same for the finer mesh with a base size of $3.76 \mathrm{~mm}$ ). The threshold values $\alpha_{\exp }$ are all below $3.0 \%$, which is consistent with the definition of the active length as all liquid pentane should then be converted. Assuming an experimental uncertainty of $10 \%$, the active length predicted by the CFD model is within the error bar. Being able to predict the active length is a good indicator that the CFD model can correctly capture the primary physics, thus validating the approach proposed in this report.

\subsubsection{The 19-nozzle sparger and 36-nozzle sparger cases}

To complete the validation study, the calibrated models were extended to the 19- and 36-nozzle sparger designs. While all designs were simulated for identical thermal and mass flow conditions, the internal response of volumetric profiles to the change in design was of significance to the investigation. It is expected that for a larger number of nozzles at a given mass flow rate, there would be a reduction in the momentum of plumes emanating per nozzle, and thus a suggested difference in the active length for a given pressure drop.

Owing to the absence of design specifications for components external to the DCHE in the experimental setup, it was decided to match the active lengths simulated with those measured in the experimental study by controlling the pressure drop over the DCHE. Further, it was decided to maintain a constant vent pressure at the top outlet (vapor vent) and to only alter the pressure at the bottom outlet, such that a head of water is always maintained at the base of the column. This serves a twofold purpose: (1) provide a continuous phase volume that can shear the inflow of the dispersed phase and (2) allow stratification of the dispersed phase so that the stratified volume is directly impinged upon by the descending jet of hot water, allowing a pseudo-steady state for the vaporization process.

Based on the change in active lengths per the mesh sensitivity study, a base size of $5 \mathrm{~mm}$ was deemed suitable to resolve the true active length within the range of error for measured values. As with the sevennozzle sparger case, a $180^{\circ}$ volume of the DCHE was simulated.

Boundary conditions are listed for each simulation in Table 10. Figure 20 shows the 3D CAD model used for each case. All other simulated conditions are identical. 


\begin{tabular}{|l|l|c|}
\hline \multicolumn{3}{|c|}{ Table 10. Boundary conditions for simulations using spargers with } \\
19 nozzles and 36 nozzles. \\
\multicolumn{1}{|c|}{ Boundary } & \multicolumn{1}{|c|}{$\begin{array}{c}\text { STAR-CCM+ } \\
\text { boundary type }\end{array}$} & Boundary value \\
\hline Liquid water inlet & $\begin{array}{l}\text { Inlet velocity and } \\
\text { temperature }\end{array}$ & $0.42773 \mathrm{~m} / \mathrm{s}, 318.16 \mathrm{~K}$ \\
\hline $\begin{array}{l}\text { Liquid pentane inlet } \\
{[19,36] \text { nozzles }}\end{array}$ & $\begin{array}{l}\text { Inlet velocity and } \\
\text { temperature }\end{array}$ & $\begin{array}{c}{[0.37229 \mathrm{~m} / \mathrm{s}, 0.19648} \\
\mathrm{m} / \mathrm{s}],[309.16 \mathrm{~K}, 309.16 \mathrm{~K}]\end{array}$ \\
\hline $\begin{array}{l}\text { Bottom outlet } \\
{[19,36] \text { nozzles }}\end{array}$ & Pressure outlet & {$[4,500 \mathrm{~Pa}, 7,500 \mathrm{~Pa}]$} \\
\hline Top outlet & Pressure outlet & $-1,500 \mathrm{~Pa}$ \\
\hline Wall boundaries & No-slip wall & $\mathrm{N} / \mathrm{A}$ \\
\hline Symmetry planes & Symmetry & $\mathrm{N} / \mathrm{A}$ \\
\hline
\end{tabular}

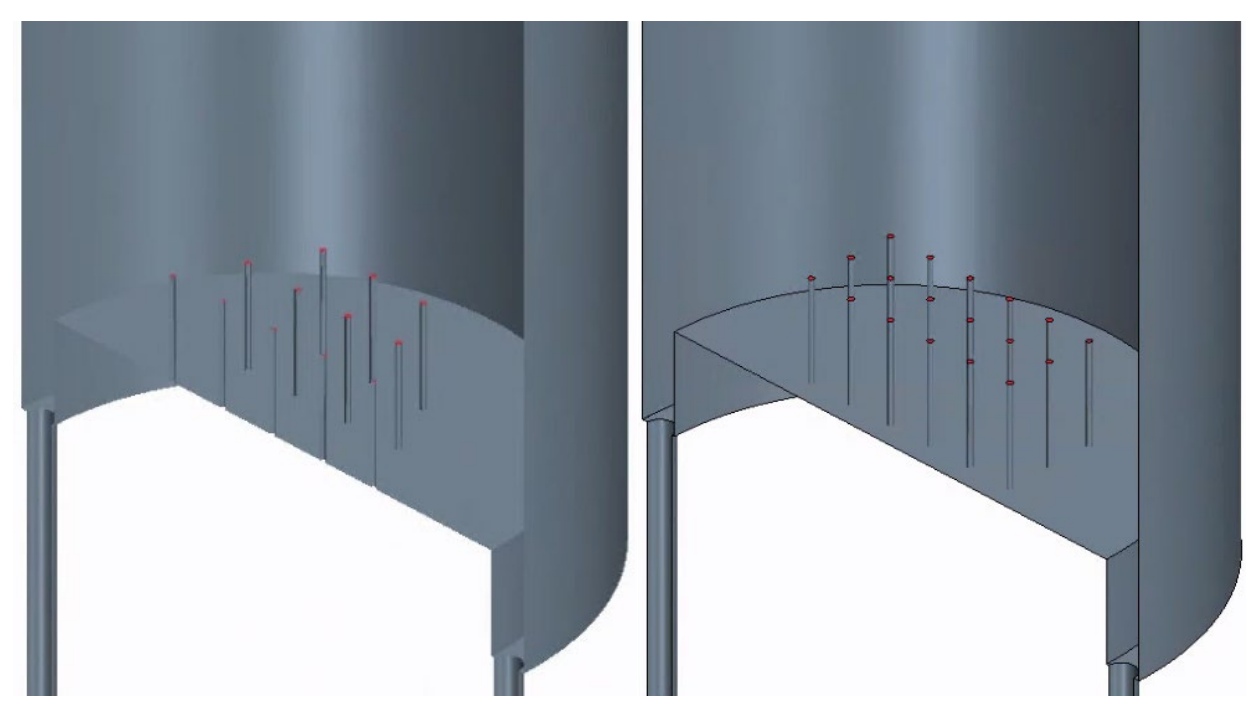

Figure 20. 3D CAD model views of 19-nozzle (left) and 36-nozzle (right) spargers.

Both the simulations were carried out, with solvers set to second-order accuracy, until the volumetric profiles stabilized; primarily, volume-averaged volume fractions of water and pentane $(\mathrm{g})$, temperature, pressure, and turbulent intensity. The pressure values set at the bottom outlet were established relative to the pressure used for the seven-nozzle sparger case.

In all the cases, mass flows of water and pentane(l) are identical. Therefore, it may be surmised that lower the number of nozzles for the inflow of pentane(1), higher will be the momentum per unit volume of pentane(1). Accordingly, for a lower number of nozzles, the inflow of pentane(l) requires a lower pressure at the bottom outlet to sustain a constant head of water at the bottom of the DCHE, allowing pentane(l) to disperse through the head of water, stratify, and evaporate over the active length into pentane(g). Thus, after some iterations, the values of pressure at the bottom outlet were estimated to match the experimental data, owing to the absence of ancillary design specifications for the experimental setup. Solution histories of volumetric profiles for both the simulations are shown in Figure 21. 

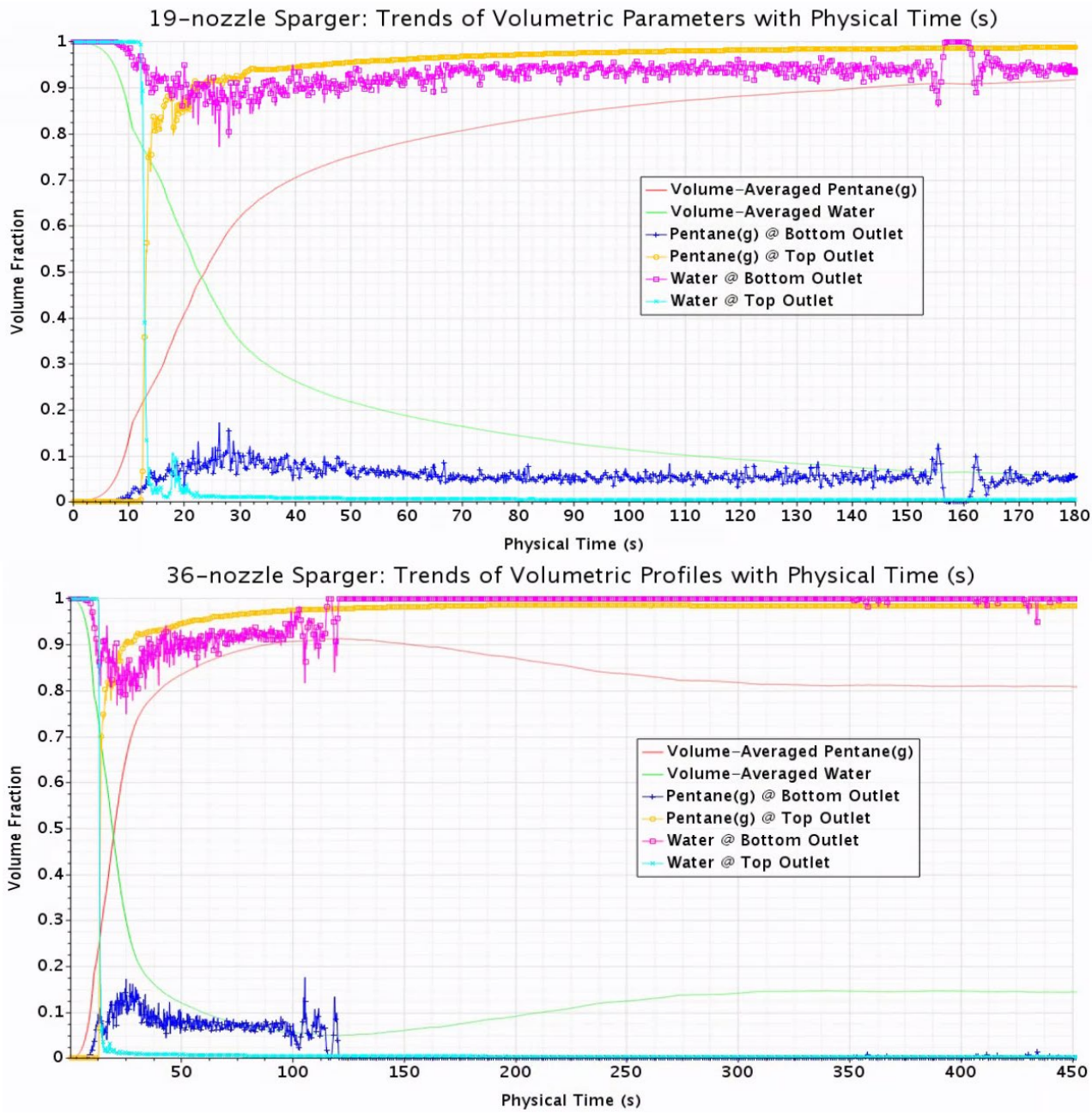

Figure 21. Solution history of volumetric profiles for the 19-nozzle sparger (top) and 36-nozzle sparger (bottom).

The use of a symmetry boundary results in several simulated half-nozzles in the 7-and 19-nozzle sparger cases, but none in the 36-nozzle sparger case. Therefore, it is essential to investigate the volumetric behavior of the dispersed phase, pentane(1), to ensure qualitatively similar performance for the designs. Iso-surfaces of pentane(1) were set up to visualize the dispersion of droplets within the head of water and downstream stratification of continuous and dispersed phases. This may be observed for both cases in Figure 22. 

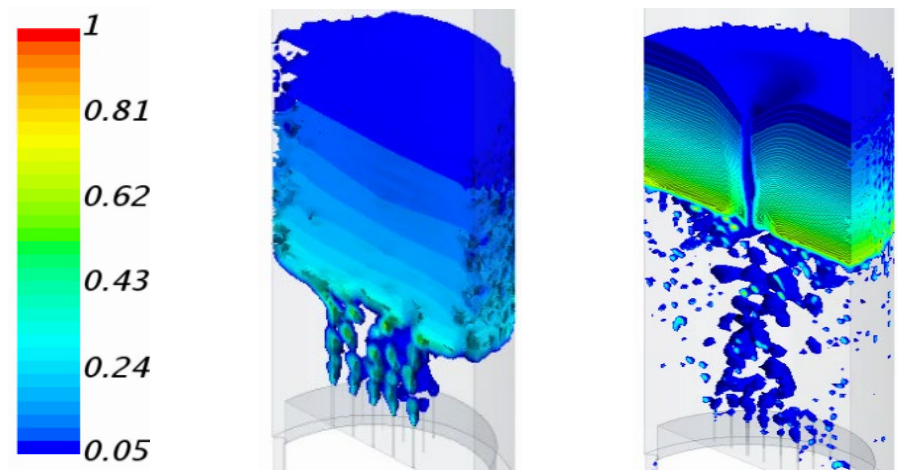

Figure 22. Volume fraction of pentane(l) dispersed by 19-nozzle (left) and 36-nozzle (right) spargers.

The axial dispersion of pentane(1) occurs over a similar distance in both cases, but dispersion of pentane(1) by the 36-nozzle sparger is notably better than by the 19-nozzle sparger. Because an increase in the number of nozzles per sparger reduces the momentum per unit volume of the dispersed phase, for a given mass inflow, the resistance faced by the dispersed phase entering the DCHE increases with the number of nozzles, and higher shear is exerted by the continuous phase on the dispersed phase via force of drag. This manifests in the form of better dispersion by the 36-nozzle sparger.

The active lengths generated by each sparger are shown in Figure 23. Simulations predict an active length of $16.8 \mathrm{~cm}$ (measured value $=17.1 \mathrm{~cm})$ and $19.5 \mathrm{~cm}($ measured value $=19.0 \mathrm{~cm})$ for 19 -nozzle sparger and 36-nozzle sparger, respectively.
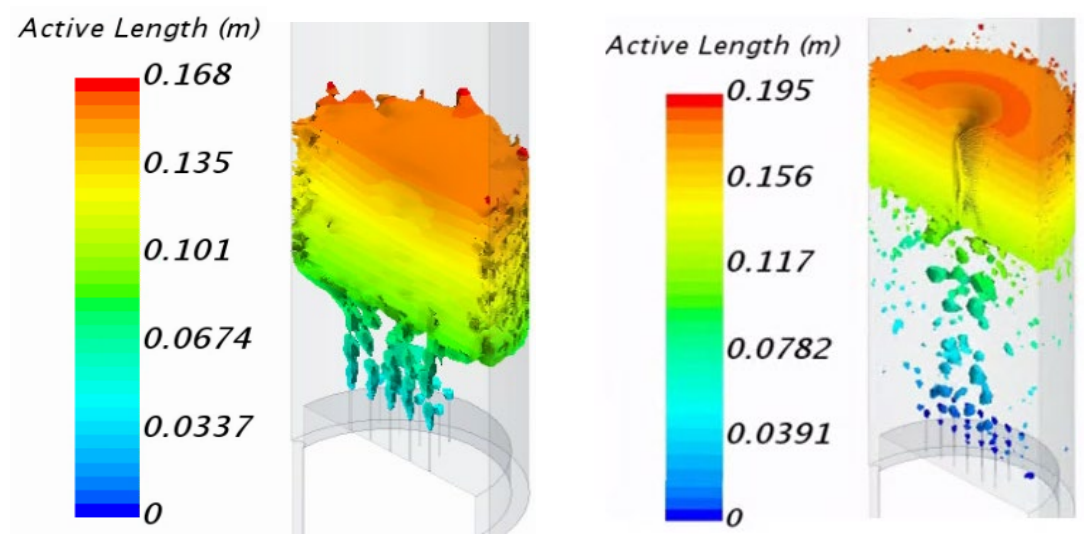

Figure 23. Active length of evaporation for 19-nozzle sparger (left) and 36-nozzle sparger (right) cases.

\subsubsection{Summary of the $V \& V$ process}

In this section, verification and validation $(\mathrm{V} \& \mathrm{~V})$ of the CFD model were presented for three different geometries of the experimental setup described in (Baqir A. M., 2016): 7-nozzle sparger, 19-nozzle sparger and 36-nozzle sparger. Multiple challenges were encountered during the V\&V process related to the stability of the solver and to accurately identify the steady-state numerical solution. 
It was shown that the active length values predicted by the CFD model match the experimental values. A mesh study also demonstrated that the CFD model could accurately capture the physics for a base size value below $5 \mathrm{~mm}$. A summary of all active length predictions is illustrated in Figure 24.

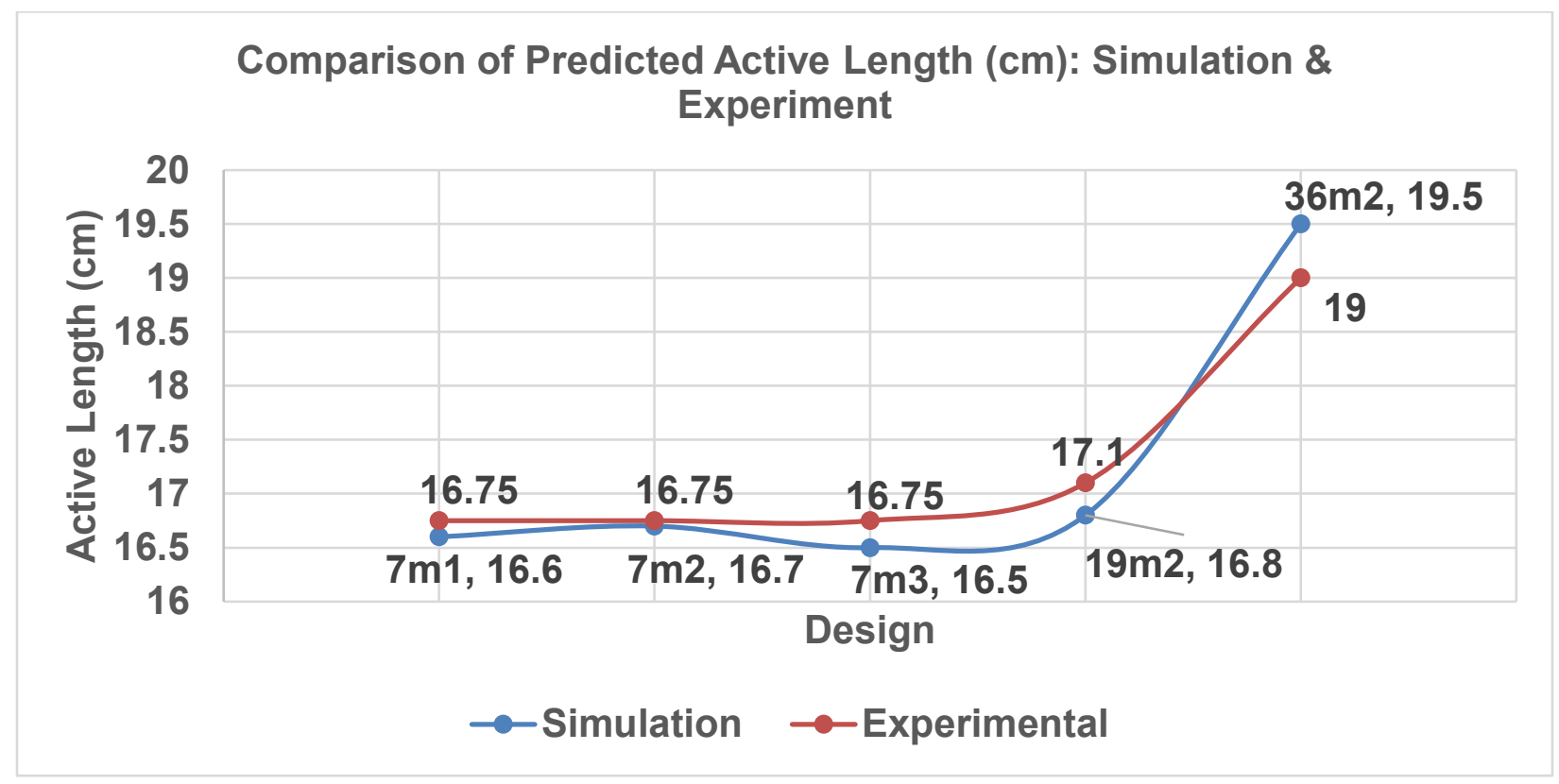

Figure 24. A comparative summary of the validation study in terms of active length (cm).

\subsection{INDUSTRIAL-GRADE DESIGN}

Design of a novel concept is a costly and lengthy process as it is iterative, selective, and corrective. The use of a CFD model along with HPC resources can help reduce cost and time by quickly sweeping a design space to identify an optimal design. Once an optimal design is identified, it is common to rely on experiments to validate the final design before pursuing industrial production.

\subsubsection{Design space and methodology}

The novel design of the DCHE proposed in this section is based on three key principles:

1. simple design with a low manufacturing cost,

2. high efficiency, and

3. an organic Rankine cycle.

A simple design should rely on proven manufacturing processes to reduce cost and production time. Three-dimensional printing offers a virtually unlimited geometric design space but still suffers from major limitations that make it incompatible with current industrial standards. It was decided to limit the components of the DCHE to simple geometric shapes such as cylinders and its derivatives that are common among heat exchanger designs. Another aspect to consider in the design of a DCHE is the separation of the gas phase from the liquid phases.

One way to reduce cost would be to integrate a built-in separator that only relies on buoyancy forces for phase separation downstream of the DCHE. Another metric to consider is the efficiency of the DCHE that will be assessed for different inlet conditions (such as inlet mass flow rates and inlet temperatures) and for 
an internal baffle configuration that enhances mixing and heat exchange between phases. Since this novel design aims to target low-temperature recovery in industrial applications, a water-pentane DCHE concept was chosen for further evaluations.

As described earlier in Sect. 3.2, the CFD models were compared against the experimental data to ensure reasonable qualitative agreement. The reference setup used in the validation study was configured about a vertical axis, with flow streams oriented in a counterflow fashion. The downward flow of the heavier continuous phase (water) is assisted by gravity, whereas the upward dispersion of pentane(l) is countered by a static head of water initially in the DCHE, as is the descending plume of water from the inflow. Consequently, the location of the vapor-liquid interface is sensitive to the pressure values imposed at both outlets. To mitigate this dependency, the industrial-grade design was configured about a horizontal axis such that the inflow streams lose momentum as they are transported downstream through the DCHE.

The DCHE was initially designed as a single column that was later separated into two columns connected by a converging-diverging nozzle. The location of the nozzle was suggested to enhance the momentum of partially separated phases in the first column, in order to stratify the phases after the flow area diverges at the end of the nozzle, thereby reducing instantaneous pressure and stabilizing the interface between the vapor and liquid phases.

An initial design of the DCHE where outflow nozzles were placed in a vertical alignment showed a large recirculation zone at the end of the second column, causing entrainment of vapor with the water. This design was altered to stagger the outlets so that the water volume can partially drain before the vapor can vent, thereby reducing the momentum of water below the interface and eliminating entrainment.

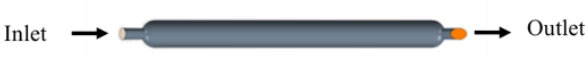

(a)

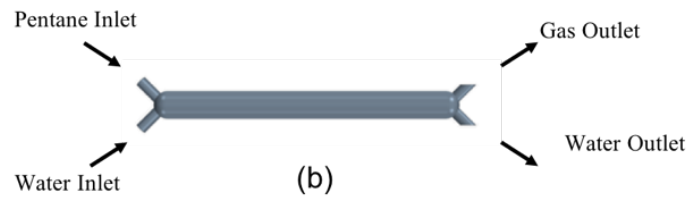

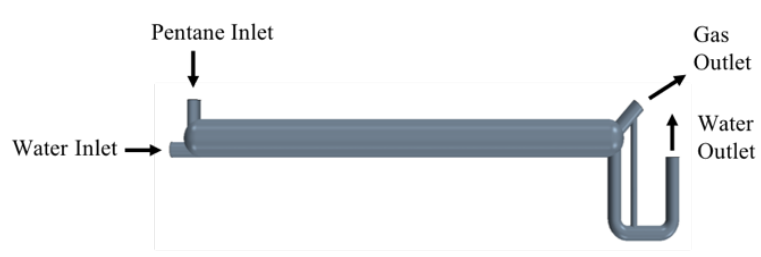

(c)

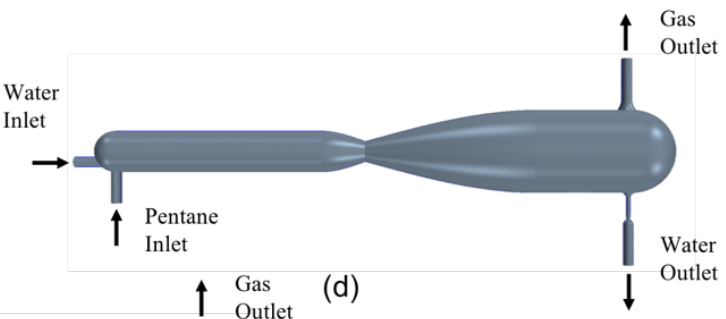

(e)

Figure 25. Various DCHE designs tested before arriving at the optimized industrial grade design.

Once a nominal design was identified, a design space relevant to industrial application was selected to assess the efficiency of the novel DCHE when used for low-temperature waste heat recovery, with temperatures ranging from $40^{\circ} \mathrm{C}$ to $200^{\circ} \mathrm{C}$ under atmospheric conditions. Because liquid water is the 
working hot source that boils at $100^{\circ} \mathrm{C}$ under atmospheric conditions, the inlet temperature of liquid water was varied from $50^{\circ} \mathrm{C}$ to $95^{\circ} \mathrm{C}$. The mass flow rates of the water and pentane phases were chosen so that the Reynolds number of the mixture remained between 4,500 and 5,000. The inlet temperature of the liquid pentane phase was assumed to be room temperature (i.e. $20^{\circ} \mathrm{C}$ ).

A total of 12 cases were run for the baseline design. All corresponding inlet conditions of the design space are summarized in Table 11 and Table 12.

Table 11. Inlet temperatures of liquid water and liquid pentane.

\begin{tabular}{|l|l|l|l|l|}
\hline \multicolumn{1}{|c|}{ Temperature ratio label } & T1 & T2 & T3 & T4 \\
\hline Water temperature $\left({ }^{\circ} \mathrm{C}\right)$ & 50 & 65 & 80 & 95 \\
\hline Pentane temperature $\left({ }^{\circ} \mathrm{C}\right)$ & 20 & 20 & 20 & 20 \\
\hline
\end{tabular}

Table 12. Mass flow rate values of liquid water and liquid pentane.

\begin{tabular}{|l|c|c|c|}
\hline \multicolumn{1}{|c|}{ Mass flow ratio label } & m1 & m2 & m3 \\
\hline Water mass flow rate $(\mathrm{g} / \mathrm{s})$ & 2 & 5 & 10 \\
\hline Pentane mass flow rate $(\mathrm{g} / \mathrm{s})$ & 3 & 7.5 & 15 \\
\hline
\end{tabular}

After the efficiency of the baseline design was quantified, more simulations were performed to further optimize the design through adding baffle features. The mass flow ratios of water to pentane $(\mathrm{m} 1, \mathrm{~m} 2$, and m3) were maintained at a constant 1.5.

\subsubsection{CFD model}

This section provides details of the geometry, the mesh settings, and the CFD models (physics, initial and boundary conditions) used for the industrial-grade design study.

\subsubsection{Geometry and mesh}

The DCHE design shown in Figure 26 has a horizontal layout to minimize the buoyancy effects. The bottom inlet is used as the pentane(l) inlet to enhance mixing. The pentane(l) comes in contact with the liquid water, causing the pentane(l) to evaporate. Pentane gas, being a less dense fluid, rises due to buoyancy while water, the denser fluid, is drawn down by gravity. The heat exchanger has two chambers; the second chamber has a larger cross-sectional area to reduce the flow rate and thus increase the residence time of the fluid inside the chamber, which helps in furthering the separation of the phases under gravity and thus increasing the exit quality of the gaseous pentane. The outlets are staggered to prevent entertainment of water by the gaseous pentane.

The final design of the baseline industrial-grade DCHE is shown in Figure 26. The inflow and estimated outflow conditions are indicated at their respective locations. 


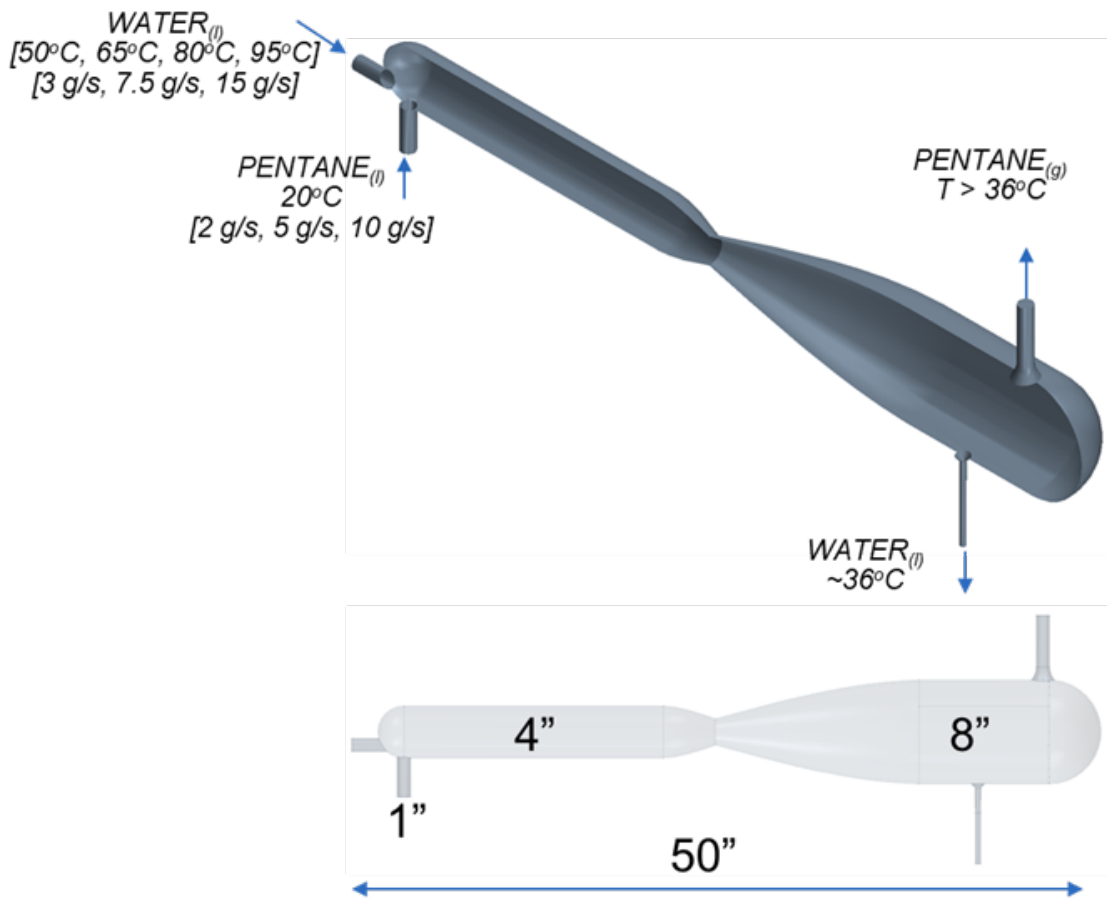

Figure 26. Industrial-grade heat exchanger geometry.

The finite volume mesh was generated in STAR-CCM+ using a Surface Remesher model for surface tessellation and a Trimmer model to generate hexahedral cells. Additionally, wall-normal refinement of the mesh was achieved with a Prism Layer model. The mesh settings are summarized in Table 13.

Table 13. Mesh settings for prism layers.

\begin{tabular}{|l|l|}
\hline \multicolumn{1}{|c|}{ Setting } & \multicolumn{1}{c|}{ Value } \\
\hline Minimum surface size $(\mathrm{mm})$ & 0.635 \\
\hline Target surface size $(\mathrm{mm})$ & 3.175 \\
\hline Maximum cell size $(\mathrm{mm})$ & 3.175 \\
\hline Number of prism layers & 2 \\
\hline Surface growth rate & 1.5 \\
\hline Total thickness of prism layers $(\mathrm{mm})$ & 0.635 \\
\hline Total number of cells & 555,500 \\
\hline
\end{tabular}

\subsubsection{Physics and solver settings}

The physics models from the validation study were initially adapted to directly simulate thermophysical phenomena in the industrial-grade design. To summarize, an Eulerian framework was used to simulate transport of momentum, mass, and heat in the DCHE. Under the Eulerian multiphase family of models in STAR-CCM+, the VOF model was used to track the interface between phases and to predict their spatial distribution in transient detail. The SST (Menter) k-omega model was used with the all $y+$ wall treatment model to resolve turbulent flow in the bulk transport as well as the near-wall momentum and thermal boundary layers. A multiphase equation of state was used with interphase interactions set to simulate the interaction area, interaction length scale, slip due to forces of drag, and surface tension (equilibrium values). Boiling phenomena were additionally resolved for liquid-vapor interactions in the thermodynamically saturated regime, using the Rohsenhow boiling model. Specific under-relaxation 
factors (URFs) used in the models are summarized in Table 14. A time step of $0.005 \mathrm{~s}$ was used for all the calculations.

Table 14. Relaxation parameters used in the CFD model of the industrial-grade design.

\begin{tabular}{|l|c|}
\hline \multicolumn{1}{|c|}{ Solver } & URF \\
\hline Phase slip velocity & 0.5 \\
\hline Segregated flow: velocity & 0.5 \\
\hline Segregated flow: pressure & 0.1 \\
\hline Segregated VOF: single-step & 0.5 \\
\hline Segregated energy: fluid & 0.5 \\
\hline k-omega turbulence & 0.5 \\
\hline k-omega turbulent viscosity & 0.5 \\
\hline
\end{tabular}

\subsubsection{Initial conditions and boundary conditions}

It was assumed that the DCHE is initially filled with water at $309 \mathrm{~K}\left(36^{\circ} \mathrm{C}\right)$, a temperature slightly below the saturation temperature of liquid pentane (i.e., 309.21 K). This was done to avoid sharp thermal gradients during the initial inflow of water and pentane(l), thus permitting the inherently transient mass transfer of pentane from liquid to vapor into a plume of vapor with enough momentum to rise as an isolated phase above the liquid mixture.

Mass flow rates at the boundaries were determined from a preliminary study to retain the Reynolds number of the mixture between 4,500 and 5,000. Since the jets mix at a $90^{\circ}$ angle, optimal velocities of $0.26 \mathrm{~m} / \mathrm{s}$ for pentane and $0.24 \mathrm{~m} / \mathrm{s}$ for water were obtained at the inlets. In terms of mass, this renders the inflow of pentane at $\sim 4 \mathrm{~g} / \mathrm{s}$ and that of water at $\sim 6 \mathrm{~g} / \mathrm{s}$. Using a ratio of 1.5:1 between water and pentane, the inflow rates of pentane were set as pairs, at $[2 \mathrm{~g} / \mathrm{s}, 3 \mathrm{~g} / \mathrm{s}](\mathrm{m} 1),[5 \mathrm{~g} / \mathrm{s}, 7.5 \mathrm{~g} / \mathrm{s}](\mathrm{m} 2)$, and $[10 \mathrm{~g} / \mathrm{s}$, $15 \mathrm{~g} / \mathrm{s}](\mathrm{m} 3)$. This was to test the behavior at a value below the optimal value and at two values above the optimal value. The inflow temperature of pentane was set at $20^{\circ} \mathrm{C}$ for all cases, and the temperature of water was tested at $\left[50^{\circ} \mathrm{C}, 65^{\circ} \mathrm{C}, 80^{\circ} \mathrm{C}, 95^{\circ} \mathrm{C}\right]$ for each combination of mass flow rates.

The liquid outlet was set to a pressure outlet boundary. The level of the liquid outlet was set to the reference altitude for pressure calculations, and the pressure at the outlet was set to $0 \mathrm{~Pa}$, with a target mass flow rate of the corresponding inflow. The vapor outlet was set to an outlet boundary, i.e., the dynamic pressure of vapor in the outflow nozzle dictated the pressure at the vent in the simulations.

\subsubsection{Convergence criteria}

Several parameters were monitored with progress of the simulation:

- volume-averaged volume fractions of water and pentane(g), as an overall indicator of volumetric stability in the three-phase mixture; surface-averaged volume fraction of pentane $(\mathrm{g})$ at the vent;

- volume-averaged temperature of the three-phase mixture; surface-averaged temperature of flow at the vent;

- volume-averaged turbulent intensity of the three-phase mixture, as an indicator of fully developed turbulent flow; surface-averaged turbulent intensity of pentane $(\mathrm{g})$ at the vent; and

- dynamic pressure at outflow. 


\subsubsection{Numerical results for the industrial-grade design}

From the simulations, it was observed that it takes about $600 \mathrm{~s}$ for the transient vaporization process to stabilize as numerical convergence in volumetric profiles. Figure 27 shows the solution history of volume fractions in transition from the transient to quasi-steady-state vaporization. Labels on the legend indicate the inlet temperature of water and the combination of mass flow rates. Thus, $50 \mathrm{~m} 1$ indicates $50^{\circ} \mathrm{C}$ as the inlet temperature of water and $\mathrm{m} 1$ as the combination of the mass flow rates of pentane and water $(2 \mathrm{~g} / \mathrm{s}$ and $3 \mathrm{~g} / \mathrm{s}$, respectively).

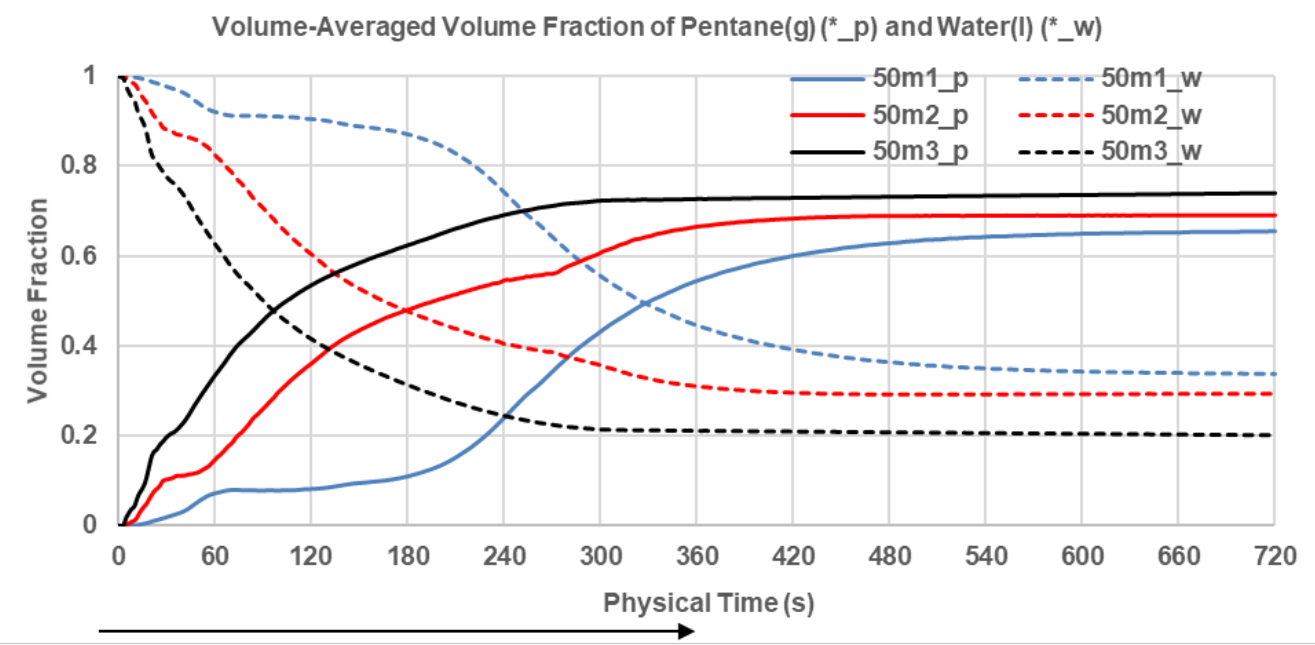

Figure 27. Volume-averaged volumetric profiles at an inlet temperature of $50^{\circ} \mathrm{C}$ for water.

The profiles in Figure 27 relate well to the development of a plume of vapor at the outlet as can be observed in Figure 28. This shows that the stabilization of volume fraction at the vent creates a local uniformity in dynamic pressure of outflow and is reflected in the volume-averaged profiles. Figure 29 illustrates perturbations in turbulent intensity, averaged over the volume, and at the outflow of pentane $(\mathrm{g})$. 


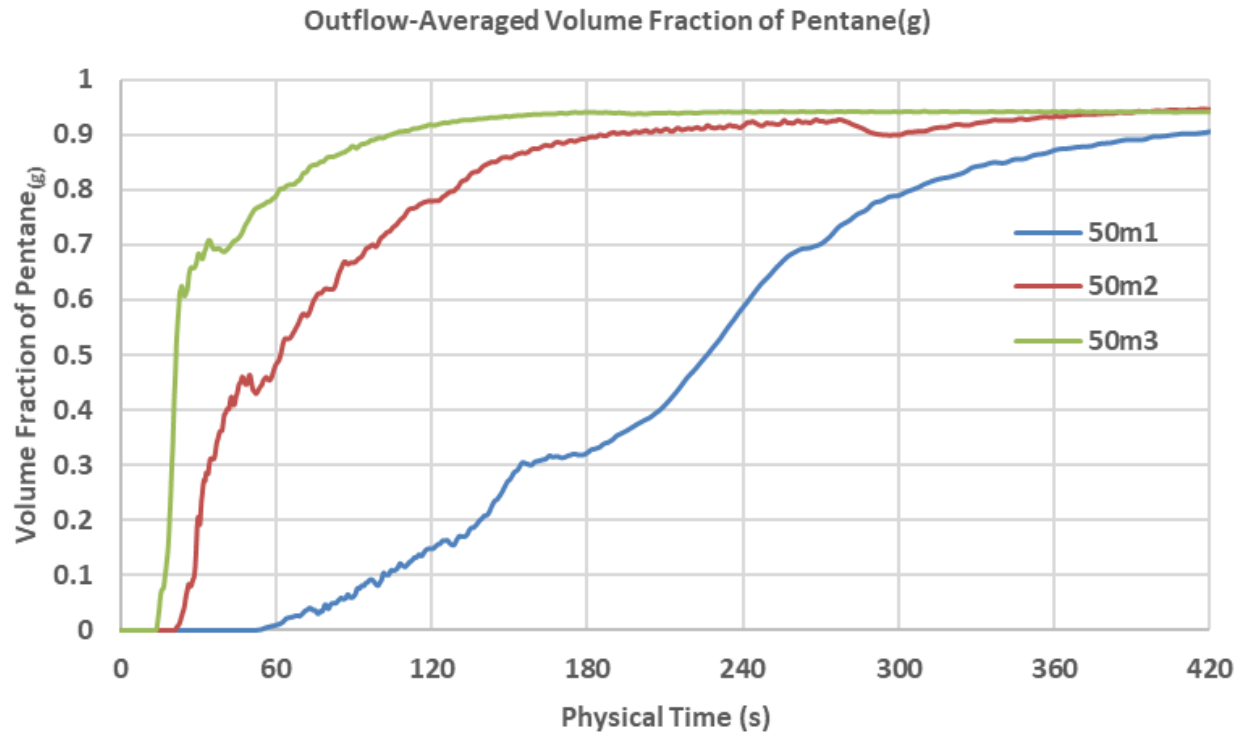

Figure 28. Volume fraction averaged at the vent for outflow of pentane(g).

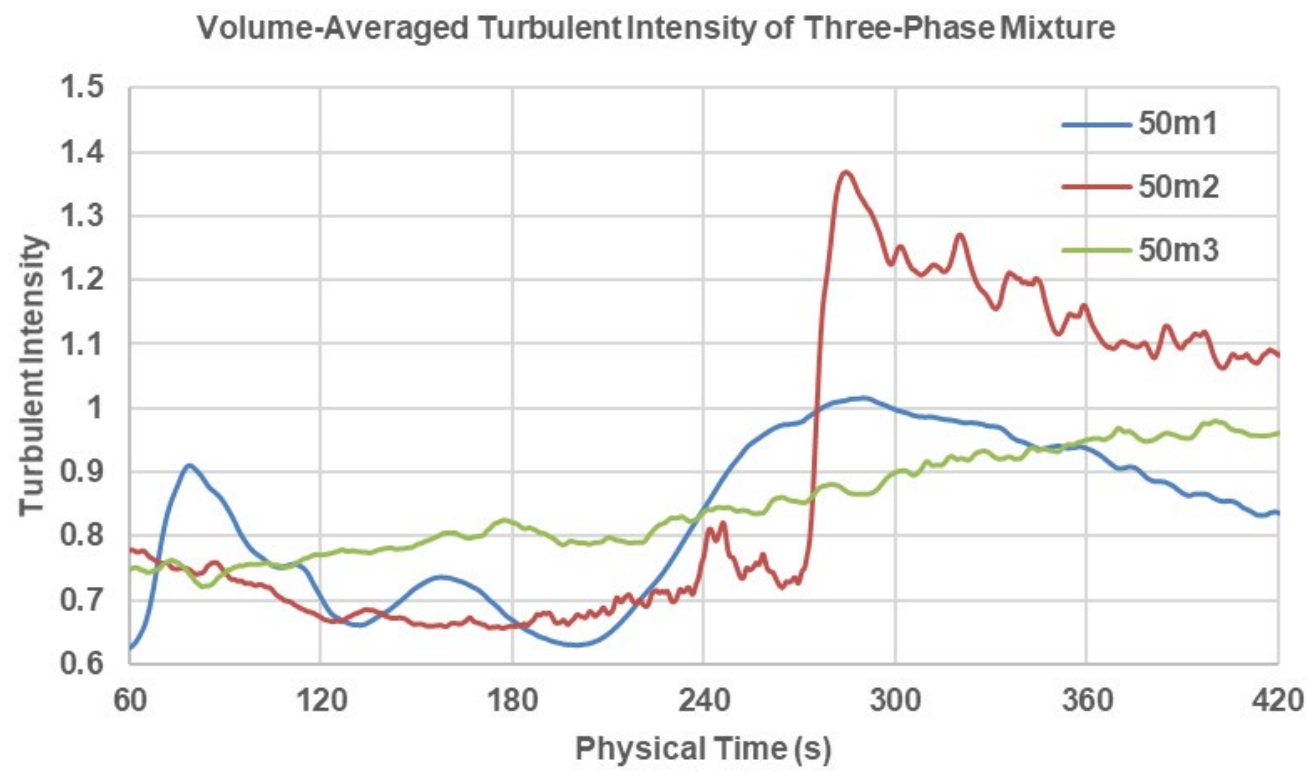




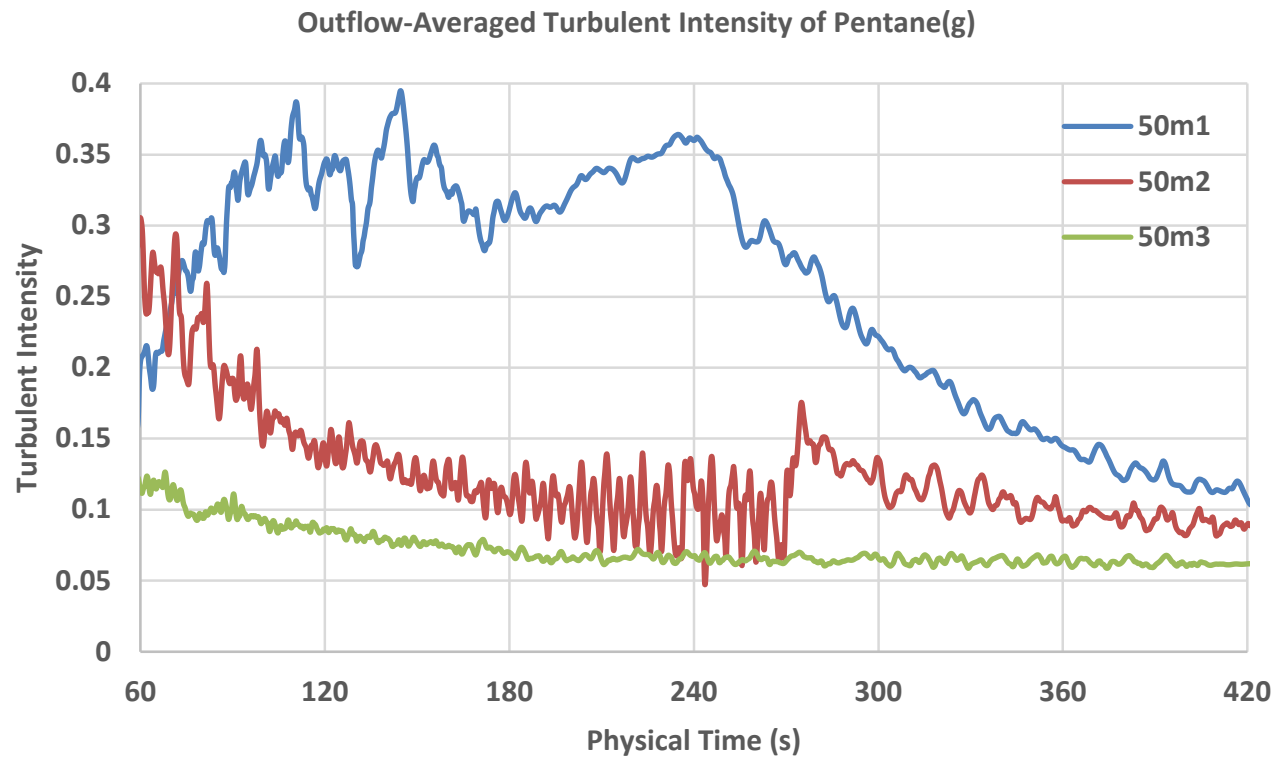

Figure 29. Turbulent intensity values of the mixture averaged over the volume (top) and of pentane(g) at the vent (bottom).

From Figure 30, Figure 31, and Figure 32, it can be observed that with the highest flow rate (m3), the resolution of the vapor-liquid interface is distorted, and there is a significant entrainment of pentane(l) through the drain (liquid outlet). This is due to insufficient energy available as latent heat for complete vaporization of pentane(1) at an inlet temperature of $50^{\circ} \mathrm{C}$ for water, as seen by uniformly low temperatures $\left(\sim T_{\text {sat }}\right)$ in Figure 33.

In contrast, Figure 34 shows a gradual increase in the volume of pentane $(\mathrm{g})$ entrained by water through the drain at higher inlet temperatures of water (i.e., $80^{\circ} \mathrm{C}, 95^{\circ} \mathrm{C}$ ). This is due to the rapid expansion of vapor at the vaporization interface, accompanied by a gain in momentum relative to that of the liquid mixture. Due to effects of slip, some of this gain in momentum is transferred to the water at the waterpentane $(\mathrm{g})$ interface and induces lateral mixing across the interface, which may be inferred from the plots of turbulent intensity and velocity vectors in Figure 35 and Figure 36. This effect is pronounced at the liquid-vapor interface at higher temperatures and in the bulk gas flow at lower temperatures. 


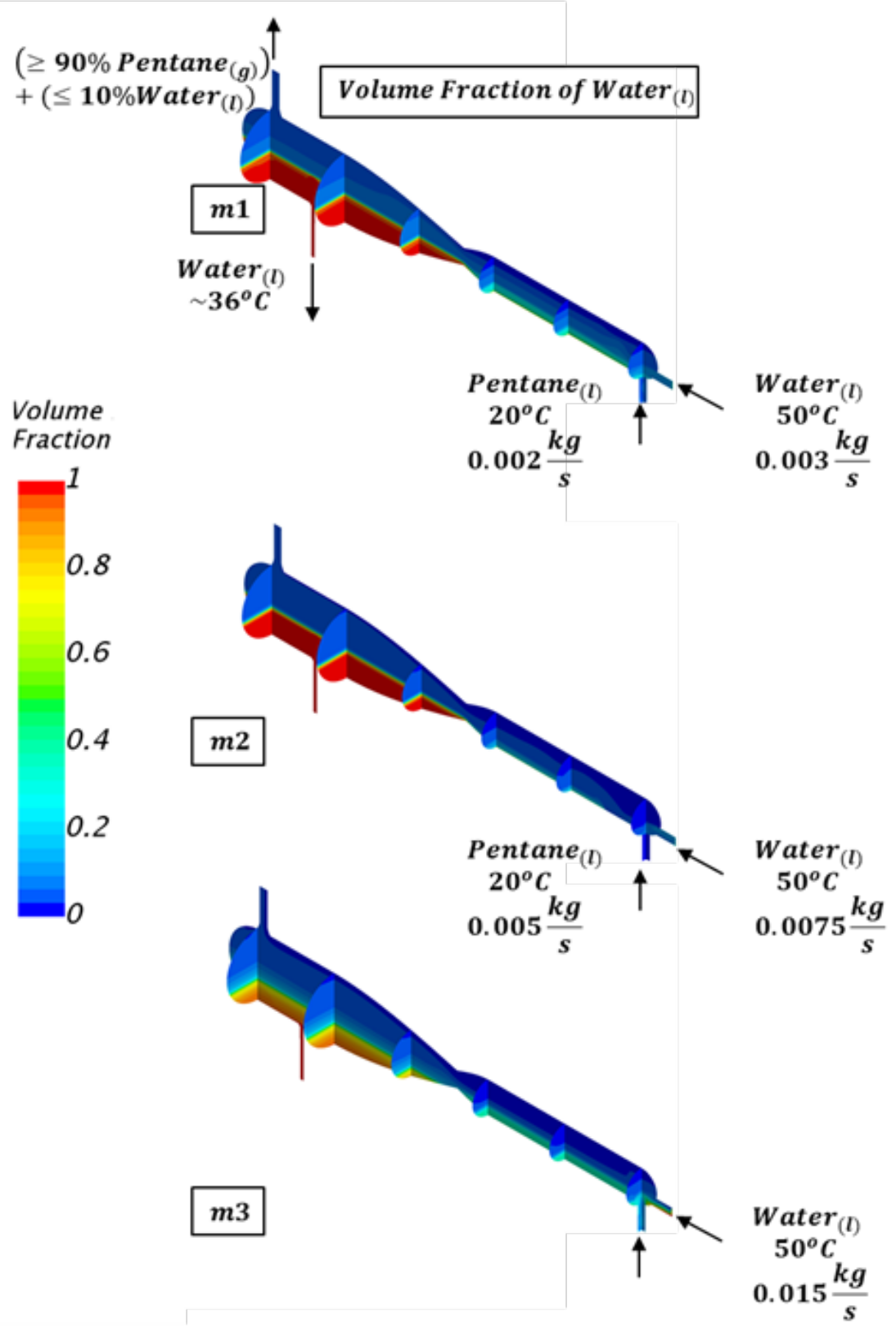

Figure 30. Cross-sectional distribution of water for an inflow temperature of $50^{\circ} \mathrm{C}$ at flow rates $\mathrm{m} 1, \mathrm{~m} 2, \mathrm{~m} 3$ (top to bottom). 


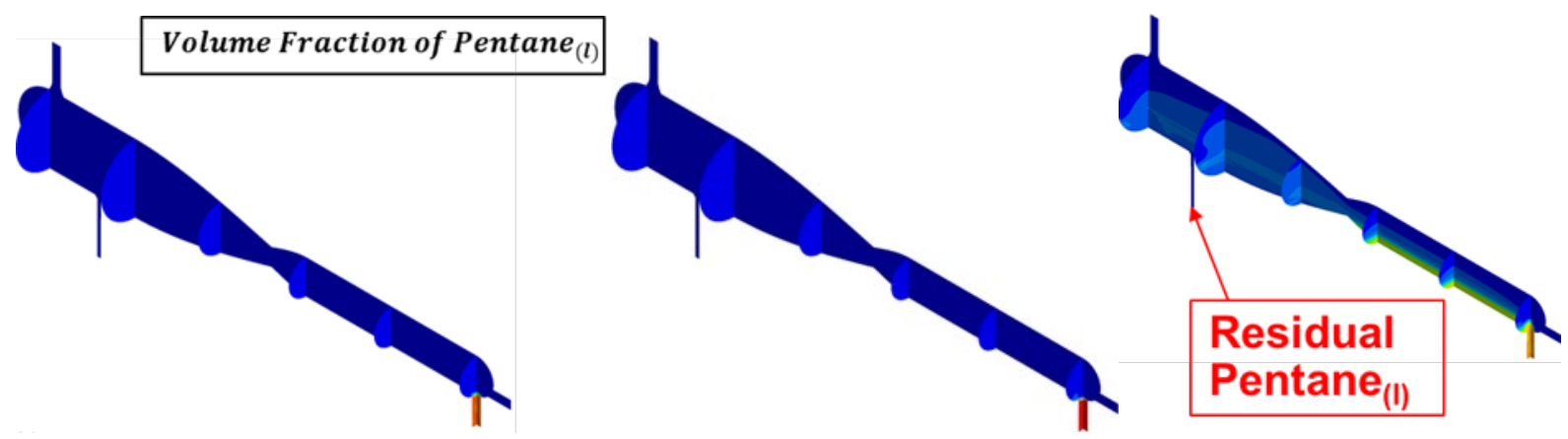

Figure 31. Cross-sectional distribution of pentane(l) for a water inflow at $50^{\circ} \mathrm{C}$ at flow rates $\mathrm{m} 1, \mathrm{~m} 2, \mathrm{~m} 3$ (left to right).

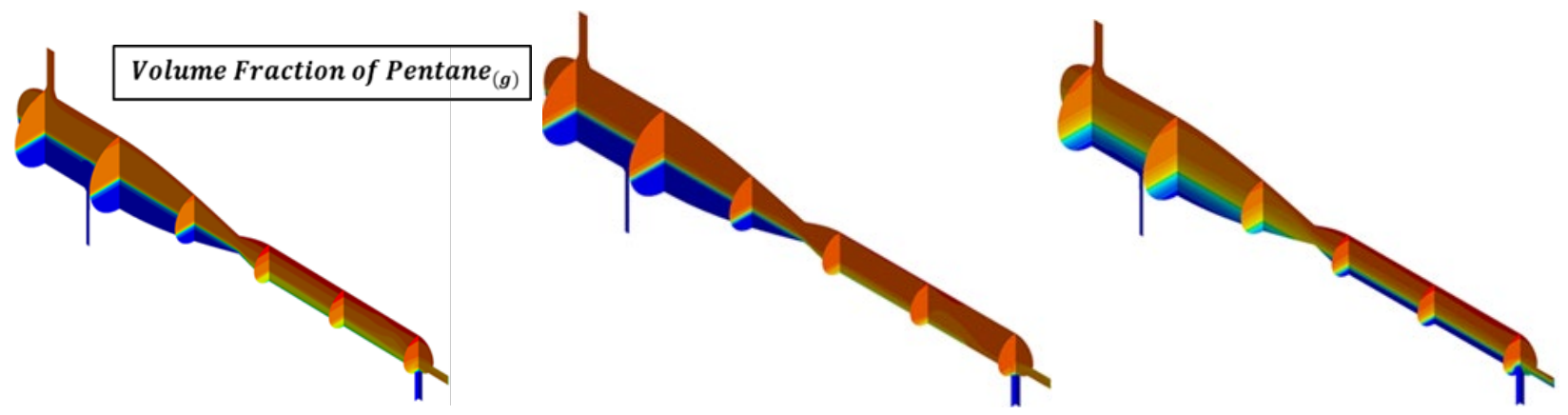

Figure 32. Cross-sectional distribution of pentane(g) for a water inflow at $50^{\circ} \mathrm{C}$ at flow rates $\mathrm{m} 1, \mathrm{~m} 2, \mathrm{~m} 3$ (left to right).

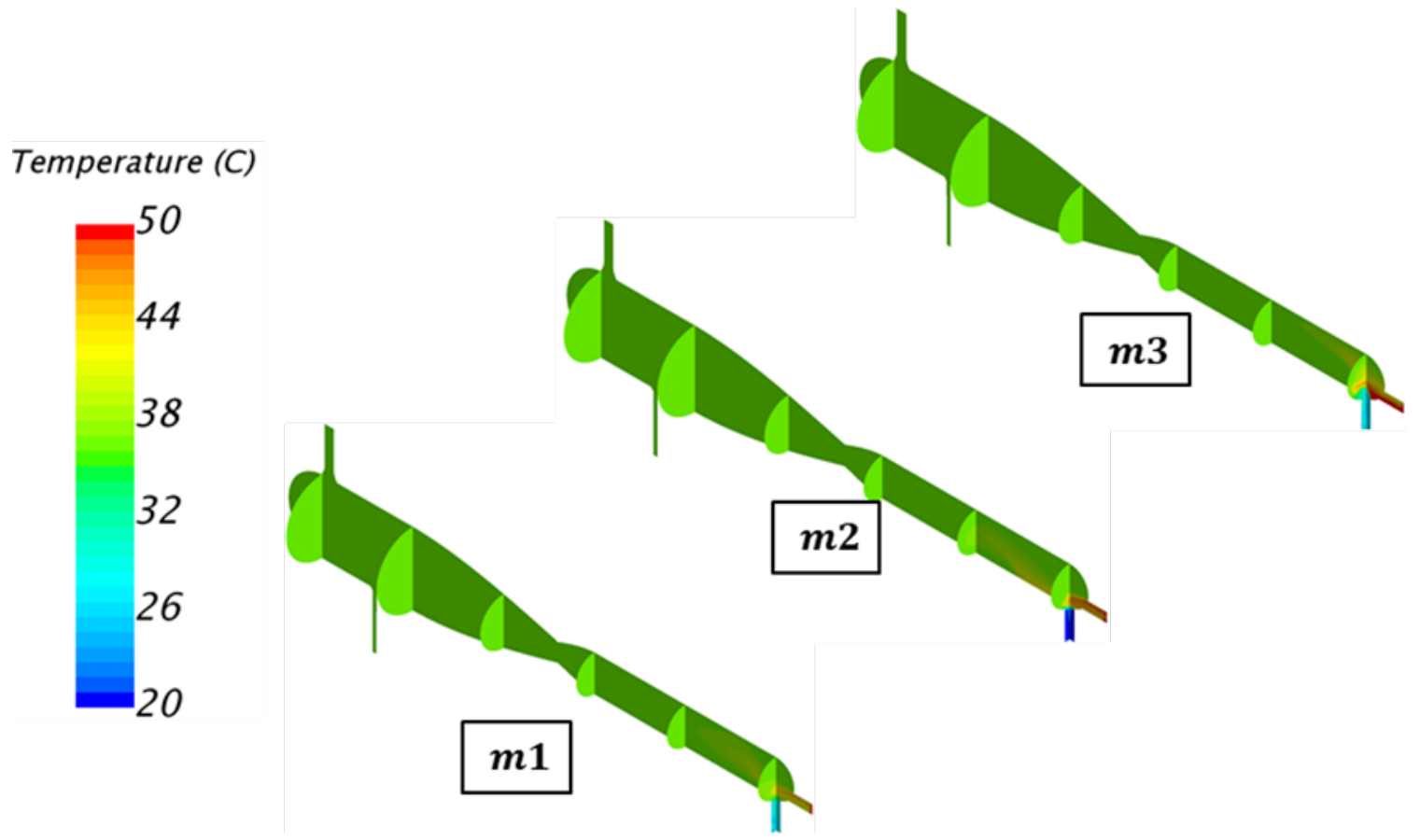

Figure 33. Cross-sectional distribution of temperature for a water inflow at $50^{\circ} \mathrm{C}$. 

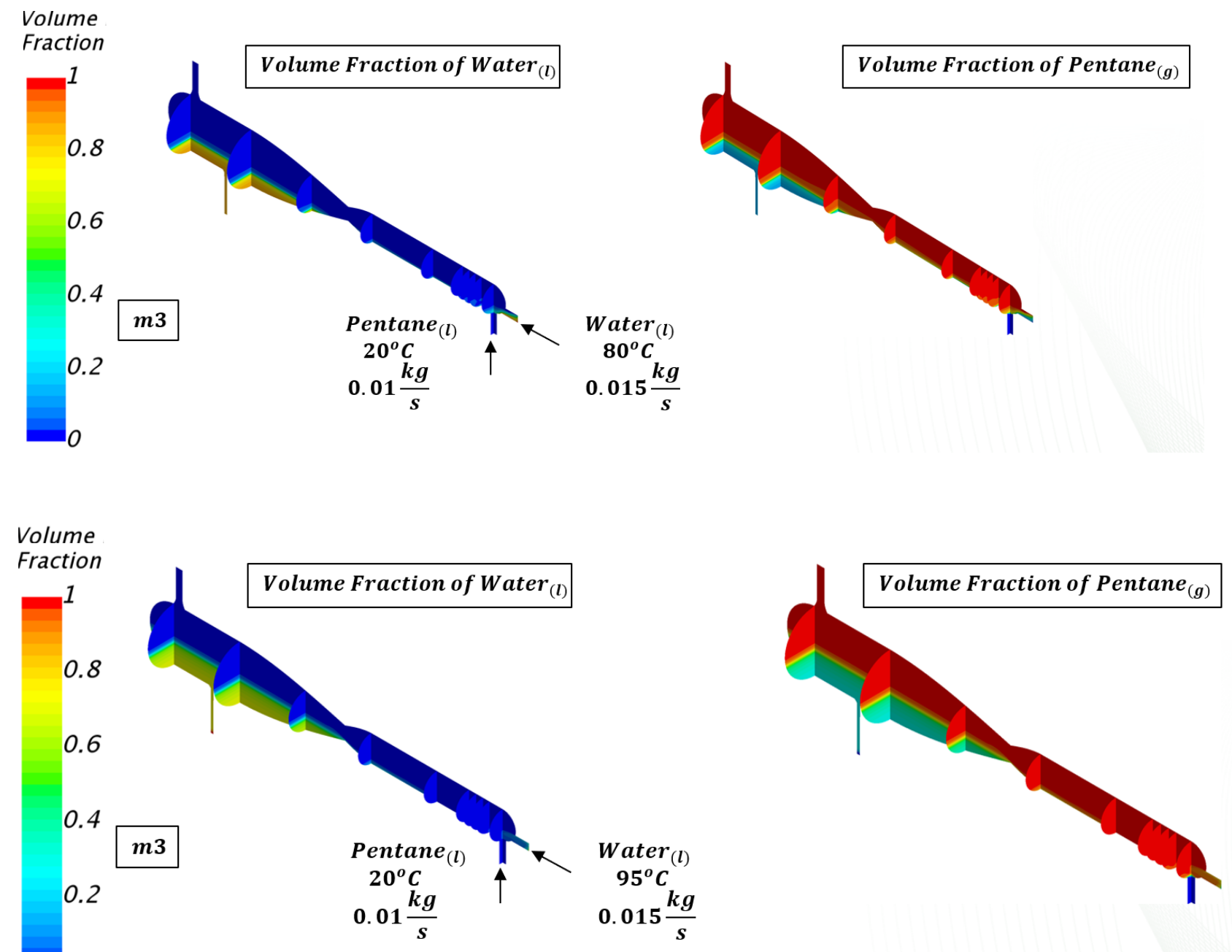

Figure 34. Entrainment of pentane(g) with water at higher temperatures $\left(80^{\circ} \mathrm{C}, 95^{\circ} \mathrm{C}\right)$ at $10 \mathrm{~g} / \mathrm{s}$ of pentane(l) inflow. 

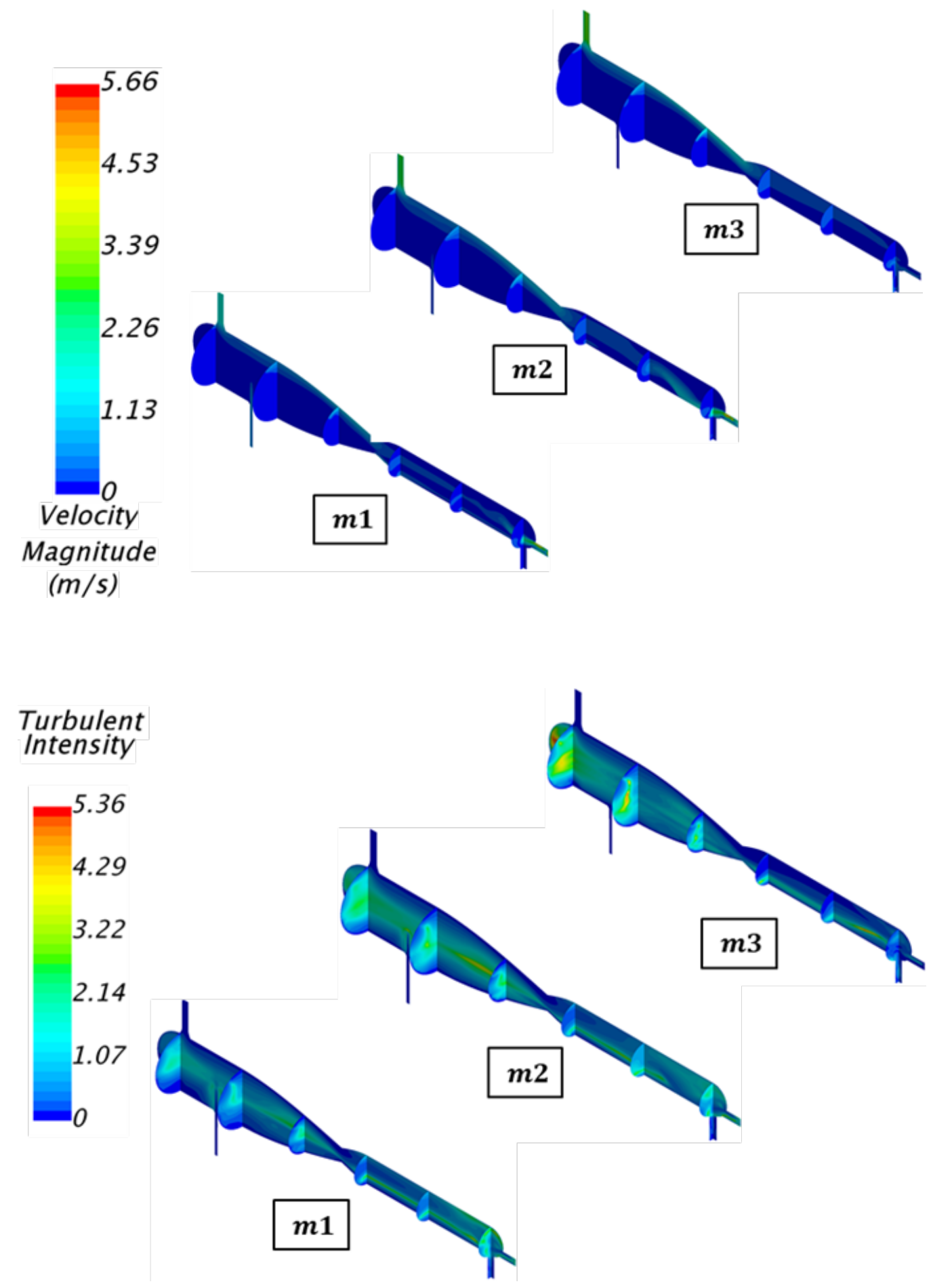

Figure 35. Cross-sectional mixtures profiles of hydraulic data. 

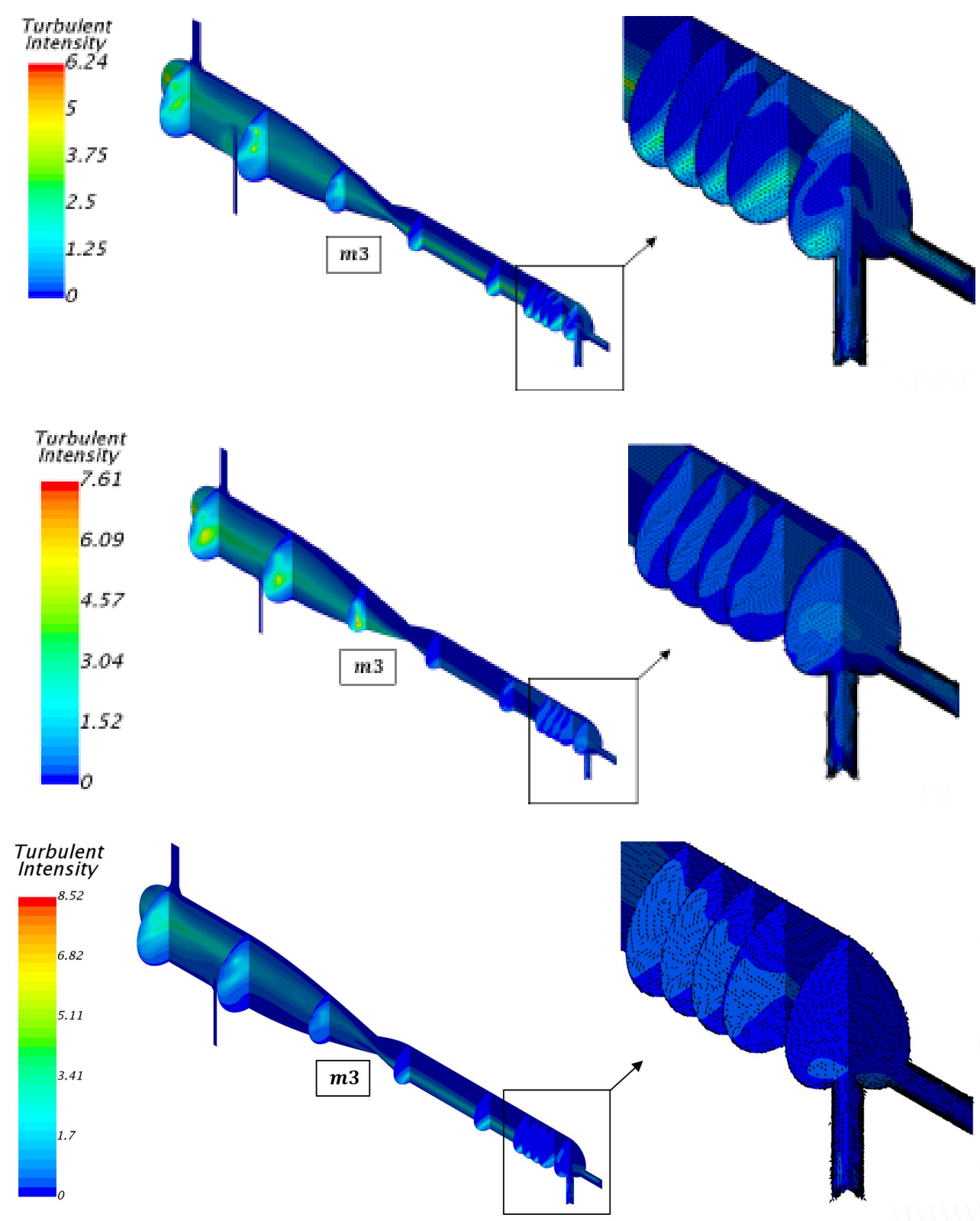

Figure 36. Lateral increase in turbulent intensity with higher temperature of water at inflow; $65^{\circ} \mathrm{C}, 80^{\circ} \mathrm{C}, 95^{\circ} \mathrm{C}$ (top to bottom).

\subsubsection{Analysis of the design}

From Sect. 3.3.3, it is evident that the design cannot provide sufficient residence time for complete vaporization of pentane(1) at flow rate combination $\mathrm{m} 3$, especially, at higher inflow temperatures of water $\left(80^{\circ} \mathrm{C}\right.$ and $\left.95^{\circ} \mathrm{C}\right)$. Therefore, in order to increase the heat transfer performance, contact time must be increased. The addition of baffles was used to accomplish that need and further improve our DCHE design. Baffles are commonly used in heat exchangers to enhance uniformity in thermal and hydraulic gradients, while mitigating flow instabilities or perturbations that may otherwise arise from jet-like flows of high inertia. A representation of the industrial-grade DCHE design with baffles is shown in Figure 37. 


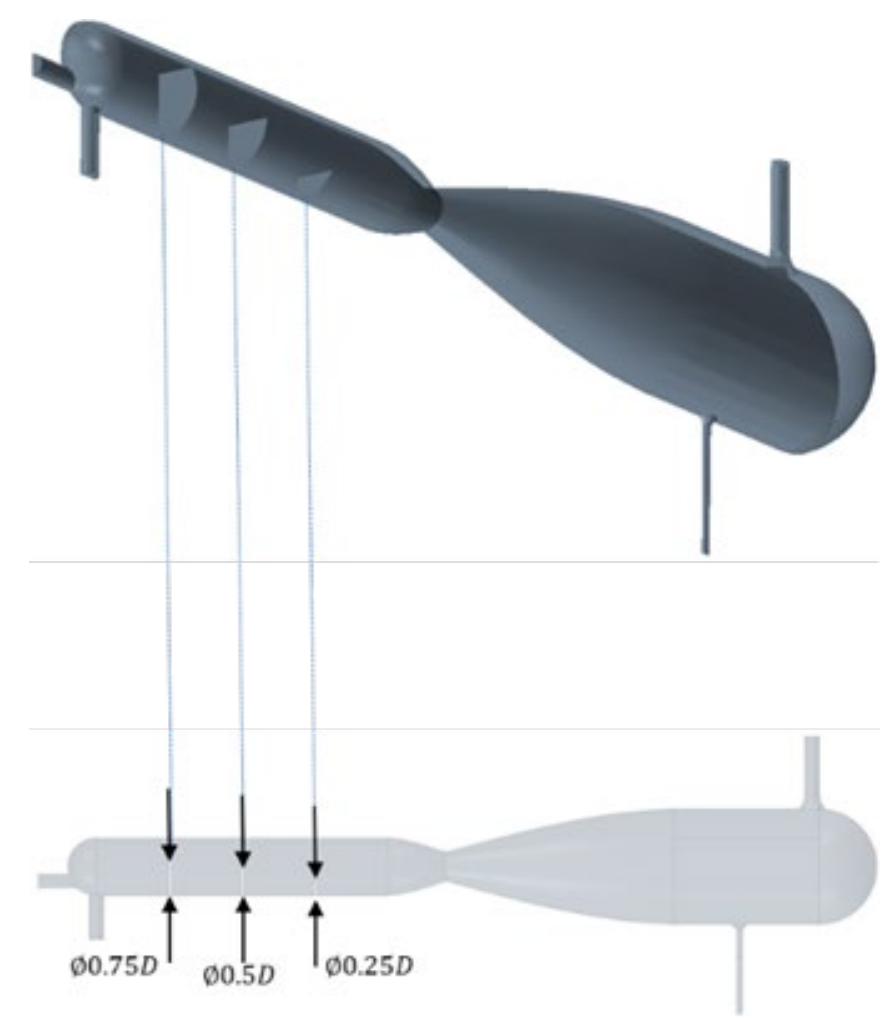

Figure 37. Industrial-grade design modified with baffles to gradually expand available flow area.

Figure 38, Figure 39 and Figure 40 show the distribution of pentane $(\mathrm{g})$, magnitude of velocity, and temperature for each simulated scenario. The distribution of pentane $(\mathrm{g})$ is influenced by the relative mass inflows of pentane(1) and water.

During vaporization, turbulent mixing and phase replacement cause a sudden expansion due to the drastic change in density of the dispersed phase at the interface, thereby increasing the momentum of vapor relative to that of the liquid mixture. Thus, for lower inflow temperatures of water $\left(50^{\circ} \mathrm{C}\right.$ and $\left.65^{\circ} \mathrm{C}\right)$, a gradual change in the level of the interface is observed downstream of the baffles. The liquid level is lowest immediately behind the first baffle, and then gradually increases to the final height of the interface after the second and third baffles. This change is visibly more diffuse for higher inflow temperatures of water $\left(80^{\circ} \mathrm{C}\right.$ and $\left.95^{\circ} \mathrm{C}\right)$.

It may be inferred that the entrainment of pentane $(\mathrm{g})$ with water in between the baffles is due to the larger volume of gas rapidly produced owing to the available enthalpy of the mixture. While there is entrainment of vapor by the water within the baffles, there is sufficient residence time in the first column for the phases to stratify by force of buoyancy in the second column, thus, avoiding entrainment of vapor through the liquid outlet at the bottom.

Conservation of momentum shows an increase in the near-wall velocity of the vapor along the upper surfaces of the DCHE. The rising vapor is significantly less dense than the liquid mixture, and thus, the velocity of expanding vapor manifests in a relatively steady stream along the upper wall, with no backflow observed at the vapor outlet. Rapid vaporization is thus accompanied by notable superheating of the vapor, with the highest superheat observed at scenario $95 \mathrm{~m} 3$. 

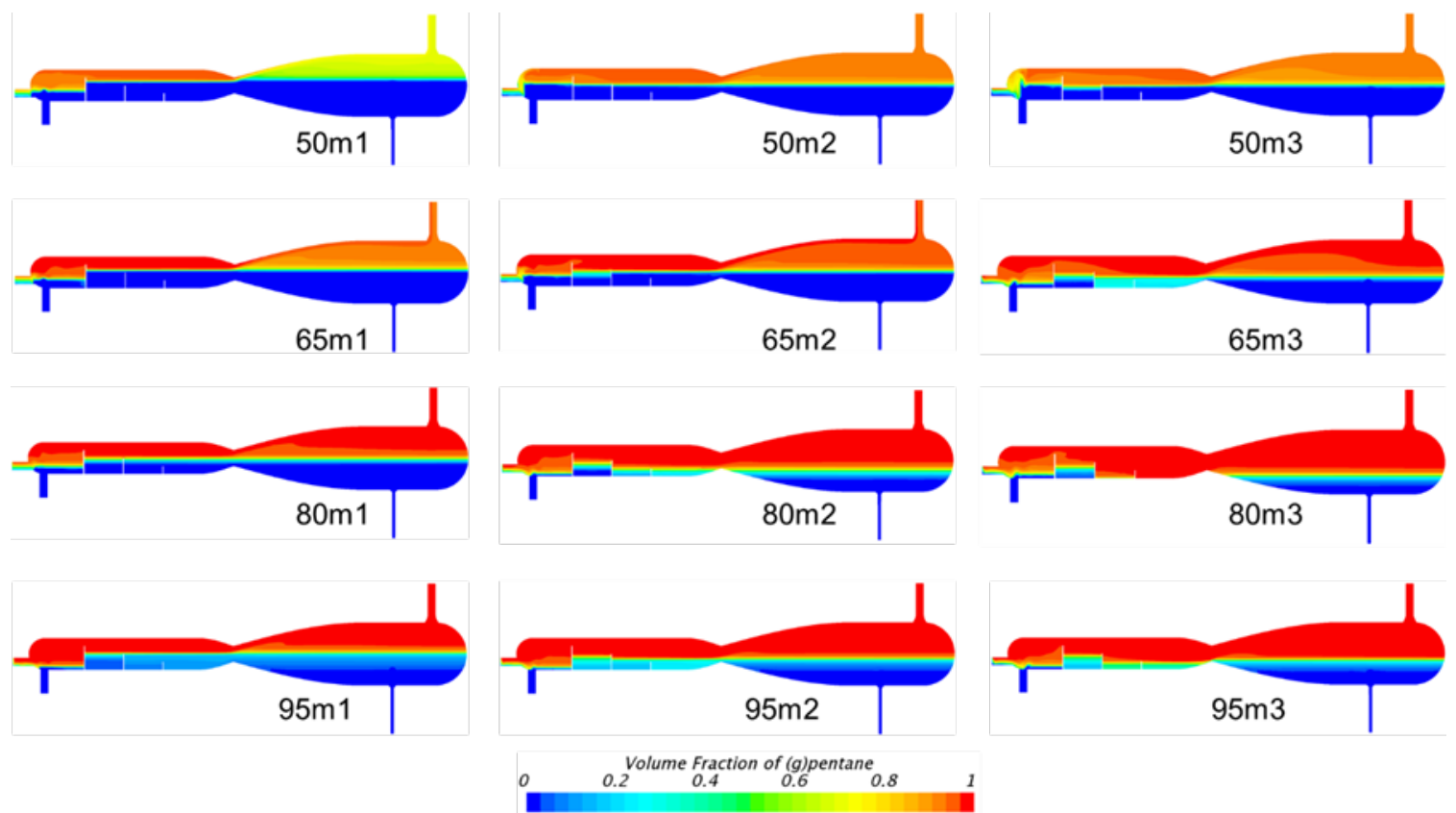

Figure 38. Distribution of pentane(g) across the symmetry plane of the simulated DCHE.
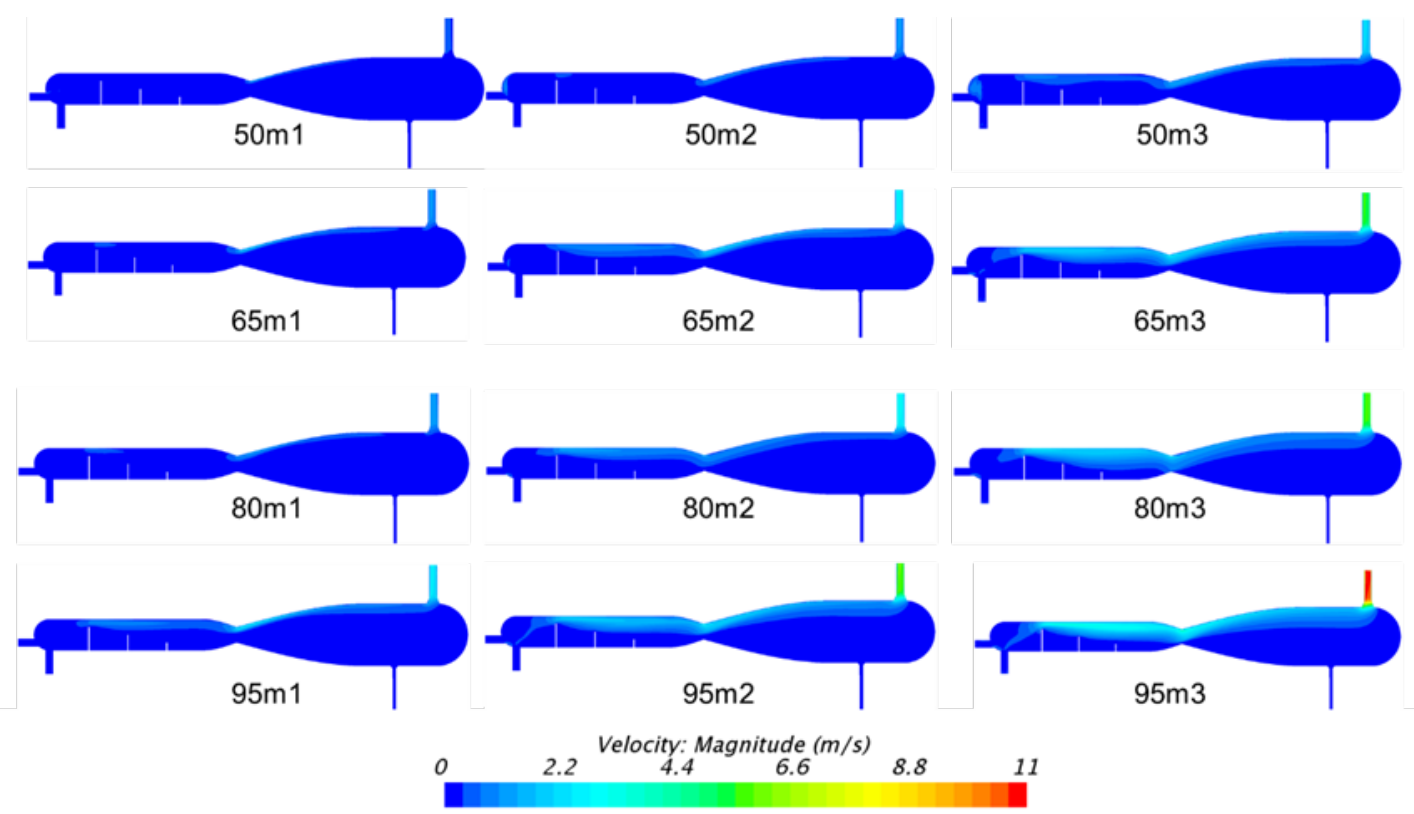

Figure 39. Distribution of the mixture velocity across the symmetry plane of the simulated DCHE. 


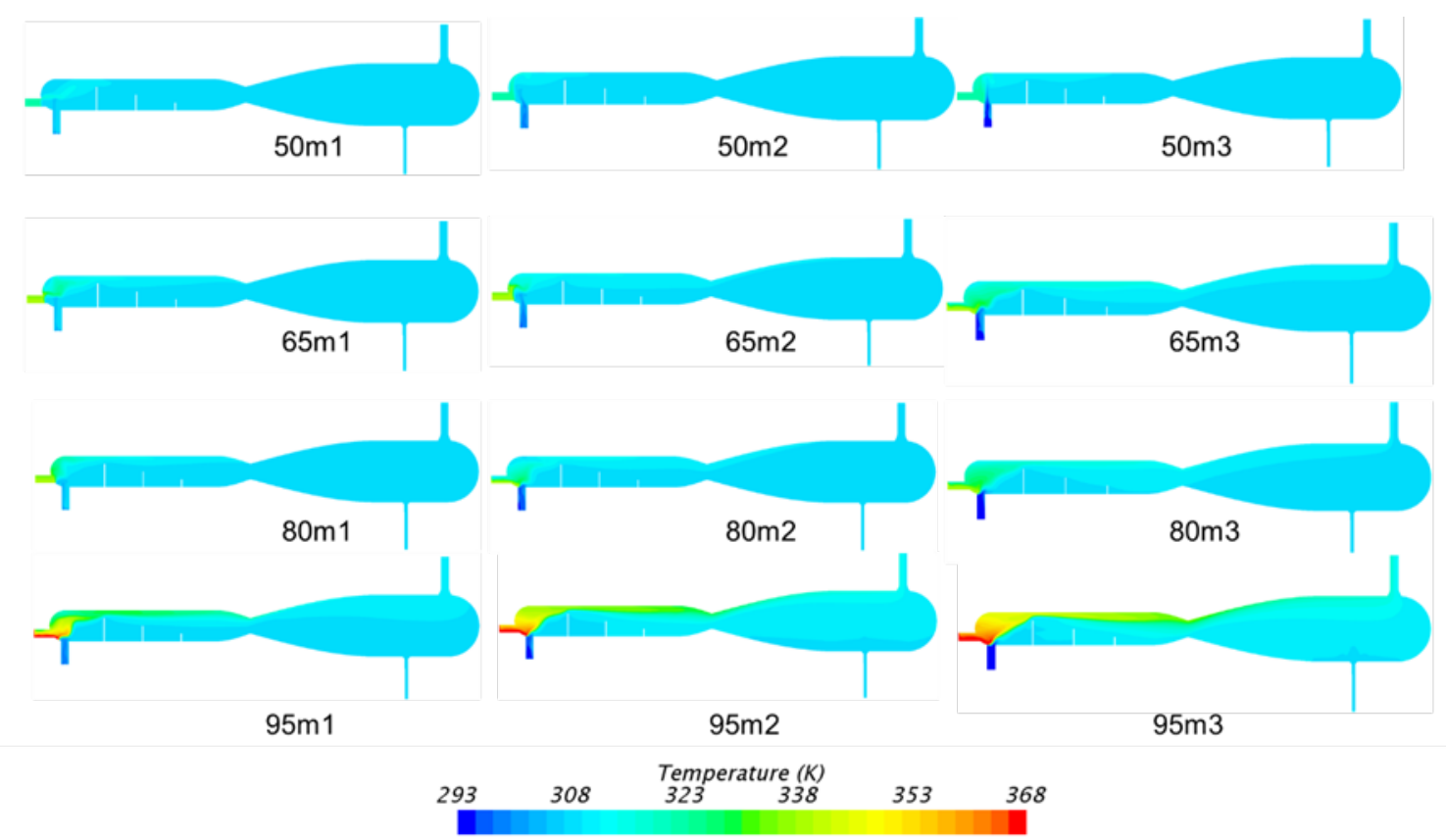

Figure 40. Distribution of mixture temperature across the symmetry plane of the simulated DCHE.

At higher inflow temperatures of water, there is a higher temperature differential in the local mixing zone created by the liquid jets impinging at right angles. The consequent plume of vapor that is generated is stabilized by the convective gradients in the impingement zone, with a larger volume of vapor generated before the first baffle for a higher inflow temperature of water at a given combination of mass inflows $(\mathrm{m} 1, \mathrm{~m} 2, \mathrm{~m} 3)$. This affects the liquid holdup downstream of each baffle, and thus, the final height of the interface that stabilizes in the second column at steady state. The outflow temperature profiles of vapor in the absence of and in presence of baffles are illustrated in Figure 41.

In summary, the addition of baffles proves to be a feasible, cost-effective approach to ensure

- complete vaporization of the dispersed phase i.e. pentane $(1)$ for all flow conditions,

- no entrainment of vapor by the water into the bottom outlet,

- sufficient residence time for the dispersed phase in the DCHE to uniformly heat and notably superheat, and

- reduced premature stratification of the liquid mixture prior to complete vaporization.

The simulated scale is proposed to scale up in dimension by a factor of 10 . The corresponding volumetric flow rates scale by a factor of 1,000. Accordingly, the simulated flow conditions reflect physical operating conditions as listed in Table 15.

Table 15. Physical operating conditions for the industrialgrade design.

\begin{tabular}{|l|c|c|c|}
\hline \multicolumn{1}{|c|}{ Mass flow ratio label } & $\mathbf{m}_{\mathbf{1}}$ & $\mathbf{m}_{\mathbf{2}}$ & $\mathbf{m}_{\mathbf{3}}$ \\
\hline Water mass flow rate $(\mathrm{kg} / \mathrm{s})$ & 2 & 5 & 10 \\
\hline Pentane mass flow rate $(\mathrm{kg} / \mathrm{s})$ & 3 & 7.5 & 15 \\
\hline
\end{tabular}


Outflow Temperature of Pentane(g) vs. Inlet Temperature of Water $\left({ }^{\circ} \mathrm{C}\right)$

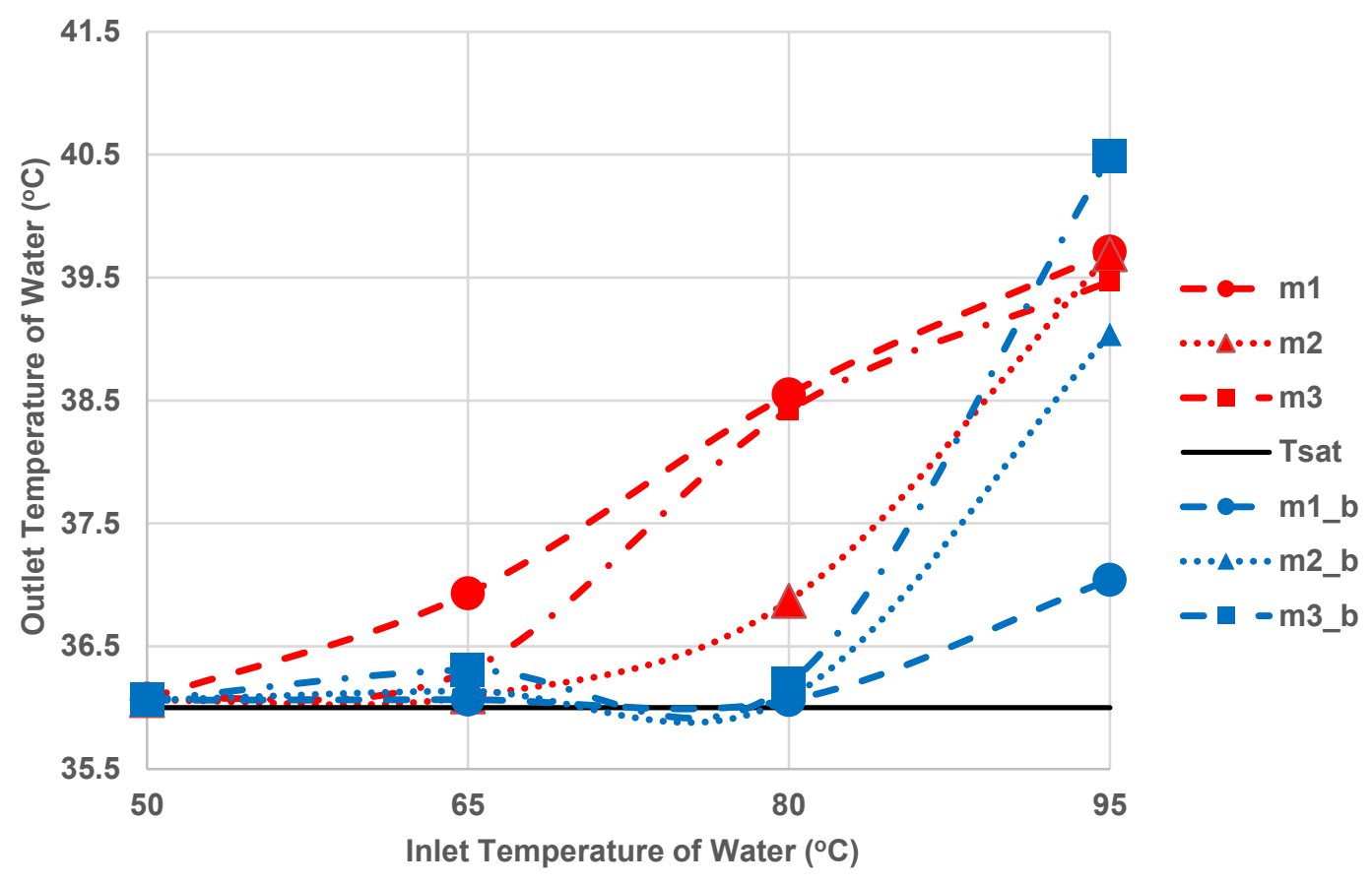

Superheat Performance: Temperature of Outflow Vapor Relative to Saturation Temperature of Dispersed Phase

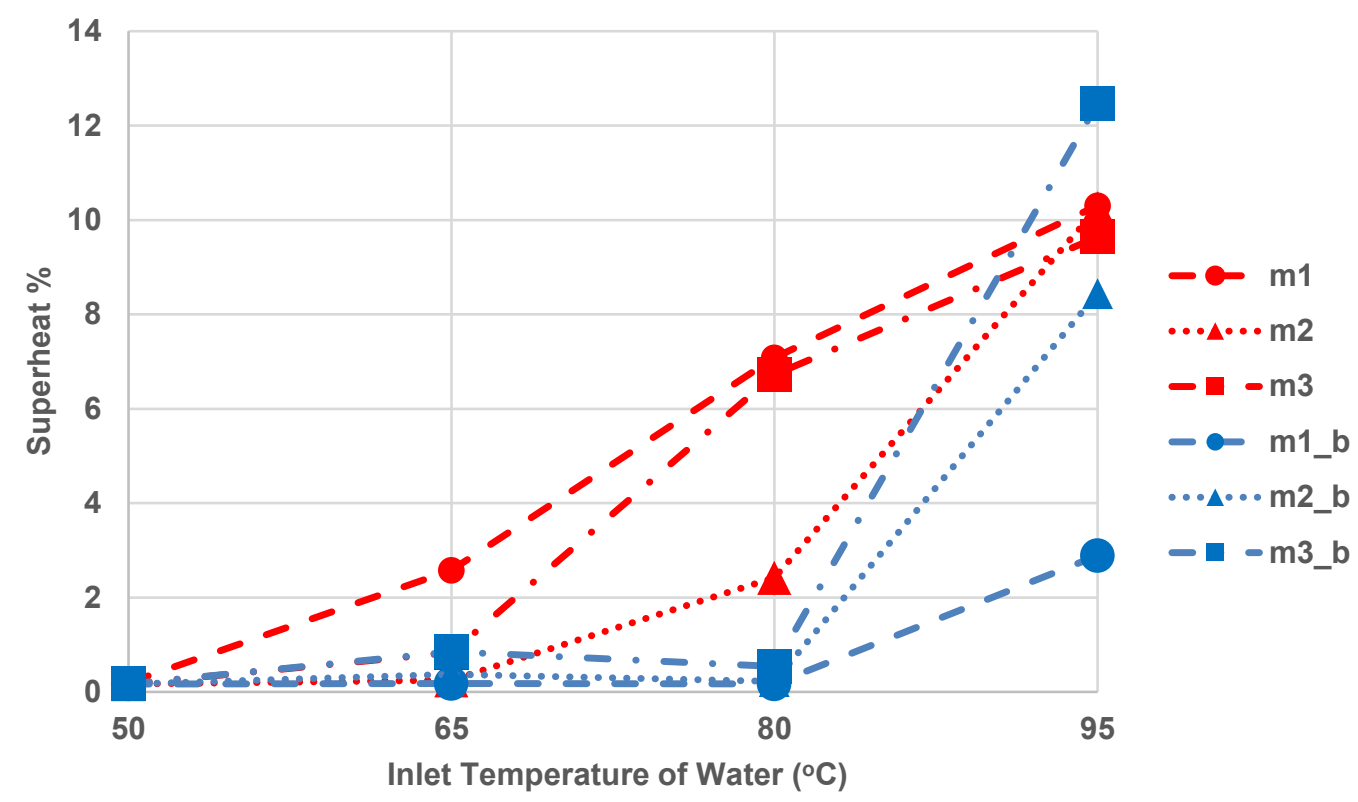

Figure 41. Outflow temperature profiles of vapor in all simulated scenarios (top) and the influence of baffles on superheat of vapor outflow (bottom). 


\section{SUBJECT INVENTIONS}

None.

\section{COMMERCIALIZATION POSSIBILITIES}

The DCHE system developed in this project is presently at a low technological readiness level and therefore would need to be matured further, through experimental validation and in situ testing, before the design can be ready for commercialization.

In addition, any follow-on project would need to continue to evolve the design using advanced HPC and experimental testing to further improve the overall system performance.

\section{PLANS FOR FUTURE COLLABORATION}

Future work would likely consist of testing the novel DCHE design with organic working fluids (waterpentane, water-methanol, for instance) for a wider operating range. The CFD model would then be leveraged to accurately identify the optimal working conditions.

As a follow up to this activity, the ORNL team will pursue new strategic partnership project opportunities with the US manufacturing industry and will propose new research projects to the DOE Office of Energy Efficiency and Renewable Energy and the DOE Advanced Research Projects Agency.

\section{CONCLUSIONS AND FUTURE WORK}

This report summarizes the work performed by the ORNL and Eaton teams to develop an innovative DCHE technology. The project was completed in two main stages.

In the first stage, a CFD model with relevant physics was developed for a DCHE system within a CFD platform, STAR-CCM+. Through investigations of a variety of multiphase models, the VOF model was found to be adequate to appropriately resolve the desired physics. The VOF model offers a variety of submodels for phase change, drag force, and turbulence and provides a robust numerical method to resolve interfaces of immiscible fluids. 2D CFD models were first developed to investigate the influence of boundary conditions, initial conditions, and solver settings to establish a converged and stable numerical solution. Important design specifications for working components of the experimental setup were not available, owing to which, an evolutionary approach was required to match the active length obtained in the experiments. Then, a 3D CFD model of the benchmark setup was developed, and numerical results were verified and validated using the experimental data. As part of the verification process, a mesh sensitivity analysis was performed. The analysis allowed the characterization of the numerical errors. Only a limited validation was performed using the experimental data for the active length. Numerical results showed a good agreement with the experimental data, and the CFD model was found to correctly capture the physics relevant to DCHE based on an organic Rankine cycle. Many challenges were encountered during this first stage related to the stiffness of the physics, but also due to the gaps in information on the correct boundary conditions. 
In the final stage of the project, the ORNL team focused on developing an innovative industrial-grade design for the DCHE. This task was lengthy and iterative and was only made possible through leveraging HPC resources. The CFD model calibrated during the first stage of the project was directly adapted to the industrial-grade design. After state-of-the art DCHE designs were reviewed, a baseline configuration was selected that consisted of two horizontal chambers connected by a converging-diverging nozzle. Heat transfer and phase change occur primarily in the first chamber; the second chamber serves as a separator, where the force of buoyancy allows stratification of liquid and vapor phases. Design of the inlets and outlets were also optimized. The inlets were oriented at a $90^{\circ}$ angle, with the cold, lighter phase located at the bottom of the first chamber, and the hot, heavier phase set to enter in a horizontal direction. This orientation was selected to allow the lighter phase to disperse through the warmer phase, thus promoting inherent turbulence, efficient heat transfer, and a steady vaporization process. The outlets in the second chamber were staggered to prevent entrainment of the gas phase by the liquid phase.

Using water and pentane as the working fluids, inflow conditions were selected to evaluate the design over a range of temperatures (from $50^{\circ} \mathrm{C}$ to $90^{\circ} \mathrm{C}$ ) and inlet mass flow rates ( 2 to $15 \mathrm{~kg} / \mathrm{s}$ ), assuming atmospheric conditions. Efficiency of the DCHE was assessed by monitoring the outlet temperature of pentane $(\mathrm{g})$ and was quantified as relative superheat of vapor (i.e., rise in temperature of vapor above saturation).

After a first design sweep was performed, it was deemed necessary to enhance the contact time between the liquid phases, and hence, the baseline geometry was modified by strategically introducing three baffles in the first chamber. Analysis of the data was provided where it was inferred that the addition of baffles provided a benefit to higher rates of inflow (above $10 \mathrm{~kg} / \mathrm{s}$ ) at higher temperatures $\left(80^{\circ} \mathrm{C}\right.$ and $95^{\circ} \mathrm{C}$ ), where the resistance to flow provided by surfaces of the baffle provided more time for thermal gradients to dissipate in the mixture, and yielded a higher temperature of superheat for vapor outflow, at a given combination of mass inflow. At lower temperatures, it was inferred that the added residence time provided by baffles provided no discernible benefit as the superheat of vapor is driven by residual enthalpy in the water after vaporization of pentane(1) has occurred. Accordingly, the difference in superheat is evident at higher inflow temperatures of water.

This project required intensive use of HPC resources to develop, verify, and validate a CFD model and then to develop an innovative DCHE design. It is estimated that 20,000 CPU hours were required to complete this project on ORNL midsize clusters (Apollo, Libby and Panacea). The scalability and highquality user interface of the commercial STAR-CCM+ CFD package was an asset for the success of this project. Throughout the duration of the project, the ORNL team developed valuable skills for the simulation of unique, multiphase flow systems and gained experience with performing optimization problems by efficiently utilizing the available computational resources. 


\section{BIBLIOGRAPHY}

Abdulrahman, M. (2016). CFD simulations of direct contact volumetric heat transfer coefficient in a slurry bubble column at a high gas temperature of a helium-water-alumina system. Applied Thermal Engineering, 224-234.

Apanasevich, P. L. (2015). CFD based approach for modeling direct contact condensation heat transfer in two-phase turbulent stratified flows. International Journal of Thermal Sciences, , 95, pp.123-135.

Banerjee, R. (2007). A numerical study of combined heat and mass transfer in an inclined channel using the VOF multiphase model. Numerical Heat Transfer, Part A: Applications, 163-183.

Banerjee, R. (2008). Turbulent conjugate heat and mass transfer from the surface of a binary mixture. International Journal of Heat and Mass Transfer, 5958-5974.

Banerjee, R. a. (2006). A study to determine vapor generation from the surface of gasoline flowing in an inclined channel using a continuous thermodynamics approach. Numerical Heat Transfer, Part A: Applications, 705-729.

Baqir, A. M. (2016). Measuring the average volumetric heat transfer coefficient of a liquid-liquid-vapour direct contact heat exchanger. Applied Thermal Engineering, 103, pp.47-55.

Baqir, A. S., Mahood, H. B., Hameed, M. S., \& Campbell, A. N. (2016). Heat transfer measurement in a three-phase spray solumn direct contact heat exchanger for utilization in energy recovery from low-grades sources. Energy Conversion and Management, 126, 342-351.

Blair, C. B. (1976). Heat transfer characteristics of a three-phase volume boiling direct contact heat exchanger. Salt Lake City (USA).: Utah Univ., Dept. of Mechanical Engineering.

Cui, X. L. (2012). Computational fluid dynamics simulations of direct contact heat and mass transfer of a multicomponent two-phase film flow in an inclined channel at sub-atmospheric pressure. International Journal of Heat and Mass Transfer, 5808-5818.

Fujita, Y. H. (1988). Flow and heat transfer characteristics in a direct contact volume-type evaporation process. JSME international journal. Ser. 2, Fluids engineering, heat transfer, power, combustion, thermophysical properties, , 31(3), pp.486-493.

Gulawani, S. J. (2006). CFD analysis of flow pattern and heat transfer in direct contact steam condensation. Chemical Engineering Science, 61(16), pp.5204-5220.

https://webbook.nist.gov/chemistry/fluid/. (2018). Retrieved from NIST Chemistry WebBook, SRD69.

Jacobs, H. a. (1987). Condensation on coolant jets and sheets including the effects of noncondensible gases. Journal of Heat Transfer, 1013-1020.

Jacobs, H. R. (1986). DIRECT CONTACT HEAT TRANSFER IN A SIEVE TRAY COLUMN. Proceedings of the Eighth International Heat Transfer Conference.; (pp. 3013-3018). San Francisco: Hemisphere Publ Corp.

Jacobs, H. R. (2011, February 2). Thermopedia/Direct Contact Heat Exchangers. Retrieved from Thermopedia: http://www.thermopedia.com/content/700/

Jiang, L. H. (2015). The effect of Dixon rings on direct contact evaporative heat transfer performance. Applied Thermal Engineering, 87, pp.336-343.

Jin, Y. H. (2017). The effect of Dixon rings on direct contact heat transfer performance: Comparison of counter and co-current evaporation. Applied Thermal Engineering, 117, 762-772.

Kreith, F. a. (2013). Direct-contact heat transfer. Springer Science \& Business Media.

Sideman, S. a. (1966). Direct contact heat transfer with change of phase: Spray-column studies of a threephase heat exchanger. AIChE Journal, 12(2), pp.296-303.

Siemens. (2018). STAR-CCM+ Simcenter Documentation 13.06.

Strotos, G. G. (2011). Numerical investigation of the evaporation of two-component droplets. Fuel. Fuel, 1492-1507.

Treybal, R. (1966). Liquid Extractor Performance. Chemical Engineering Progress , 62(9), p.67.

Wang, W. L. (2015). Numerical simulation study on discharging process of the direct-contact phase change energy storage system. Applied Energy, 61-68. 
Wohak, M. a. (1998). Numerical simulation of direct-contact evaporation of a drop rising in a hot, less volatile immiscible liquid of higher density-Possibilities and limits of the SOLA-VOF/CSF algorithm. Numerical Heat Transfer, Part A Applications, 561-582. 
